\title{
Rectangular Spiral Inspired Approach for Estimating Area of Solar Photovoltaic Plants in India
}

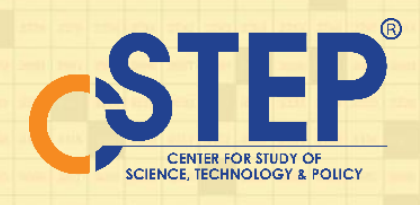




\section{Rectangular Spiral Inspired Approach for Estimating Area of Solar Photovoltaic Plants in India}

Contributors:

Harshid Sridhar

Thirumalai N.C.

Center for Study of Science, Technology and Policy (CSTEP)

September 2019 
Center for Study of Science, Technology and Policy (CSTEP) is a private, not-for-profit (Section 25) Research Corporation registered in 2005.

Designed and Edited by CSTEP

\section{Disclaimer}

While every effort has been made for the correctness of data/information used in this report, neither the authors nor CSTEP accepts any legal liability for the accuracy or inferences for the material contained in this report and for any consequences arising from the use of this material.

(C) 2019 Center for Study of Science, Technology and Policy (CSTEP)

Any reproduction in full or part of this publication must mention the title and/or citation, which is provided below. Due credit must be provided regarding the copyright owners of this product.

Contributors: Harshid Sridhar, Thirumalai N.C.

This report should be cited as: CSTEP. (2019). Rectangular Spiral Inspired Approach for Estimating Area of Solar Photovoltaic Plants in India. (CSTEP-RR-2019-06).

September 2019

\section{Center for Study of Science, Technology and Policy}

\section{Bengaluru Office}

No. $18,10^{\text {th }}$ Cross, Mayura Street, Papanna Layout, Nagashettyhalli, RMV II Stage, Bengaluru-560094, Karnataka (India)

Tel.: +91 (80) 6690-2500

Fax: +91 (80) 2351-4269

Email: cpe@cstep.in

Website: www.cstep.in

\section{Noida Office}

Studio No. 206, International Home Deco Park (IHDP),

Plot No. 7, Sector 127, Taj Expressway, Noida-201301, Uttar Pradesh (India)

Tel.: +91 (121) 484-4003 


\section{Acknowledgements}

The authors are also thankful to Prof. V. S. Chandrasekaran, Prof. M. A. Ramaswamy, Dr Jai Asundi, and N.S. Suresh for their critical review in improving the manuscript. The authors are grateful to Dr Anshu Bharadwaj, Dr Mridula Dixit Bharadwaj, Abhinav Mishra, and Merlin Francis for their encouragement and support. 



\section{Executive Summary}

In pursuit of achieving its clean energy goals, India is moving aggressively towards establishing large solar plants. Land being a finite resource in a densely populated country like India, an approach for planning for these plants aiming towards better utilisation of available land resource is certainly of interest. There is merit in looking at a design approach which aides planning by offering high packing density leading to reduced land utilisation. The objective of this work is to propose a method which can provide the rational area estimate of a plant factoring sizing considerations from electrical, maintenance, and shading aspects. The idea for the plant design is inspired by the number pattern illustrated in the Ulam spiral. From the perspective of planning, the proposed approach aims to provide an area estimate which could set the boundary conditions in term of realistic potential estimation and minimum land area required. Further, this report provides insights with respect to land area requirements across the latitudinal spread for India. Also, it provides an estimate of the solar power potential for ground mounted utility scale plants in India.

The highlights of this work are as follows:

- Proposes a novel approach for estimating land area of a solar PV plant

- State wise benchmark area estimates per MWp of plant capacity are derived

- Better land utilisation could increase the solar power potential by $20 \%$

- The revised solar energy potential for utility scale PV systems is estimated to be about 391 GWp 



\section{Table of Contents}

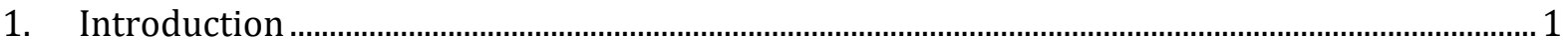

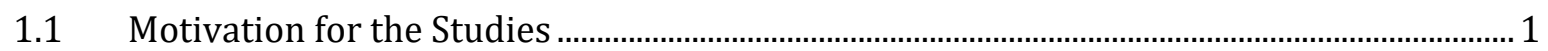

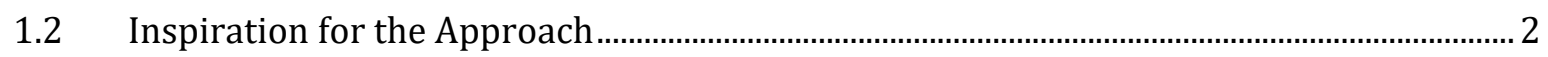

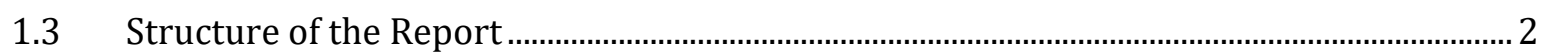

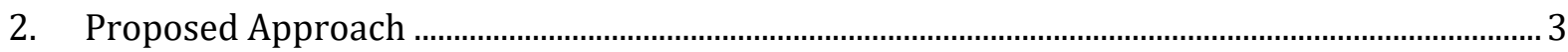

$2.1 \quad$ Estimation of Sizing of System Components and Capacity ……................................................. 3

2.2 Estimation of Inter-Row and Inter-Column Spacing for Various Time Windows .............. 5

$2.3 \quad$ Estimation of Plant Area........................................................................................................ 5

2.3.1 Inferences From the Spiral Pattern and Designing a Generic Algorithm .................... 7

2.3.2 Applying the Generic Algorithm for Area Estimation of PV Plant .............................. 10

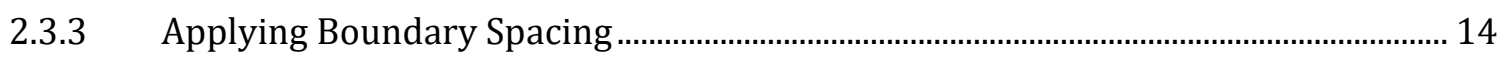

2.3.4 Packing Density and Deviation Factor ........................................................................... 17

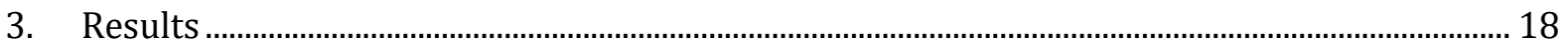

3.1 Case Simulation to Illustrate the Proposed Approach .............................................................. 18

3.2 Testing the Approach to Predict Area of Active PV Plants ....................................................... 20

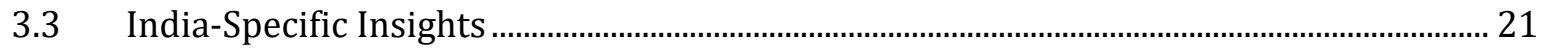

4. Estimating the Solar Power Potential for India............................................................................. 24

5. Conclusions and Policy Implications ............................................................................................ 30

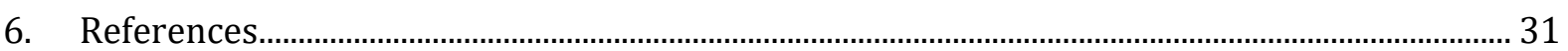

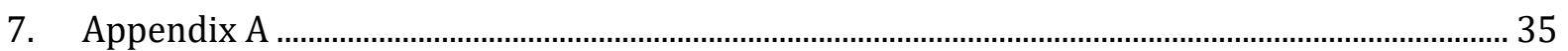

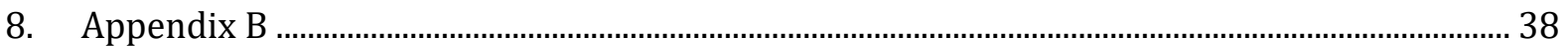

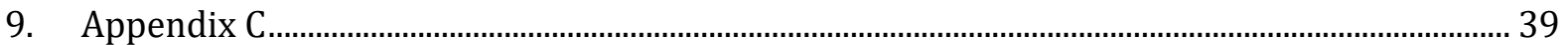

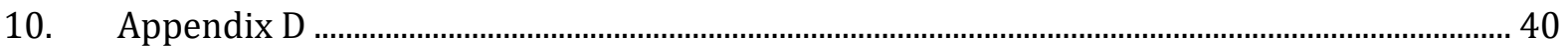

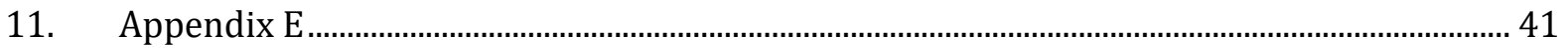

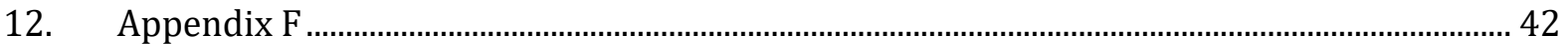

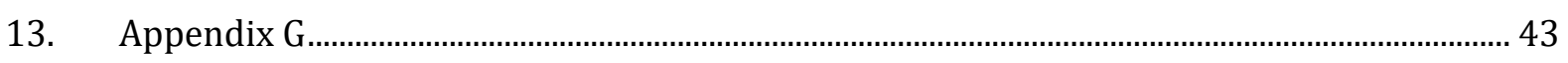

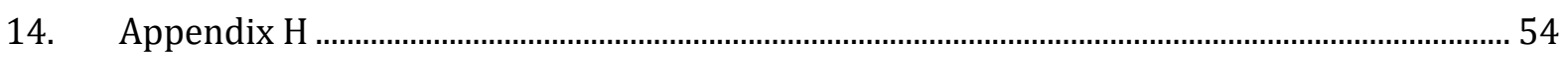

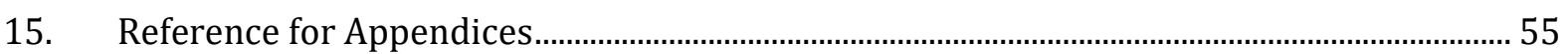




\section{List of Figures}

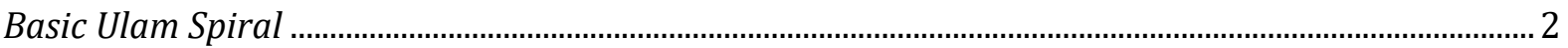

Illustrative process flow for area estimation ........................................................................................... 3

Illustration of solar angles for a panel at fixed tilt facing due south $\left(\gamma=0^{\circ}\right)$........................................ 6

A schematic representation of units being placed in the clockwise spiral pattern ................................. 7

Illustration of transition sets, square, and rectangular matrices ............................................................ 7

Representation of generic unit (dimensions in black and area in red) ...................................................... 8

Illustration of enclosed and outlying set for $X=24$ units.......................................................................

Generic algorithm for implementing the spiral pattern .......................................................................... 12

Generic algorithm for implementing the spiral pattern .................................................................... 13

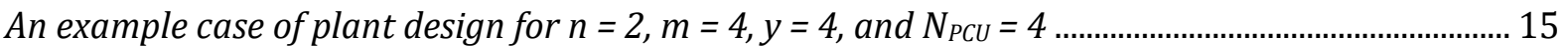

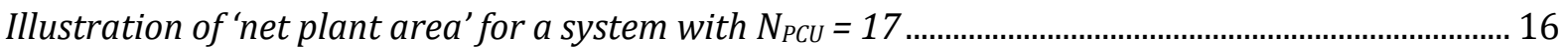

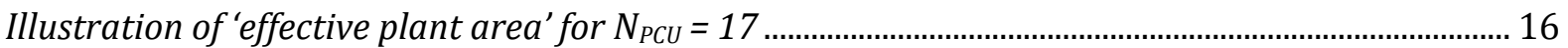

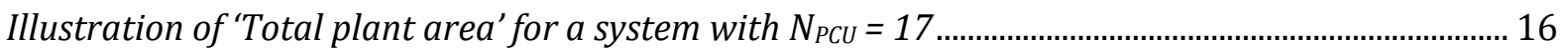

Area estimates for a 1MWp plant near Bengaluru for different technologies...................................... 19

PD and DF for 1MWp plant near Bengaluru for different technologies .............................................. 20

Total plant area including auxiliary area requirements for $1 M W p$ plant across time windows...... 22

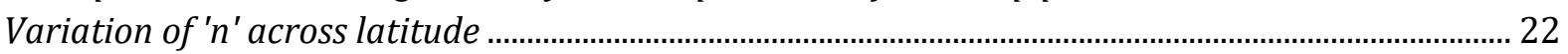

Capacity wise Total plant area (including auxiliary area) for 9 am to 3 pm window for latitudes 8

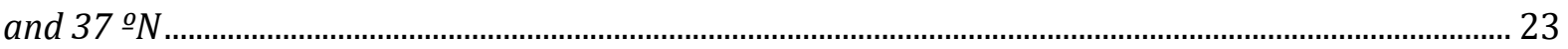

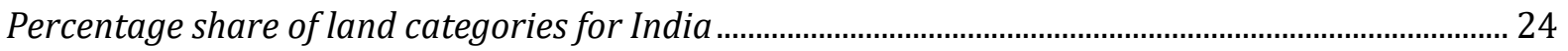

Percentage share of wasteland categories in India ……....................................................................... 24

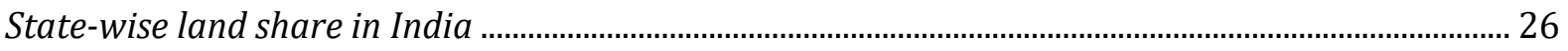

State-wise benchmark area for 1 MWp plant considering the Proposed Method (PM) ..................... 27

Latitude wise estimate of $1 \mathrm{MWp} P V$ plant area for a time window of 9 am to $3 \mathrm{pm}$ using the

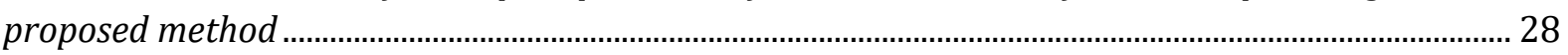

Estimated solar potential for $3 \%$ of all wasteland and select wasteland areas................................... 28

Category wise potential for $3 \%$ of select wasteland areas ...................................................................... 28

State-wise solar power plant potential estimated based on the proposed method .............................. 29

\section{List of Tables}

Benchmark estimates of area requirement for solar PV plants in India ................................................. 1

Distribution of dimensions of matrix set for a given set of ' $X$ ' units ......................................................... 8

Summary of simulation results for technology comparison for a test case for a location at latitude

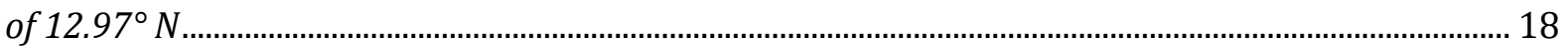

Summary of comparison of actual declared area of select existing plants and estimated area ....... 20 


\section{Introduction}

\subsection{Motivation for the Studies}

In a densely populated and agriculture dependent country like India, land is a critical resource. It is not short in availability per se but due to challenges in its acquisition, the effective land area available for setting up land-intensive Renewable Energy (RE) plants is relatively scarce (NITI Aayog, CII, SSEF, \& RAP, 2015). In contrast, to keep up with its climate goals, India is pursuing an aggressive RE target of $175 \mathrm{GW}$ by $2022^{1}$ (NITI Aayog, 2016). This is a fraction of the true RE potential identified throughout the country. The total solar power potential across the country was identified to be around $748 \mathrm{GWp}$ (NISE \& MNRE, 2014) and the on shore wind power potential at $100 \mathrm{~m}$ hub height was estimated to be about $302 \mathrm{GW}$ (NIWE, 2015).

In the effort towards realising this potential, one crucial aspect of discussion has been concerning the land required for meeting all energy needs from RE sources. Based on estimates, considering that land acquisition might be difficult, it was initially indicated that India cannot meet all of its energy requirements with RE sources alone, (Sukhatme, 2011). Contrasting insights were later presented with respect to land area requirement covering two important aspects namely -'Land Transformation' and 'Land Occupation'. The focus of this report is towards building solar plants (with no mechanical tracking systems). In this context, it was pointed that, a solar plant would occupy more land area to set up compared to a coal power plant; however, it transforms less area when compared to the same. Finally, it was concluded that land availability may not be a limiting constraint for tapping the requisite solar energy resources (Mitavachan, H; Srinivasan, 2012). This aspect was acknowledged and the original assessment was revised (Sukhatme, 2012). These discussions indicate that there is merit in developing a generic approach which quantifies the land area requirements factoring in the technical aspects of a solar power plant.

Currently, India has an installed solar power capacity of 25 GW (CEA, 2019). Considering its current official target and declared potential there is a need to assess and estimate the land area requirements towards meeting these goals. The approach covered in this report aims to provide useful insights in this context. The various estimates for land area required per unit MW for a solar Photovoltaic (PV) plant in the Indian context are listed in Table 1. These estimates serve as benchmarks for various sectoral analyses. But, they do not capture effects of increased power rating of the PV module for the same module area and the latitude of the site (and hence the tilt angle of the module) tailored to a plant for a specific site. In an effort to provide a comprehensive estimate, this report presents an approach for sizing a solar photovoltaic plant considering electrical, maintenance, and shading aspects.

Table 1: Benchmark estimates of area requirement for solar PV plants in India

\begin{tabular}{|l|l|l|l|l|}
\hline S.no & Remark & Area per MWp (acres) & Entity & Reference \\
\hline 1 & Generic consideration for all India & 5 & CERC & (CERC, 2014) \\
\hline 2 & $\begin{array}{l}\text { Minimum area required for setting } \\
\text { a solar plant }\end{array}$ & 3.7 & SECI & $\begin{array}{l}\text { (Kumar \& Thapar, } \\
\text { 2017) }\end{array}$ \\
\hline \multirow{2}{*}{3} & Generic area requirement & $4-5$ & IREDA & (IREDA, n.d.) \\
\cline { 2 - 3 } & Mono-crystalline plant & $3-4$ & & \\
\cline { 2 - 3 } & Thin film plant & $7.5-9$ & & \\
\hline
\end{tabular}

1 This constitutes $100 \mathrm{GW}$ from solar (60 GW from utility scale, $40 \mathrm{GW}$ from roof top photovoltaic systems), $60 \mathrm{GW}$ from wind, $10 \mathrm{GW}$ from biomass and $5 \mathrm{GW}$ from small hydro power based capacity (MNRE, 2015; NITI Aayog, 2016). 


\subsection{Inspiration for the Approach}

Nature has inspired some of the best engineering designs. One such case is inspired by the phyllo-taxis disc pattern which is the configuration of florets on the head of a sunflower (Vogel, 1979). This concept was used for providing a theoretical design for the heliostat field arrangement in concentrated solar power plants (Noone, Torrilhon, \& Mitsos, 2011). The work covered in this report for PV plants draws inspiration from the prime spiral also known as the Ulam spiral (Stein, Ulam, \& Wells, 1964). The Ulam spiral is a simple method of visualising prime numbers that reveals the apparent tendency of certain quadratic polynomials to generate unusually large number of primes. Ulam began to number intersections, starting near the centre, with 1, and moving out in a counter-clockwise spiral. He began circling all the prime numbers. The prime numbers seemed to have a tendency to crowd into diagonal lines as illustrated in Figure 1. Near the centre of the spiral the lining up of primes is to be expected because of great "density" of primes and the fact that all primes, except 2, are odd (Gardener, 1971). The pattern presented by the Ulam's spiral has been used in applications ranging from identifying patterns in distribution of nucleotides in DNA (Cattani, 2011), to data record extraction for web technology applications (Anderson \& Hong, 2013), and also to 'object and pattern' identification using raster models (Kitano, Katsuhiko, Kakimoto, Urakawa, \& Araki, 2015).

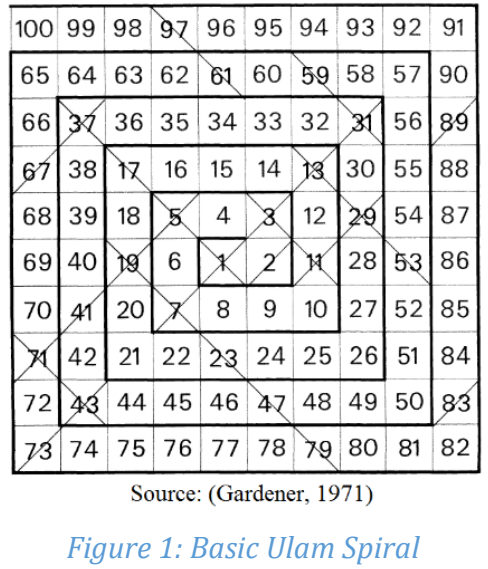

In this report we don't focus on the pattern of prime numbers, rather we focus on the placement of numbers which builds this rectangular/square spiral. We use this pattern to map the physical placement of PV arrays and Power Conditioning Unit (PCU) blocks towards building the plant. Before delving into the application of the spiral (described in detail in section 2.3.2), an understanding of the framework of proposed approach is necessary.

\subsection{Structure of the Report}

Post setting the context in sections 1.1 and 1.2, the proposed approach for area estimation is then explained in detail (section 2). A case illustrating the proposed approach is provided (section 2). To check the robustness of the approach, the area estimated for select existing plants is compared with that of the declared area in public records (summary in section 3.2, details in Appendix G). We derive and illustrate some India specific insights, (section 3.3). We estimate the solar power potential in India using the proposed method (section 4). Finally, we draw conclusions, identify scope for future work and identify applications of this work in related policy implications (section 5). The nomenclature for various parameters indicated in this report is provided in Appendix A. 


\section{Proposed Approach}

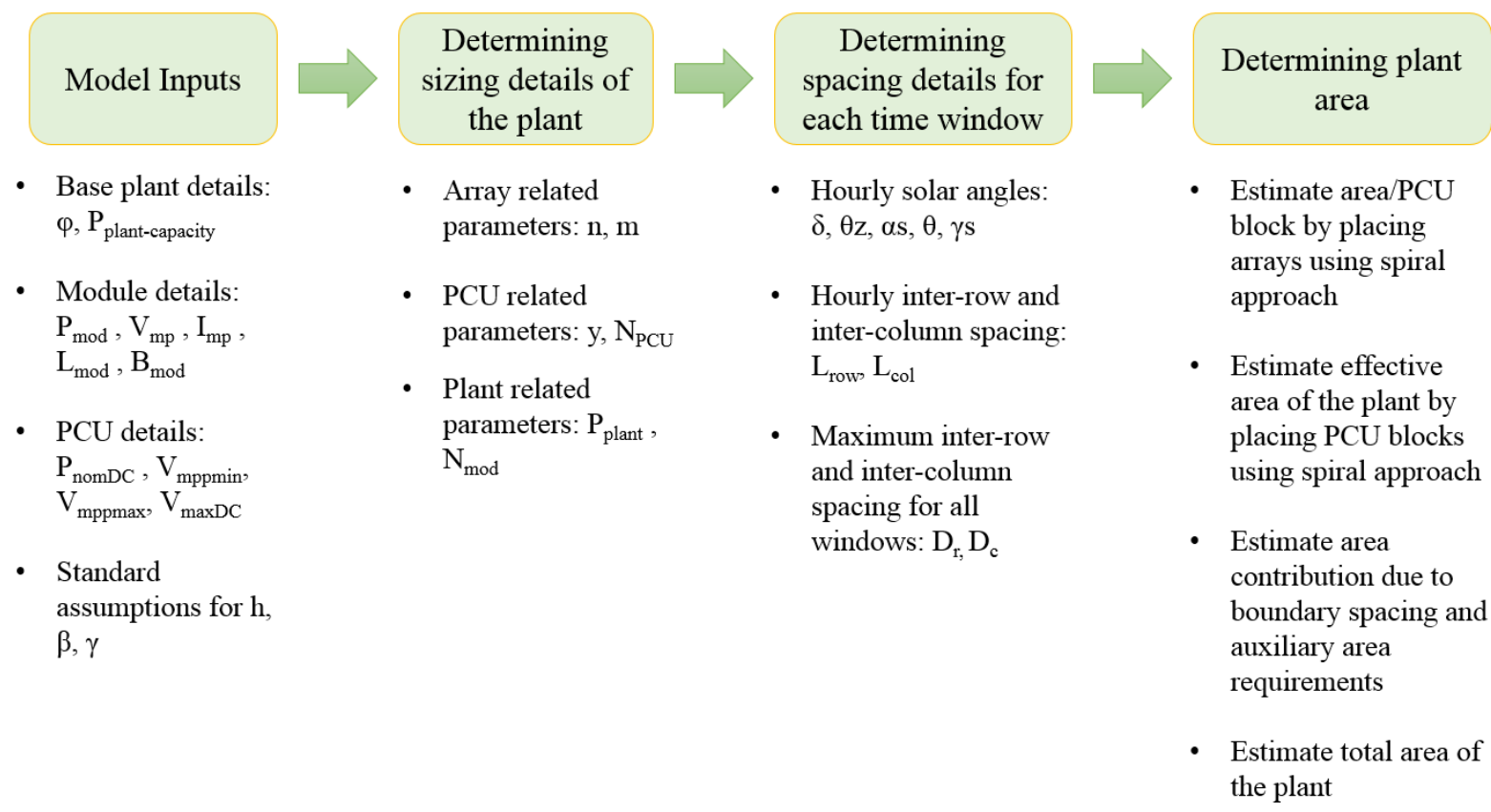

Figure 2: Illustrative process flow for area estimation

Figure 2 summarises the process flow for the proposed approach. The objective is to arrive at the best rectangular area for setting up the plant for a given time window of operation (considered in Local Apparent Solar Time referred as solar time in this report). A time window of operation is typically the hours during which the solar plant operates, such that the shadows of the surrounding structures like neighbouring PV arrays, do not affect the power output of any module. Here, we consider three time windows of operation: 7 am to 5 pm, 8 am to 4 pm and 9 am to $3 \mathrm{pm}$. It can be noticed that these windows are of decreasing duration. This consideration is due to the fact that in the early hours of sunrise, the sun's rays are too oblique and hence would cast longer shadows. This in turn would require greater distance between array structures to ensure shadow-free panels which leads to a higher land area requirement. The idea is to consider the decreasing length of shadows subtended by the tilted panels for the hours beyond sunrise for spacing between module structures, thus reducing the land requirements. This makes us choose the optimum time window, where the trade-off between the energy gains and additional land area needed is suitable. The list of assumptions considered in this approach are listed in Appendix B.

\subsection{Estimation of Sizing of System Components and Capacity}

The first step is to obtain the number of inverters/PCUs required for a plant of target capacity, $\mathrm{P}_{\text {plant-target }}$ (in MWp, DC)

No. of PCUs in plant $=\mathrm{N}_{\mathrm{PCU}}=\frac{\mathrm{P}_{\text {plant-target }}}{\mathrm{P}_{\text {nomDC }}}$ 
The result for $\mathrm{N}_{\mathrm{PCu}}$ obtained above is rounded down to the nearest integer in order to provide a conservative design and not oversize the system. By virtue of specification of voltages in the PCU datasheets, they bear the relation: $\mathrm{V}_{\text {mppmin }}<\mathrm{V}_{\text {start }}<\mathrm{V}_{\text {mppmax }}<\mathrm{V}_{\operatorname{maxDC}}$. We consider the midpoint of the Maximum Power Point Tracking (MPPT) range of the PCU as the design point (as indicated in point 7, Appendix B). This reference point would give an appreciable margin for variation across both extreme limits of the MPPT range. The corresponding voltage and rated current at this midpoint can be calculated as follows:

$\mathrm{V}_{\text {mid }}=\frac{\mathrm{V}_{\text {mppmin }}+\mathrm{V}_{\operatorname{mppmax}}}{2}$

$\mathrm{I}_{\text {mid }}=\frac{\mathrm{P}_{\text {nomDC }}}{\mathrm{V}_{\text {mid }}}$

It can be noted that during plant operation, the operating voltage is free to fluctuate within the MPP range. The design point of the module would be the MPP condition at Standard Testing Condition (STC) $\left(\mathrm{V}_{\mathrm{mp}}, \mathrm{I}_{\mathrm{mp}}\right)$. Hence, using this, the number of modules in series for voltage addition (forming 1 module string) can be calculated as:

$\mathrm{m}=\frac{\mathrm{v}_{\mathrm{mid}}}{\mathrm{V}_{\mathrm{mp}}}$

The value of ' $m$ ' can be rounded up (as applied here) or rounded down to the nearest integer.

The DC power seen by the PCU is a product of voltage and current. The module strings account for matching the appropriate reference PCU voltage. The current matching is done by sizing the required number of module strings in parallel (' $n$ ') to meet the power rating of the PCU. Ideally, a single array of ' $\mathrm{m} \times \mathrm{n}$ ' panels should meet the power requirements of the PCU. However, the resultant array may not be feasible from maintenance stand point. Hence, the number of module strings in parallel is split into two components:

- ' ' $n$ ' module strings in parallel per array

- ' 'y' arrays in parallel per PCU.

The size of the array is limited by the height of the structure (as indicated in point 3 , Appendix B). This consideration is agnostic to the dimensions of the module.

First we estimate ' $n$ ', considering the array to be tilted at an angle of $\beta$ with respect to the horizontal (ground surface) facing due south $\left(\gamma=0^{\circ}\right.$, for sites in Northern hemisphere) in line with point 2 from Appendix B. The height of the array structure not considering the ground clearance can be generically represented as ' $h$ '. Considering point 3 from Appendix B, for this study $\mathrm{h}=1.5$ metres

$$
\mathrm{n}=\left(\mathrm{h} /\left(\mathrm{L}_{\bmod } \times \sin \beta\right)\right)
$$

' $n$ ' is rounded down to the nearest integer to adhere to the array height restriction. In similar fashion, the number of arrays in parallel ' $y$ ' could be estimated as:

$\mathrm{y}=\mathrm{I}_{\mathrm{mid}} /\left(\mathrm{n} \times \mathrm{I}_{\mathrm{mp}}\right)$

' $y$ ' is rounded down to the nearest integer to limit the current addition at peak conditions to be close to design point. In summary, the number of modules at various levels is indicated as follows:

No. of modules per string $=\mathrm{m}$

No. of modules per array $=m \times n$ 
No. of modules per PCU $=\mathrm{m} \times \mathrm{n} \times \mathrm{y}$

No. of modules for the plant $=\mathrm{N}_{\text {mod }}=\mathrm{m} \times \mathrm{n} \times \mathrm{y} \times \mathrm{N}_{\mathrm{PCU}}$

Rated Capacity of the plant $\left(\mathrm{MW}_{\mathrm{p}}\right)=\mathrm{P}_{\text {plant }}=\mathrm{N}_{\text {mod }} \times \mathrm{P}_{\text {mod }} / 1000000$

Pure module area of the plant $=\mathrm{N}_{\text {mod }} \times \mathrm{L}_{\text {mod }} \times \mathrm{B}_{\text {mod }}$

\subsection{Estimation of Inter-Row and Inter-Column Spacing for Various Time Windows}

In order to calculate the inter-row and inter-column spacing, the appropriate solar angles are computed for no shading operation tailored to the location of interest. The various solar angles considered have been listed in Table A.1 of Appendix A and the relevant equations are listed in Appendix C (Duffie \& Beckman, 2013). An illustration of these solar angles is presented in Figure 3.

The inter-row and inter-column spacing is dependent on the time window of observation; closer the time window is to the sunrise period, longer are the shadows subtended by the arrays and hence greater would be the inter-row and inter-column spacing. Theoretically, the benefit of a wider time window (one that is closer to sunrise and sunset) is that the solar radiation captured and hence converted to electrical energy is slightly higher. However, the relative contribution due to this extended time window is minimal, as during the hours closer to sunrise and sunset the intensity of the solar radiation is reduced. In this approach, we focus only on the aspects related to plant area. In this context, the length of shadow subtended by the tilted panel is first computed for every hour along the E-W ( $\left.\mathrm{L}_{\mathrm{col}}\right)$ and N-S ( $\left.\mathrm{L}_{\text {row }}\right)$ directions using the following equations:

$\mathrm{L}_{\text {row }}=\mathrm{n} \times \mathrm{L}_{\text {mod }} \times \sin \beta \times \cos \gamma_{\mathrm{s}} / \tan \alpha_{\mathrm{s}}$

$\mathrm{L}_{\text {col }}=\mathrm{n} \times \mathrm{L}_{\text {mod }} \times \sin \beta \times \sin \gamma_{\mathrm{s}} / \tan \alpha_{\mathrm{s}}$

For the time windows: 7 am to $5 \mathrm{pm}, 8$ am to $4 \mathrm{pm}$, and 9 am to $3 \mathrm{pm}$, the maximum of $\mathrm{L}_{\text {row }}$ and $\mathrm{L}_{\mathrm{col}}$ are identified as $\mathrm{D}_{\text {row }}$ and $\mathrm{D}_{\text {col }}$ respectively. A collection of these elements is represented as inter-row $\left(D_{r}\right)$ and inter-column $\left(D_{c}\right)$ spacing sets.

$\mathrm{D}_{\text {row }}=\operatorname{Max}\left(\mathrm{L}_{\text {row }}\right), \quad$ here $\mathrm{D}_{\text {row }} \varepsilon \mathrm{D}_{\mathrm{r}}$

$\mathrm{D}_{\text {col }}=\operatorname{Max}\left(\mathrm{L}_{\mathrm{col}}\right), \quad$ here $\mathrm{D}_{\text {col }} \varepsilon \mathrm{D}_{\mathrm{c}}$

\subsection{Estimation of Plant Area}

Post determining $D_{r}$ and $D_{c}$, we estimate area of the plant in stages as described in Figure 2. We first build a generic algorithm for applying the spiral pattern (described in section 2.3.1), next we apply this to build the algorithm for estimating the area of the plant (covered in section 2.3.2) and finally we cover the aspects related to boundary spacing and metrics assessing land utilisation (covered in section 2.3.3 and 2.3.4). 


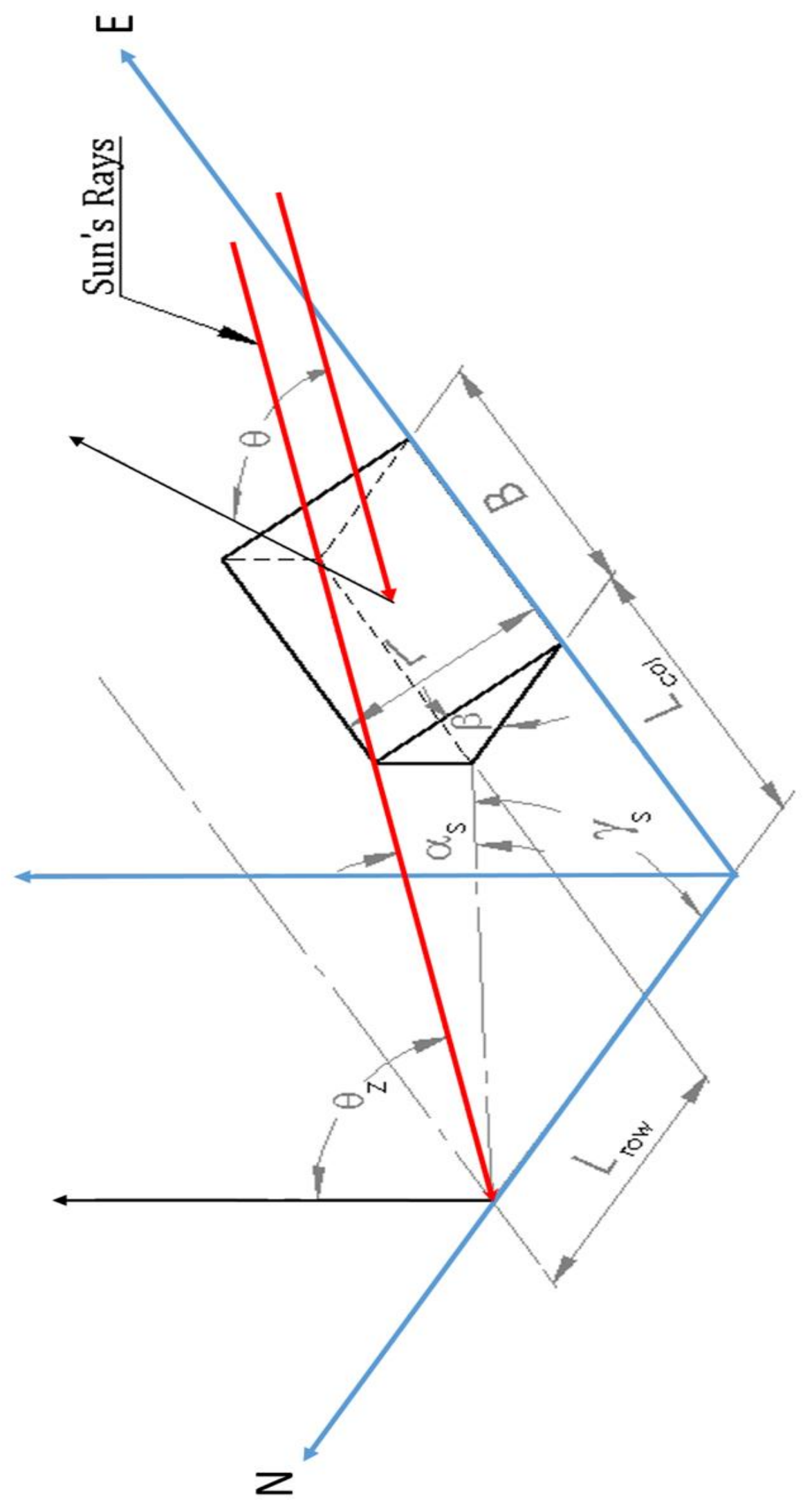

Figure 3: Illustration of solar angles for a panel at fixed tilt facing due south $\left(\gamma=0^{\circ}\right)$ 


\subsubsection{Inferences From the Spiral Pattern and Designing a Generic Algorithm}

Before we move to the specifics of area estimation, an understanding of the spiral pattern would be useful. To present a generic case, let us consider ' $\mathrm{X}$ ' units each of length ' $\mathrm{L}$ ' and breadth ' $\mathrm{B}$ ', to be arranged along the spiral pattern. For a given time window, each unit would be spaced with the corresponding $D_{\text {row }}$ and $D_{\text {col }}$ with respect to the other units. These units would be further enclosed with a boundary spacing of ' $a$ ' along length and ' $b$ ' along breadth. Figure 4 illustrates above mentioned arrangement for $\mathrm{X}=25$ units along with the direction conventions for length and breadth. Note, the direction of the spiral considered here is clockwise whereas the direction indicated in Figure 1 was anticlockwise. This change in direction of spin does-not affect the properties exhibited by the spiral which holds true for both cases. For the purposes of this study we will consider a spiral with a clockwise spin.

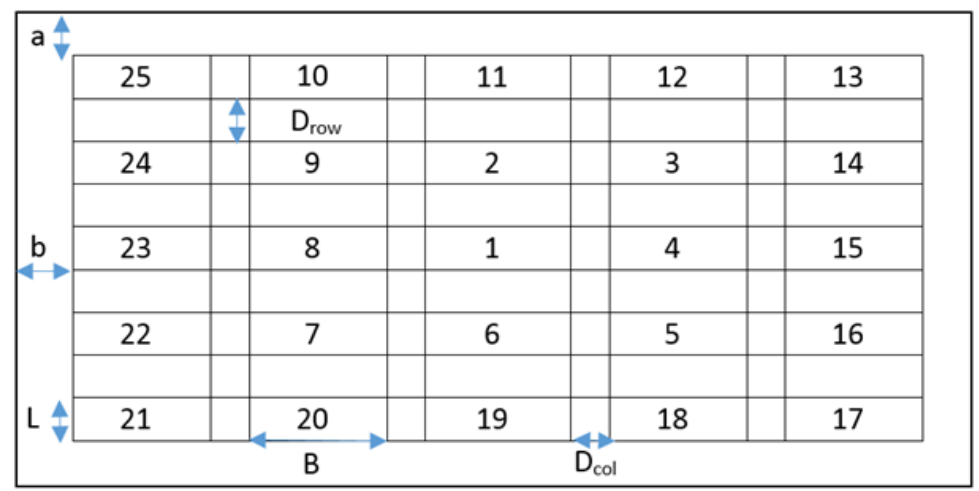

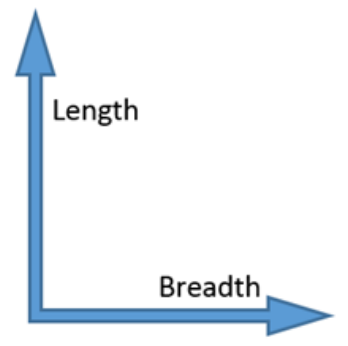

Figure 4: A schematic representation of units being placed in the clockwise spiral pattern

The spiral poses some very interesting symmetries, which could be tapped for designing an algorithm which mimics this pattern. If we neglect the quantum of spacing and look at the mere placement of numbered units in the spiral, it appears as shown in Figure 5.

\begin{tabular}{|c|c|c|c|c|c|}
\hline 25 & 10 & 11 & 12 & 13 & \\
\hline 24 & 9 & 2 & 3 & 14 & \\
\hline & & & & & $\begin{array}{l}\text { Transition sets } \\
\text { Perfect Square }\end{array}$ \\
\hline 23 & 8 & 1 & 4 & 15 & \\
\hline 22 & 7 & 6 & 5 & 16 & \\
\hline 21 & 20 & 19 & 18 & 17 & \\
\hline
\end{tabular}

Figure 5: Illustration of transition sets, square, and rectangular matrices

We find that the numbers (say $\mathrm{N}$ ) which are perfect squares form a square matrix with dimensions $\sqrt{\mathrm{N}}$. If $\mathrm{N}$ forms a rectangular matrix, then post $\mathrm{N}+1$ the direction of placement of units (or numbers in this case) is shifted by $90^{\circ}$ in the clockwise direction unless it reaches a unit corresponding to a square matrix. This set $(\mathrm{N}, \mathrm{N}+1)$ will henceforth be termed as the transition set. Once encountering a block which forms a square matrix, the direction of placement of blocks is again shifted by $90^{\circ}$ in the clockwise direction. It can be noticed that due 
to the pattern of the spiral, a unit completing a rectangular matrix increases the dimension of the matrix along the length and a unit completing a square matrix increases the dimension of the matrix along breadth.

Further, the identification of the dimensions of the nearest square/rectangular blocks of the matrix for a given number of units X (neglecting the inter-row/column spacing) is as illustrated in Table 2. Here $\mathrm{N}_{\mathrm{L}}$ and $\mathrm{N}_{\mathrm{B}}$ are blocks along the length and breadth which in turn reflect the dimensions of the matrix formed by X units.

Table 2: Distribution of dimensions of matrix set for a given set of ' $X$ ' units

\begin{tabular}{|c|c|c|c|c|c|c|}
\hline \multicolumn{7}{|c|}{$\mathbf{N}_{\mathbf{L}}{ }^{*} \mathbf{N}_{\mathbf{B}}=\mathbf{X}$ units (for square/rectangular blocks) } \\
\hline $\mathbf{N}_{\mathbf{L}} \downarrow / \mathbf{N}_{\mathbf{B}} \rightarrow$ & $\mathbf{1}$ & $\mathbf{2}$ & $\mathbf{3}$ & $\mathbf{4}$ & $\mathbf{5}$ & $\mathbf{6}$ \\
\hline $\mathbf{1}$ & 1 & & & & & \\
\hline $\mathbf{2}$ & 2,3 & $\mathbf{4 , 5}$ & & & & \\
\hline $\mathbf{3}$ & & $6,7,8$ & $9,10,11$ & & & \\
\hline $\mathbf{4}$ & & & $12,13,14,15$ & $\mathbf{1 6 , 1 7 , 1 8 , 1 9}$ & & \\
\hline $\mathbf{5}$ & & & & $20,21,22,23,24$ & $25,26,27,28,29$ & \\
\hline $\mathbf{6}$ & & & & $30,31,32,33,34,35$ & $36 \ldots$. \\
\hline
\end{tabular}

Now that we understand how the dimensions of the spiral matrix work, next we build a generic algorithm for incorporating $D_{r}$ and $D_{c}$. Let us consider a generic unit with its corresponding space components as indicated in Figure 6 . The unit considered is of dimensions $\mathrm{L} \times \mathrm{B}$ (length $\times$ breadth), with a generic inter-row spacing set of $D_{r}$ and inter-column spacing set of $D_{c}$.

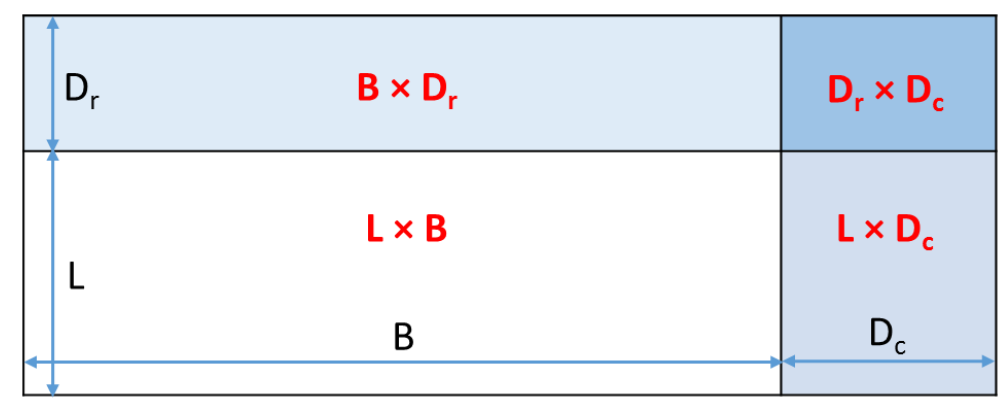

Figure 6: Representation of generic unit (dimensions in black and area in red)

The nomenclature for various parameters related to the application of the spiral algorithm is listed in Table A.2 of Appendix A. The area of the unit indicated in Figure 6 can be indicated as follows:
$\mathrm{A}_{\text {unit }}=$
Area of the unit
$=\quad\left(\mathrm{L}+\mathrm{D}_{\mathrm{r}}\right) \times\left(\mathrm{B}+\mathrm{D}_{\mathrm{c}}\right)$
$\mathrm{L} \times \mathrm{B}+\mathrm{B} \times \mathrm{D}_{\mathrm{r}}+\mathrm{L} \times \mathrm{D}_{\mathrm{c}}+\mathrm{D}_{\mathrm{r}} \times \mathrm{D}_{\mathrm{c}}$

We can classify the unit area in terms of four components. Each component is obtained by the product of two parameters. They are namely,

$\mathrm{L} \times \mathrm{B} \quad=\quad$ Area of the unit of dimensions $\mathrm{L}, \mathrm{B}$ 

$\mathrm{L} \times \mathrm{D}_{\mathrm{c}}=\quad$ Area contributed by dimensions $\mathrm{L}$ and the inter-column spacing $\left(\mathrm{D}_{\mathrm{c}}\right)$
$\mathrm{B} \times \mathrm{D}_{\mathrm{r}}=$ Area contributed by dimensions B and the inter-row spacing $\left(D_{r}\right)$
$\mathrm{D}_{\mathrm{r}} \times \mathrm{D}_{\mathrm{c}}=$ Area contributed by intersection of $D_{r}$ and $D_{c}$.

With reference to Figure 4, when the units are arranged using the spiral, the blocks are further segregated into two categories:

- Enclosed set: The combination of units which form a square or rectangular matrix. Parameters related to this are denoted with subscript ' $e$ '

- Outlying set: The combination of units which do not conform to the square or rectangular matrix structure. Parameters related to this denoted with subscript ' $o$ '

Based on the structure of the spiral discussed earlier, one can estimate the area of both the sets using the following relation:

$A_{e}=$ Area of enclosed set $=\left(N_{L e} \times L+N_{R e} \times D_{r}\right) *\left(N_{B e} \times B+N_{C e} \times D_{c}\right)$

$A_{o}=$ Area of outlying set $=\left(N_{L o} \times L+N_{R o} \times D_{r}\right) *\left(N_{B o} \times B+N_{C o} \times D_{c}\right)$

Here,

$\mathrm{N}_{\mathrm{Le} / \mathrm{o}} \quad=$ Number of units along length contributing to the enclosed or outlying set

$\mathrm{N}_{\mathrm{Re} / \mathrm{o}} \quad=$ Number of inter-row spacing sections along length contributing to the enclosed or outlying set

$\mathrm{N}_{\mathrm{Be} / \mathrm{o}} \quad$ = Number of units along breadth contributing to the enclosed or outlying set

$\mathrm{N}_{\mathrm{Ce} / \mathrm{o}} \quad=$ Number of inter-column spacing sections along breadth contributing to enclosed or outlying set

Consider an example illustrated in Figure 7 for $\mathrm{X}=24$ units, units up to 20 make the enclosed set and units 21 to 24 make the outlying set. Here $\mathrm{N}_{\mathrm{Le}}=5, \mathrm{~N}_{\mathrm{Lo}}=4, \mathrm{~N}_{\mathrm{Re}}=4, \mathrm{~N}_{\mathrm{Ro}}=3, \mathrm{~N}_{\mathrm{Be}}=4, \mathrm{~N}_{\mathrm{Bo}}=$ $1, \mathrm{~N}_{\mathrm{Ce}}=3, \mathrm{~N}_{\mathrm{Co}}=1$

$\mathrm{A}_{\text {block }}=\mathrm{A}_{\mathrm{e}}+\mathrm{A}_{\mathrm{o}}$

A generalised representation of the above expression in term of a single variable for each of the area components is indicated in Appendix D.

\begin{tabular}{|c|c|c|c|c|}
\hline & 10 & 11 & 12 & 13 \\
\hline 24 & 9 & 2 & 3 & 14 \\
\hline & & t. & & 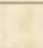 \\
\hline 23 & 8 & 1 & 4 & 15 \\
\hline & & & & \\
\hline 22 & 7 & 6 & 5 & 16 \\
\hline 5 & - & 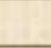 & & t \\
\hline 21 & 20 & 19 & 18 & 17 \\
\hline
\end{tabular}

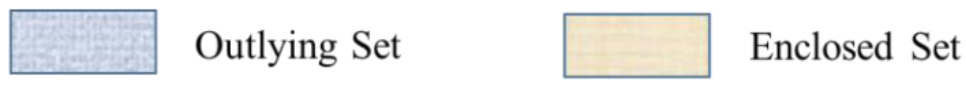


In summary, if we consider $\mathrm{X}$ units of dimensions $\mathrm{L} x \mathrm{~B}$ with inter-row spacing of $\mathrm{D}_{\mathrm{r}}$ and inter column spacing of $D_{c}$, then the following steps illustrate the generic approach to estimate the various coefficients for arranging these units in a spiral pattern:

1. Obtain the number of units $(\mathrm{X})$ to be arranged in the spiral pattern

a. $\mathrm{X}=\mathrm{y}$, for estimating module area cover for one PCU block

b. $\mathrm{X}=\mathrm{N}_{\mathrm{PCU}}$, for estimating module area cover for the entire plant

2. Initialise, the two main counters are ' $R$ ' and ' $S$ '.

a. $\mathrm{R}$ traces the growth of the units along length and $\mathrm{S}$ traces the growth of the units along breadth.

b. Further, due to the nature of the spiral and hence the matrix pattern created by it, $\mathrm{R}$ and $\mathrm{S}$ trace the formation of a rectangular and square matrix respectively

c. $\mathrm{R} \times \mathrm{S}$ gives the dimension of the enclosed set

3. Estimating the dimensions of the enclosed set. The unit counter (U) is set to 1 and is looped to $\mathrm{X}$ in steps of 1 :

a. First we account for the area contributed by the unit itself

b. If the $\mathrm{U}$ is a perfect square, we increment $\mathrm{S}$ by 1 , acknowledging growth of matrix along the breadth

c. We initiate the rectangular matrix count at $\mathrm{U}=2$ by incrementing $\mathrm{R}$ by 1 . Also, we initiate the space area due to inter-row spacing by incrementing A_BDr by 1

d. Beyond $U=3$, the accounting for both inter-row and inter-column spacing must be done. An interesting feature of the spiral is that when $U$ creates a rectangular matrix (marking the $1^{\text {st }}$ element of a transition set), the number of inter-column spacing (A_LDc) is a perfect square. But, it has to be noted that the transition sets (such as $U, U+1: 6,7 ; 12,13 ; 20,21$... etc.) share the inter-column spacing, with no addition of the inter-row spacing. This is accounted by tracing and applying appropriate correction using a set of '_temp' variables for A_BDr and A_LDc. Further, crossing a transition set typically marks the formation of a rectangular matrix and hence $\mathrm{R}$ is incremented by 1 . The appropriate counters are reset once we cross the second element of the transition set.

4. Estimate the number of units in the outlying set $\left(\mathrm{N}_{\mathrm{o}}\right)$.

5. Estimate $\mathrm{N}_{\mathrm{Le}}, \mathrm{N}_{\mathrm{Be}}, \mathrm{N}_{\mathrm{Lo}}, \mathrm{N}_{\mathrm{Bo}}, \mathrm{N}_{\mathrm{Re}}, \mathrm{N}_{\mathrm{Ro}}, \mathrm{N}_{\mathrm{Ce}}, \mathrm{N}_{\mathrm{Co}}$ and the direction of adding outlying set (along breadth or length). This should account for aspect of the spiral that:

a. If the enclosed set is a square matrix $(R=S)$, the outlying set is added along the breadth (B_Flag $=1$ )

b. If the enclosed set is a rectangular matrix $(\mathrm{R}>\mathrm{S})$, the outlying set is added along length (L_Flag = 1)

It has to be noted that when we combine the enclosed and the outlying sets to form a single matrix, if the outlying set is added along the breadth (B_Flag $=1$ ), then length of the combined matrix would increase by a factor of $\left(L+D_{r}\right)$. Similarly, if the outlying set is added along the length ( $L_{-}$flag $\left.=1\right)$, then the breadth of the combined matrix $\left(B+D_{c}\right)$.

The algorithm for implementation of the spiral algorithm is provided in Figure 8 and Figure 9. Here, the principal of counting follows, by first accounting for the block and then the spacing associated with it.

\subsubsection{Applying the Generic Algorithm for Area Estimation of PV Plant}

The inter-row and inter-column spacing of $D_{r}$ and $D_{c}$ respectively are applied consistently for spacing the arrays and PCU blocks. The area estimation at both levels would be done for all 
three time windows. The L and B will change appropriately based on level of the area estimation (for one PCU block or the plant).

For estimating the area of a PCU block, the generic unit is an array and there ' $y$ ' arrays that need to be arranged to build one PCU block each of dimensions:

$\mathrm{L}=$ Length of an array strip $=\mathrm{n} \times \mathrm{L}_{\text {mod }} \times \cos \beta$

$\mathrm{B}=$ Breadth of the array strip $=\mathrm{m} \times \mathrm{B}_{\bmod }$

The dimensions of the PCU block for each time window can be computed by applying the spiral algorithm as follows:

$\mathrm{L}_{-} \operatorname{array}_{\mathrm{e}}=\mathrm{N}_{\mathrm{Le}} \times \mathrm{L}+\mathrm{N}_{\mathrm{Re}} \times \mathrm{D}_{\mathrm{r}}$

B_array $_{\mathrm{e}}=\mathrm{N}_{\mathrm{Be}} \times \mathrm{B}+\mathrm{N}_{\mathrm{Ce}} \times \mathrm{D}_{\mathrm{c}}$

$\mathrm{L} \__{-} \operatorname{array}_{0}=\mathrm{N}_{\mathrm{Lo}} \times \mathrm{L}+\mathrm{N}_{\mathrm{Ro}} \times \mathrm{D}_{\mathrm{r}}$

B_arrayo $=\mathrm{N}_{\mathrm{Bo}} \times \mathrm{B}+\mathrm{N}_{\mathrm{Co}} \times \mathrm{D}_{\mathrm{c}}$

Net_Area_PCU $=$ L_array $\times$ $\times$ B_arraye + L_array ${ }_{0} \times$ B_arrayo $_{-}$

$\mathrm{LPCU}_{\mathrm{P}}=\mathrm{L}_{-} \mathrm{array}_{\mathrm{e}}+\mathrm{B} \_$flag $\times\left(\mathrm{L}+\mathrm{D}_{\mathrm{r}}\right)$

$\mathrm{B}_{\mathrm{PCU}}=\mathrm{B}_{-}$arraye $+\mathrm{L}_{-}$flag $\times\left(\mathrm{B}+\mathrm{D}_{\mathrm{c}}\right)$

Effective_PCU_Area $=$ LPCU $\times$ BPCU

Here the coefficients, $\mathrm{N}_{\mathrm{Le}}, \mathrm{N}_{\mathrm{Be}}, \mathrm{N}_{\mathrm{Lo}}, \mathrm{N}_{\mathrm{Bo}}, \mathrm{N}_{\mathrm{Re}}, \mathrm{N}_{\mathrm{Ro}}, \mathrm{N}_{\mathrm{Ce}}, \mathrm{N}_{\mathrm{Co}}, \mathrm{B}$ _flag, and L_flag correspond to the arrangement of ' $y$ ' arrays in spiral. 


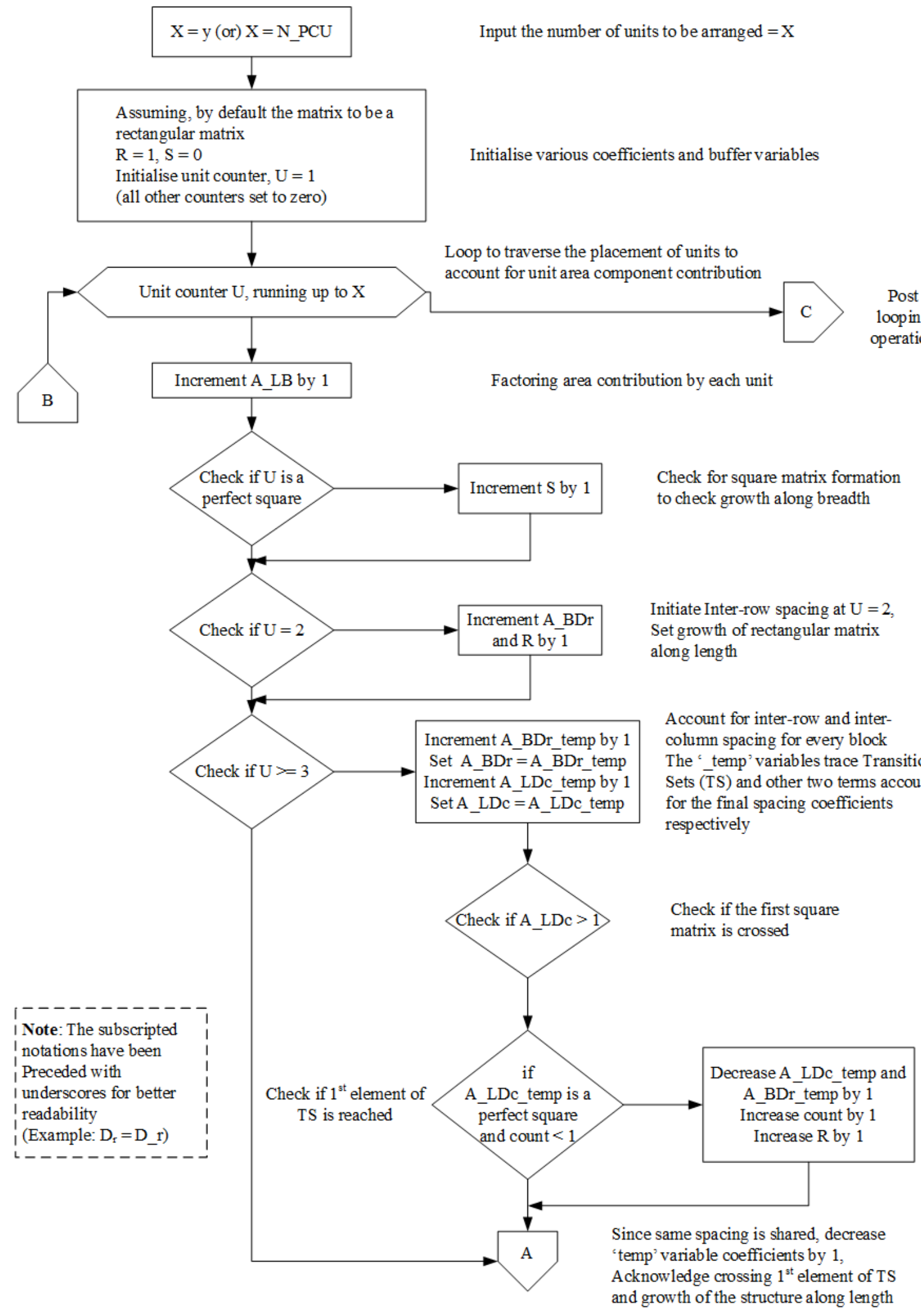

Figure 8: Generic algorithm for implementing the spiral pattern 


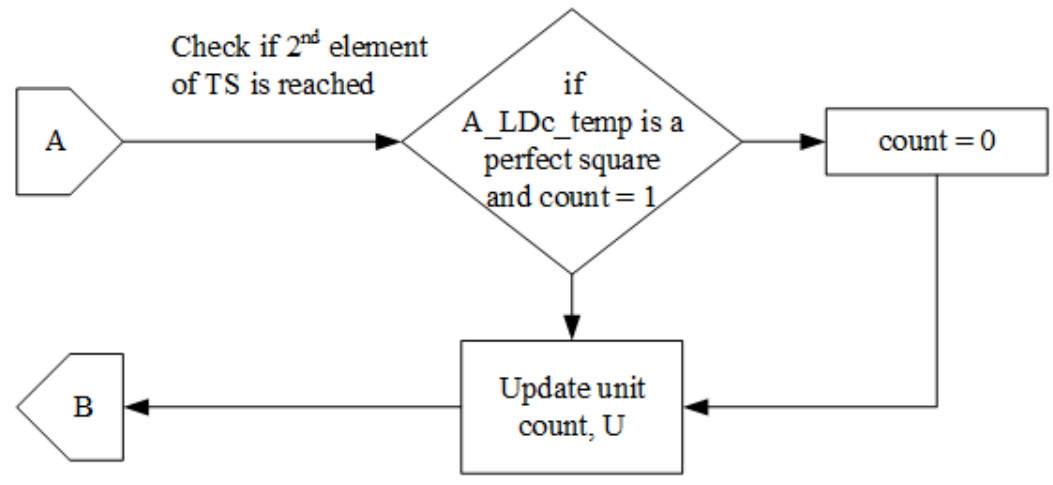

End of loop

Checking if the enclosed set forms a perfect square
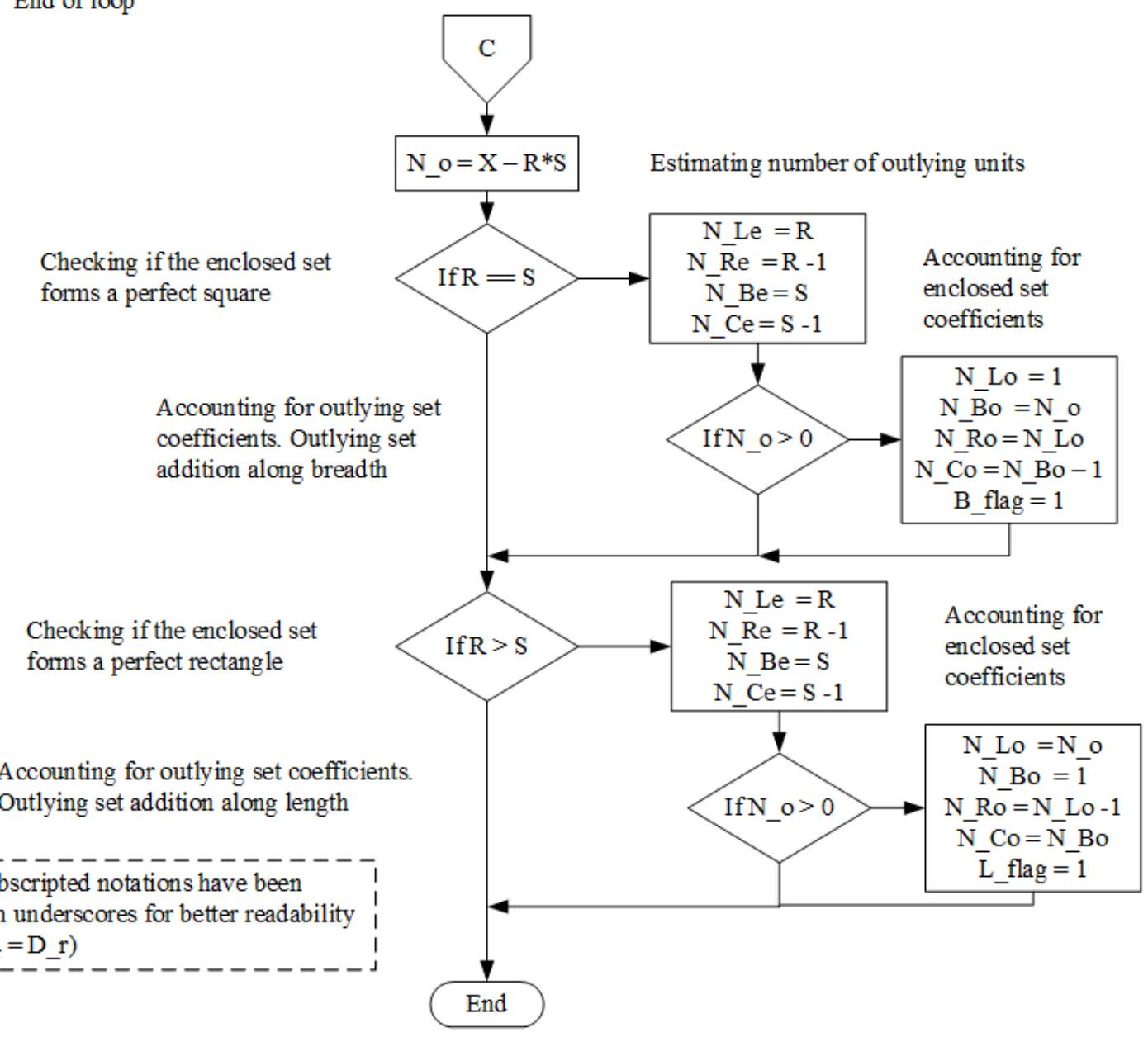

Figure 9: Generic algorithm for implementing the spiral pattern

When computing the area of a plant, the length (L) and breadth (B) of the generic block, for the spiral, becomes the length of the PCU block (LPCU) and breadth of the PCU block (BPCU). The dimensions of the plant for each time window by applying the spiral algorithm for ' $\mathrm{N}_{\mathrm{PCU}}$ ' could be computed as follows:

$\mathrm{L}=\mathrm{LPCU}$

$\mathrm{B}=\mathrm{B}$ PCU

$\mathrm{L}_{-} \mathrm{PCU}_{\mathrm{e}}=\mathrm{N}_{\mathrm{Le}} \times \mathrm{L}+\mathrm{N}_{\mathrm{Re}} \times \mathrm{D}_{\mathrm{r}}$

B_PCU $\mathrm{PCN}_{\mathrm{e}}=\mathrm{N}_{\mathrm{Be}} \times \mathrm{B}+\mathrm{N}_{\mathrm{Ce}} \times \mathrm{D}_{\mathrm{c}}$ 
$\mathrm{L}_{-} \mathrm{PCU}_{\mathrm{o}}=\mathrm{N}_{\mathrm{Lo}} \times \mathrm{L}+\mathrm{N}_{\mathrm{Ro}} \times \mathrm{D}_{\mathrm{r}}$

$\mathrm{B}_{-} \mathrm{PCU}_{\mathrm{o}}=\mathrm{N}_{\mathrm{Bo}} \times \mathrm{B}+\mathrm{N}_{\mathrm{Co}} \times \mathrm{D}_{\mathrm{c}}$

Net_Area_Plant $=\mathrm{L}_{-} \mathrm{PCU}_{\mathrm{e}} \times \mathrm{B}_{-} \mathrm{PCU} \mathrm{U}_{\mathrm{e}}+\mathrm{L}_{-} \mathrm{PCU}_{\mathrm{o}} \times \mathrm{B}_{-} \mathrm{PCU}_{\mathrm{o}}$

$\mathrm{L}_{\text {Plant }}=\mathrm{L}_{-} \mathrm{PCU}_{\mathrm{e}}+\mathrm{B}_{-}$flag $\times\left(\mathrm{L}+\mathrm{D}_{\mathrm{r}}\right)$

$\mathrm{B}_{\text {Plant }}=\mathrm{B}_{-} \mathrm{PCU}_{\mathrm{e}}+\mathrm{L}_{-}$flag $\times\left(\mathrm{B}+\mathrm{D}_{\mathrm{c}}\right)$

Effective_Plant_Area $=$ LPlant $\times$ BPlant

Here the coefficients, $\mathrm{N}_{\mathrm{Le}}, \mathrm{N}_{\mathrm{Be}}, \mathrm{N}_{\mathrm{Lo}}, \mathrm{N}_{\mathrm{Bo}}, \mathrm{N}_{\mathrm{Re}}, \mathrm{N}_{\mathrm{Ro}}, \mathrm{N}_{\mathrm{Ce}}, \mathrm{N}_{\mathrm{Co}}, \mathrm{B}$ flag, and L_flag correspond to the arrangement of ' $\mathrm{N}_{\mathrm{PCu}}$ ' PCUs in spiral. An illustration of the growth of the plant to various levels is indicated in Figure 10.

\subsubsection{Applying Boundary Spacing}

The next step would involve the addition of the area contributed by the boundary spacing components ' $a$ ' and ' $b$ ', using the pattern illustrated in Figure 6 as reference. Using the following formulae, this could be accounted and total area of the plant can be calculated:

Area_BS_along_length $=2 \times \mathrm{b} \times($ LPlant $+2 \times \mathrm{a})$

Area_BS_along_breadth $=2 \times \mathrm{a} \times$ BPlant

Total_Plant_Area $=$ Effective_Plant_Area + Area_BS_along_length + Area_BS_along_breadth

Figure 11, Figure 12 and Figure 13 provide a visual illustration of estimation of plant area, for an asymmetric number of PCUs $\left(\mathrm{N}_{\mathrm{PCU}}=17\right)$. The auxiliary area requirement for administrative buildings, PCU housings, and extended pathways is further added to the 'Total plant area' of the setup. The auxiliary area considerations are elaborated in Appendix E. The core idea of the proposed method focusses on generating the closest rectangular or square area formation for $\mathrm{N}_{\mathrm{PCu}}$ blocks for a PV plant. In cases where $\mathrm{N}_{\mathrm{PCU}}$ doesn't exactly form a square or rectangular matrix there is a possibility, that there is no need for auxiliary area requirement. This is due to the fact that the area left over due to the asymmetry of the layout (shaded area indicated in Figure 12 and Figure 13) could more than compensate for this requirement. The correction in auxiliary area requirement due to asymmetry of sizing parameters is indicated in Appendix E. 

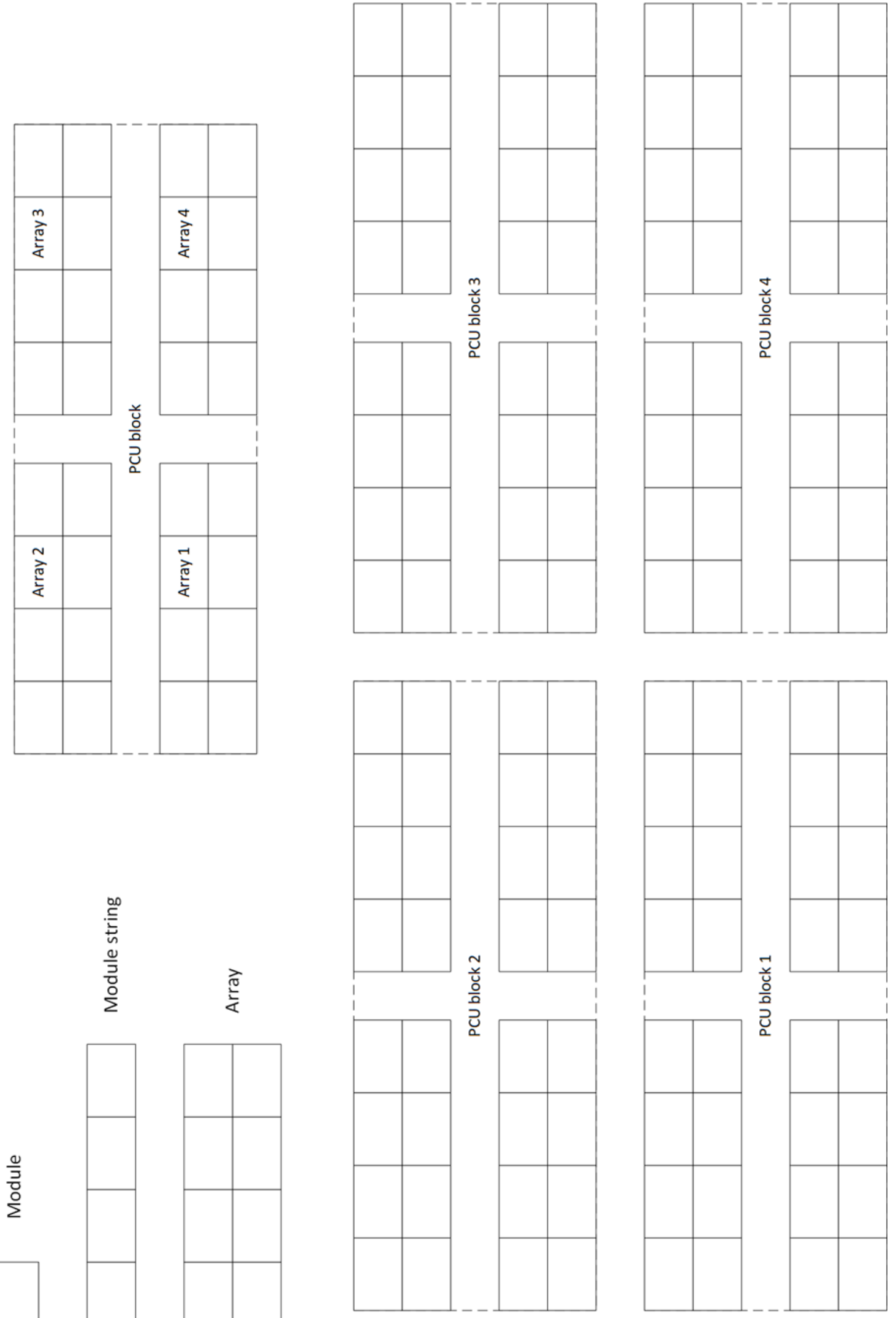

Figure 10: An example case of plant design for $n=2, m=4, y=4$, and $N_{P C U}=4$ 


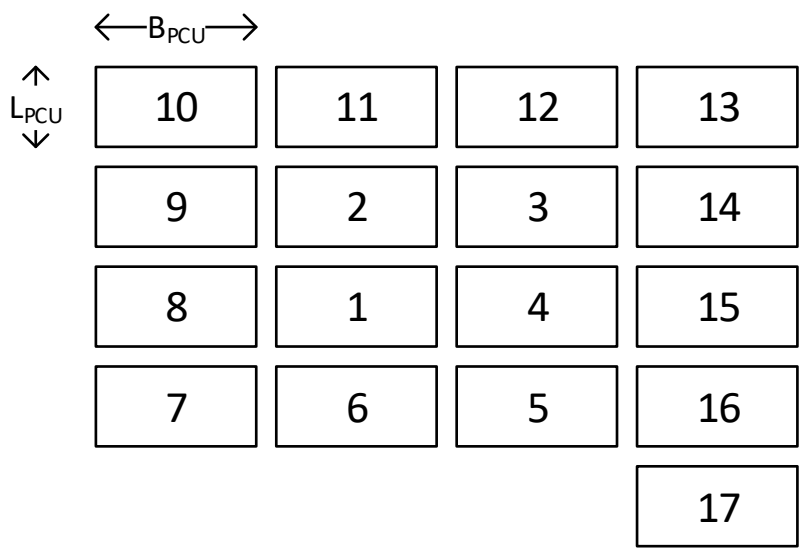

Figure 11: Illustration of 'net plant area' for a system with NPCU $=17$

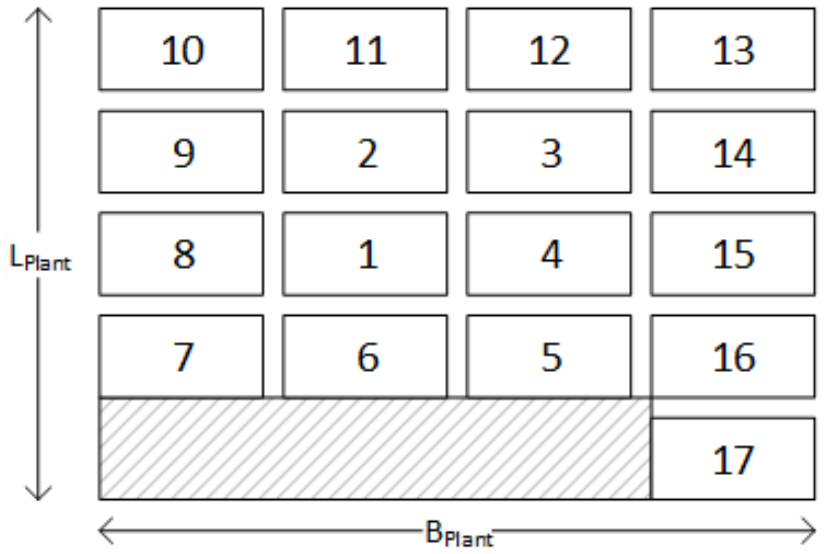

Figure 12: Illustration of 'effective plant area' for $N_{P C U}=17$

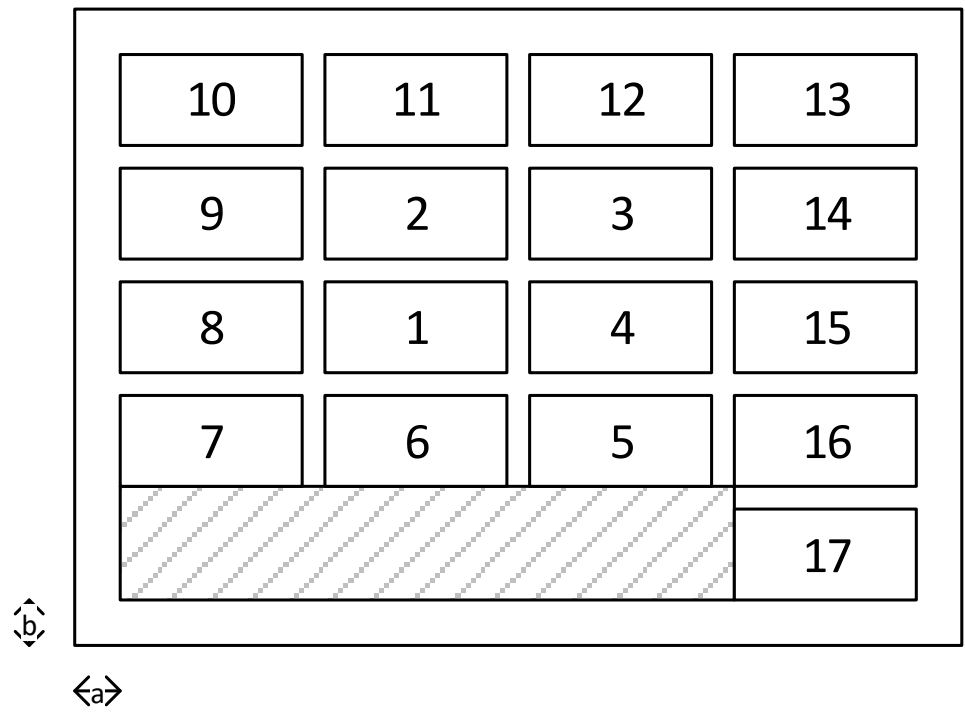

Figure 13: Illustration of 'Total plant area' for a system with NPCU $=17$ 


\subsubsection{Packing Density and Deviation Factor}

We define packing density (PD) as the ratio of active module area to total plant area for a given time window and configuration. This factor gives an indication of the active land area utilised for power generation.

$\mathrm{PD}=\frac{\text { Active module area }}{\text { Total_Plant_Area_with_Aux }}=\frac{\mathrm{N}_{\mathrm{mod}} \times \mathrm{L}_{\mathrm{mod}} \times \mathrm{B}_{\mathrm{mod}}}{\text { Total_Plant_Area_with_Aux }}$

In order to assess the extent of deviation in the estimated area, we introduce a deviation factor (DF), which is the ratio of the estimated total plant area to the benchmark area. In this study, we consider the benchmark area to be the norm suggested by CERC of 5 acres/MWp. DF is positive, if the estimated area is greater than benchmark area and negative if it is lesser

$\mathrm{DF}=\frac{\text { Total_plant_Area_with_Aux (in acres) }-\mathrm{P}_{\text {plant }} \times \text { Benchmark Area }}{\mathrm{P}_{\text {plant }} \times \text { Benchmark Area }}$ 


\section{Results}

\subsection{Case Simulation to Illustrate the Proposed Approach}

To illustrate the application of the proposed approach, we build the algorithm in Python and simulate a $1 \mathrm{MWp}$ plant at location close Bengaluru (latitude $12.97^{\circ} \mathrm{N}$ ) with mono-crystalline, multi-crystalline, and thin-film technology options. To provide a fair comparison, modules of same power rating are considered. Table 3 provides a summary of the simulation results. Appendix F provides details of spiral related parameters and specifics about the output.

Table 3: Summary of simulation results for technology comparison for a test case for a location at latitude of $12.97^{\circ} \mathrm{N}$

\begin{tabular}{|c|c|c|c|c|c|c|c|c|c|}
\hline $\begin{array}{l}\text { Parameters } \\
\downarrow / \text { Technology } \rightarrow\end{array}$ & \multicolumn{3}{|c|}{ Mono-crystalline } & \multicolumn{3}{|c|}{ Multi-crystalline } & \multicolumn{3}{|c|}{$\begin{array}{l}\text { Thin-Film } \\
\text { (Amorphous } \\
\text { Silicon) }\end{array}$} \\
\hline $\begin{array}{l}\text { Target Plant Capacity } \\
\text { in MWp (Pplant-target) }\end{array}$ & \multicolumn{9}{|c|}{1} \\
\hline Module model & \multicolumn{3}{|c|}{$\begin{array}{l}\text { Adani Solar, ASM-7- } \\
\text { PERC-350, Mono, } 72 \text { cells } \\
\text { (Adani Solar, n.d.) }\end{array}$} & \multicolumn{3}{|c|}{$\begin{array}{l}\text { REC Solar, REC-350-TP2S } \\
\text { 72, Multi-PERC, } 144 \text { cells } \\
\text { (REC Solar, n.d.) }\end{array}$} & \multicolumn{3}{|c|}{$\begin{array}{c}\text { Moserbaer Solar, FS } \\
\text { series A-Si, Thin film } \\
\text { (Moserbaer Solar, } \\
\text { 2010) } \\
\end{array}$} \\
\hline $\begin{array}{l}\text { Module power (Wp at } \\
\text { STC) }\end{array}$ & \multicolumn{9}{|c|}{350} \\
\hline$V_{m p}$ at STC (V) & \multicolumn{3}{|c|}{38.59} & \multicolumn{3}{|c|}{38.9} & \multicolumn{3}{|c|}{133.6} \\
\hline$I_{\mathrm{mp}}$ at STC (A) & \multicolumn{3}{|c|}{9.08} & \multicolumn{3}{|c|}{9} & \multicolumn{3}{|c|}{2.62} \\
\hline PCU Manufacturer & \multicolumn{9}{|c|}{ Eaton, Power Xpert Solar 250 kW Inverter (Eaton, 2015) } \\
\hline No. of PCUs (NPCU) & \multicolumn{3}{|c|}{4} & \multicolumn{3}{|c|}{4} & \multicolumn{3}{|c|}{4} \\
\hline $\begin{array}{l}\text { No. of modules } \\
\text { strings/array (n) }\end{array}$ & \multicolumn{3}{|c|}{6} & \multicolumn{3}{|c|}{6} & \multicolumn{3}{|c|}{3} \\
\hline $\begin{array}{l}\text { No. of modules in } \\
\text { series/string (m) }\end{array}$ & \multicolumn{3}{|c|}{11} & \multicolumn{3}{|c|}{11} & \multicolumn{3}{|c|}{3} \\
\hline $\begin{array}{l}\text { No. of arrays in } \\
\text { parallel per } P C U(y)\end{array}$ & \multicolumn{3}{|c|}{11} & \multicolumn{3}{|c|}{11} & \multicolumn{3}{|c|}{79} \\
\hline $\begin{array}{l}\text { Total no. of modules } \\
\text { in plant }\left(\mathrm{N}_{\text {plant }}\right)\end{array}$ & \multicolumn{3}{|c|}{2904} & \multicolumn{3}{|c|}{2904} & \multicolumn{3}{|c|}{2844} \\
\hline $\begin{array}{l}\text { Design Plant capacity } \\
\text { (PPlant) in MWp }\end{array}$ & \multicolumn{3}{|c|}{1.016} & \multicolumn{3}{|c|}{1.016} & \multicolumn{3}{|c|}{0.995} \\
\hline $\begin{array}{l}\text { Time window wise } \\
\text { parameters }\end{array}$ & $\begin{array}{l}7 \text { am } \\
\text { to } 5 \\
\text { pm }\end{array}$ & $\begin{array}{c}8 \text { am } \\
\text { to } 4 \\
\text { pm }\end{array}$ & $\begin{array}{l}9 \text { am } \\
\text { to } 3 \\
\text { pm }\end{array}$ & $\begin{array}{l}7 \text { am } \\
\text { to } 5 \\
\text { pm }\end{array}$ & $\begin{array}{l}8 \text { am } \\
\text { to } 4 \\
\text { pm }\end{array}$ & $\begin{array}{l}9 \text { am } \\
\text { to } 3 \\
\text { pm }\end{array}$ & $\begin{array}{l}7 \text { am } \\
\text { to } 5 \\
\text { pm }\end{array}$ & $\begin{array}{c}8 \text { am } \\
\text { to } 4 \\
\text { pm }\end{array}$ & $\begin{array}{l}9 \text { am } \\
\text { to } 3 \\
\text { pm }\end{array}$ \\
\hline $\mathbf{D}_{\mathbf{r}}(\mathrm{m})$ & 4.14 & 1.83 & 1.31 & 4.18 & 1.85 & 1.32 & 4.59 & 2.03 & 1.45 \\
\hline $\mathrm{D}_{\mathrm{c}}(\mathrm{m})$ & 8.32 & 2.97 & 1.60 & 8.40 & 2.99 & 1.61 & 9.23 & 3.29 & 1.77 \\
\hline $\begin{array}{l}\text { Pure module area } \\
\text { (acres) }\end{array}$ & & 1.407 & & & 1.440 & & & 4.020 & \\
\hline Net plant area (acres) & 3.20 & 2.13 & 1.90 & 3.28 & 2.17 & 1.95 & 14.23 & 7.29 & 5.92 \\
\hline $\begin{array}{l}\text { Effective plant area } \\
\text { (acres) }\end{array}$ & 3.20 & 2.13 & 1.90 & 3.28 & 2.17 & 1.95 & 14.23 & 7.29 & 5.92 \\
\hline $\begin{array}{l}\text { Total plant area } \\
\text { (acres) }\end{array}$ & 4.53 & 3.23 & 2.96 & 4.61 & 3.30 & 3.02 & 16.76 & 9.10 & 7.55 \\
\hline $\begin{array}{l}\text { Total plant area with } \\
\text { Aux (acres) }\end{array}$ & 4.53 & 3.23 & 2.96 & 4.61 & 3.30 & 3.02 & 17.00 & 9.10 & 7.55 \\
\hline PD & 0.31 & 0.43 & 0.48 & 0.31 & 0.44 & 0.48 & 0.24 & 0.44 & 0.53 \\
\hline DF @ 5 acres/MWp & -0.11 & -0.36 & -0.42 & -0.09 & -0.35 & -0.41 & 2.42 & 0.83 & 0.52 \\
\hline
\end{tabular}


It can be seen that the thin-film module offers very high voltage addition and hence requires less modules to be connected in series; this is indicated by a reduced ' $m$ '. However, its current addition is poor and therefore a large number of modules need to be connected in parallel, resulting in a large ' $y$ '. This aspect affects the area requirements of the plant. The combined effect of all the plant scaling parameters is reflected in the plant area requirements. This is captured in Figure 14, here the estimated plant area is compared with the IREDA and CERC benchmarks. It can be seen that for all the three technologies, when considering time windows 8 am to $4 \mathrm{pm}$ and 9 am to $3 \mathrm{pm}$ the area estimates lie within, or are less than the IREDA and CERC estimates. It has to be noted that for a multi-crystalline plant the upper limit of IREDA and CERC benchmarks are the same ( 5 acres/MWp). It can be seen that, due to the module dimensions and hence the sizing parameters (n, $\mathrm{m}, \mathrm{y}$ ) the area estimates of mono and multi-crystalline technology based plants are very similar, but the thin film technology based plants differ significantly. It can be seen that for a given time window, the difference between the $D_{r}$ and $D_{c}$ components across technology options is not much. This is because of the cap on the maximum array structure height. The resulting higher area requirements due to sizing parameters are reflected in the PD and DF estimates appropriately in Figure 15. It is to be noted that DF is negative when the estimated area is lesser than the CERC benchmark. Since the number of PCUs in all cases is 4 (a perfect square) the 'Net plant area' and the 'Effective plant area' work out to be the same.

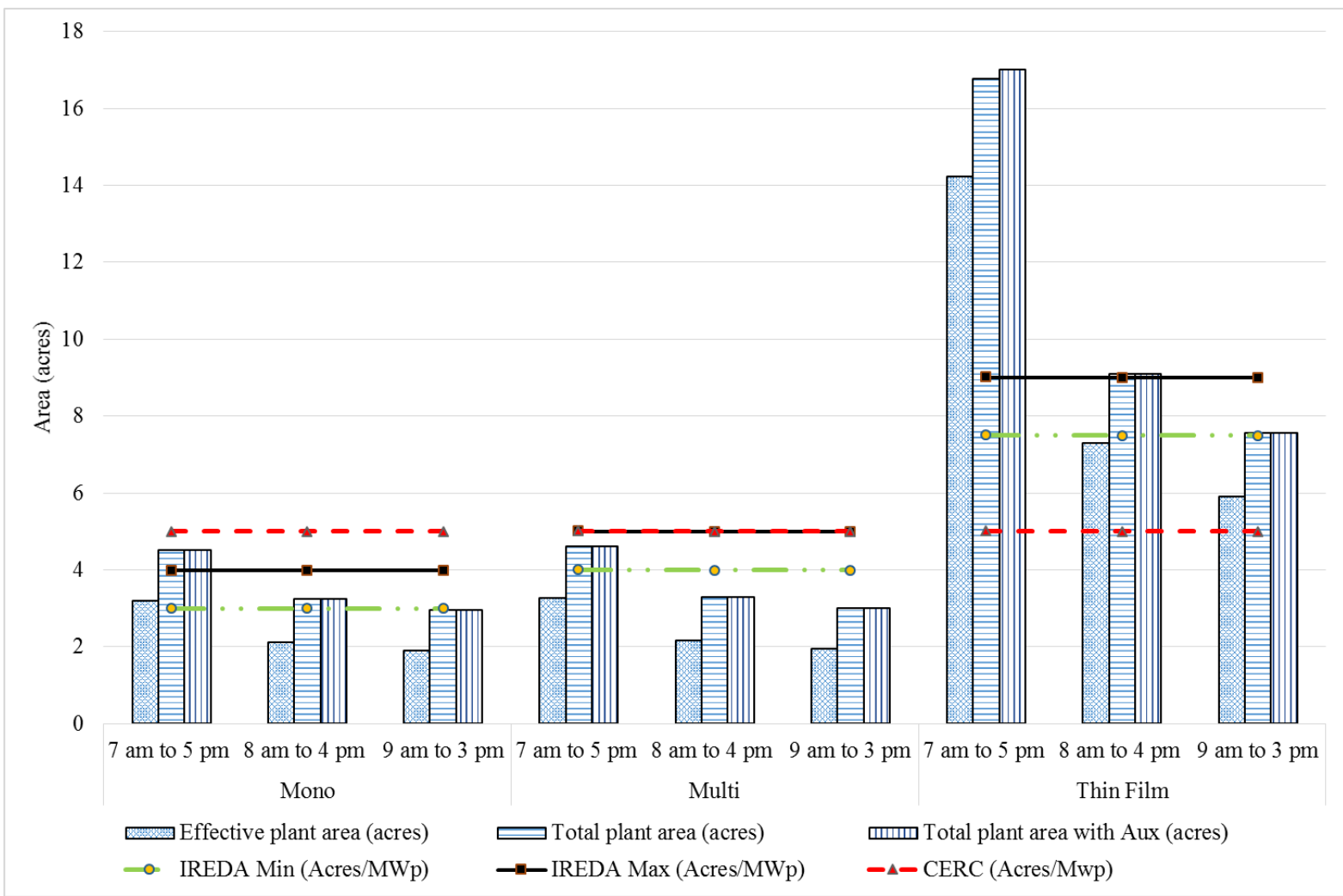

Figure 14: Area estimates for a 1MWp plant near Bengaluru for different technologies 


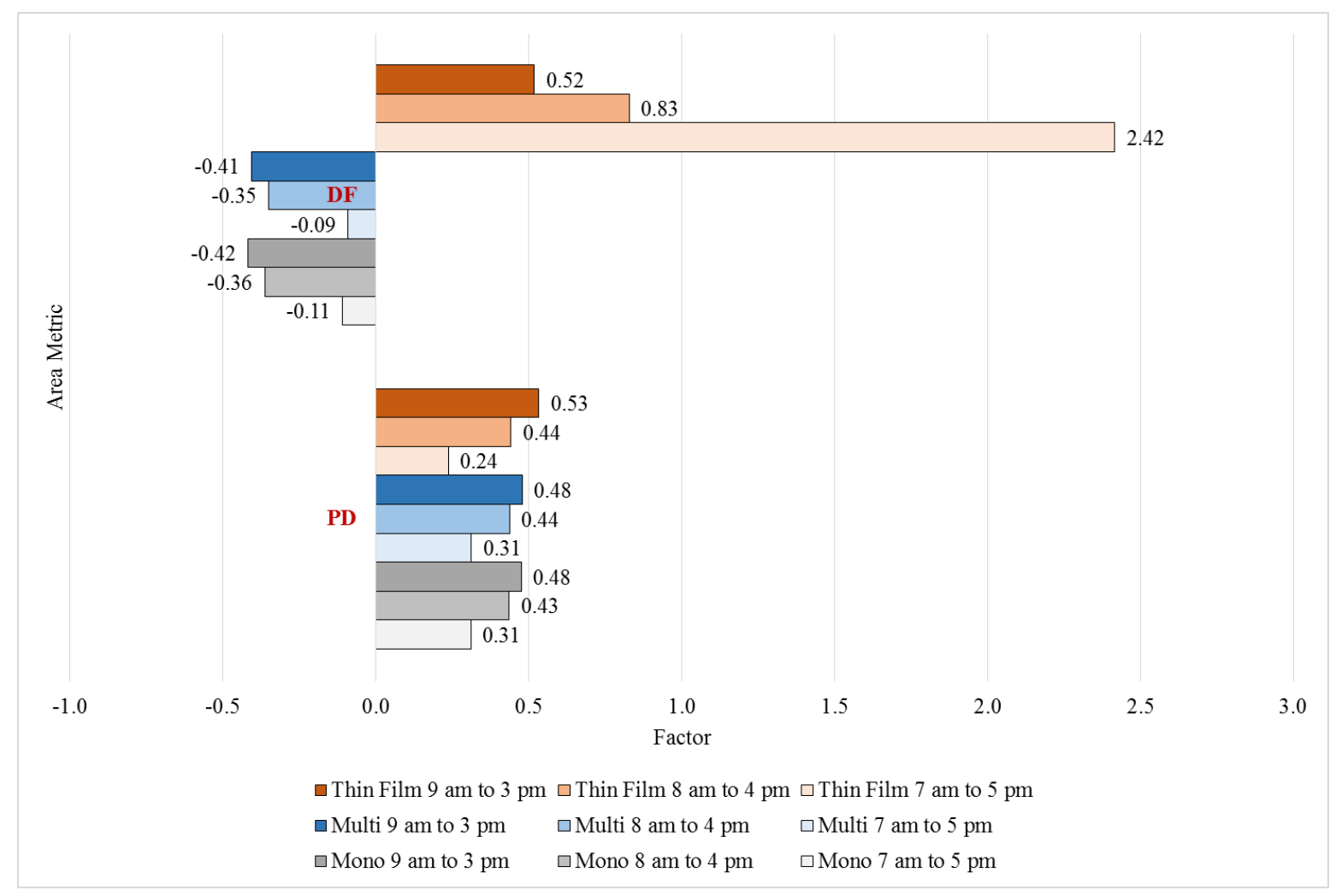

Figure 15: PD and DF for 1MWp plant near Bengaluru for different technologies

\subsection{Testing the Approach to Predict Area of Active PV Plants}

To check the robustness of the approach, we estimate the area of some existing plants and check the deviation margins when compared to their declared area. Table 4 provides a summary of the estimates. Appendix G details the relevant considerations and calculations. The deviation in the area could be attributed to applicability of assumption for estimating the auxiliary area, which is a plant specific criteria and a strong function of terrain undulations. Another factor, which could create variations in the estimate, is the tilt angle of the modules considered in design, since it could not be confirmed from public records, it is possible that $\beta \neq \varphi$ for plants which show positive deviation. It has to be noted that theoretically it is possible to design these plants in lesser area too (detailed in Appendix G).

Table 4: Summary of comparison of actual declared area of select existing plants and estimated area

\begin{tabular}{|l|l|l|c|c|c|}
\hline $\begin{array}{l}\text { Plant } \\
\text { no. }\end{array}$ & Plant & Coordinates & $\begin{array}{l}\text { Declared } \\
\text { land area } \\
\text { (Acres) }\end{array}$ & $\begin{array}{l}\text { Estimated } \\
\text { area } \\
\text { (acres) }\end{array}$ & Deviation \\
\hline 1 & $\begin{array}{l}\text { Grid connected 3 MWp Solar } \\
\text { PV power plant (UNFCCC - } \\
\text { CDM, 2011) }\end{array}$ & $\begin{array}{l}16^{\circ} 24^{\prime} 03^{\prime \prime} \mathrm{N}, \\
74^{\circ} 39^{\prime} 48^{\prime \prime} \mathrm{E}\end{array}$ & 15 & 15.61 & $4 \%$ \\
\hline 2 & $\begin{array}{l}5 \text { MW Solar PV Power Project } \\
\text { at NTPC Faridabad (UNFCCC - } \\
\text { CDM, 2014) }\end{array}$ & $\begin{array}{l}28^{\circ} 17^{\prime} 08^{\prime \prime} \mathrm{N}, \\
77^{\circ} 19^{\prime} 02^{\prime \prime} \mathrm{E}\end{array}$ & 20 & 19.33 & $-3 \%$ \\
\hline 3 & $\begin{array}{l}\text { 5 MW Solar PV Power Project } \\
\text { at Port Blair (A\&N) (UNFCCC - } \\
\text { CDM, 2012b) }\end{array}$ & $\begin{array}{l}11^{\circ} 36^{\prime} 40^{\prime \prime} \mathrm{N}, \\
92^{\circ} 42^{\prime} 36^{\prime \prime} \mathrm{E}\end{array}$ & 24.71 & 21.58 & $-13 \%$ \\
\hline
\end{tabular}




\begin{tabular}{|l|l|l|c|c|c|}
\hline 4 & $\begin{array}{l}15 \text { MW Solar Photovoltaic } \\
\text { Power Plant in Gujarat } \\
\text { UNFCCC - CDM, 2012a) }\end{array}$ & $\begin{array}{l}23^{\circ} 21^{\prime} 37^{\prime \prime} \mathrm{N}, \\
70^{\circ} 03^{\prime} 15^{\prime \prime} \mathrm{E}\end{array}$ & 106 & 92.17 & $-13 \%$ \\
\hline \multirow{5}{*}{5} & $\begin{array}{l}5 \mathrm{MW} \text { AC }(\text { 5.75 MWp) Grid } \\
\text { Connected Solar PV based } \\
\text { power generation at Naini, } \\
\text { Allahabad (UNFCCC - CDM, } \\
\text { 2012c) }\end{array}$ & $\begin{array}{l}25^{\circ} 22^{\prime} 22^{\prime \prime} \mathrm{N}, \\
81^{\circ} 52^{\prime} 18^{\prime \prime} \mathrm{E}\end{array}$ & 27 & 28.28 & $5 \%$ \\
\hline
\end{tabular}

\subsection{India-Specific Insights}

India is spread across latitudes $8.067^{\circ} \mathrm{N}$ to $37.1^{\circ} \mathrm{N}$. When applying the proposed approach, due to $\beta=\varphi$, the ' $n$ ' in an array would be different across latitudes, since the array height is capped at $2 \mathrm{~m}$. This would lead to varying inter-row and inter-column spacing at different latitudes. To shed some light on the land area requirements for a PV plant across the latitudinal spread, we size the plant details as needed for different locations (illustrated in Figure 16). Here a $1 \mathrm{MWp}$ system is sized using Tata Power multi-crystalline TS250 - $250 \mathrm{Wp}$ module (Tata Power Solar, 2014 ) and a $250 \mathrm{~kW}$ Eaton power conditioning unit (Eaton, 2015) and the base assumptions mentioned earlier are simulated across the latitude range $8^{\circ} \mathrm{N}$ to $37^{\circ} \mathrm{N}$ at $1^{\mathrm{o}}$ resolution. For time windows 7 am to $5 \mathrm{pm}$ and 8 am to $4 \mathrm{pm}$, results for only those latitudes whose area falls below 5 acres is plotted. For 9 am to 3 pm however, the results are plotted for the entire range. If we consider the upper limit of area requirement/MWp to be 5 acres/MWp, from Figure 16 it can be seen that, a 7 am to 5 pm time window would be suitable for latitudes up to $11^{\mathrm{o}} \mathrm{N}$ and 8 am to 4 pm time window is suited up to $23^{\circ} \mathrm{N}$, beyond this 9 am to $3 \mathrm{pm}$ seems like the most suitable time window. The kinks in the profile is attributed to the change in ' $n$ ' as indicated in Figure 17. Also the decreasing trend in area needs from $8^{\circ} \mathrm{N}$ to $10^{\circ} \mathrm{N}$ and again from $12^{\circ} \mathrm{N}$ to $14^{\circ} \mathrm{N}$ is due to asymmetry in sizing introduced by ' $y$ '.

Another aspect of focus, is to consider the area requirements with increase in plant capacity. To capture the extreme cases, we estimate the area requirements for the extreme latitudes of $8^{\circ} \mathrm{N}$ and $37^{\circ} \mathrm{N}$ from 1 to $100 \mathrm{MWp}$. Figure 18 captures this for a 9 am to $3 \mathrm{pm}$ solar time window. It could be seen that, when comparing it with the benchmark area estimates as per CERC, the area estimates for latitude of $37^{\circ} \mathrm{N}$ only slightly exceed the benchmark area requirements. Whereas, the area estimates for latitude of 8 $\mathrm{N}$ are significantly much less than the CERC estimates. This indicates that the CERC norms over-estimate the area requirements at lower latitudes. As a support to this claim the 3 MW Yelasandra plant (Mitavachan, H; Srinivasan, J; Gokhale, 2011) at

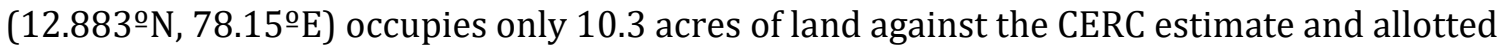
land area of 15 acres. This translates to 3.43 acres/MWp. Considering a rough estimate from Figure 16, it can be seen that the area estimate at $13^{\circ} \mathrm{N}$ (closest latitude) works out to be 3.45 acres/MWp for a time window of 8 am to $4 \mathrm{pm}$ and 3.16 acres/MWp for a time window of 9 am to $3 \mathrm{pm}$. The step pattern observed in the Figure 18 is due to the correction applied to minimise auxiliary area assignment as explained in Appendix E. The analysis indicated in section $3.1 \mathrm{can}$ be extended to the extreme latitudes $\left(8^{\circ} \mathrm{N}\right.$ and $\left.37^{\circ} \mathrm{N}\right)$ and results are presented in Appendix $\mathrm{H}$. 


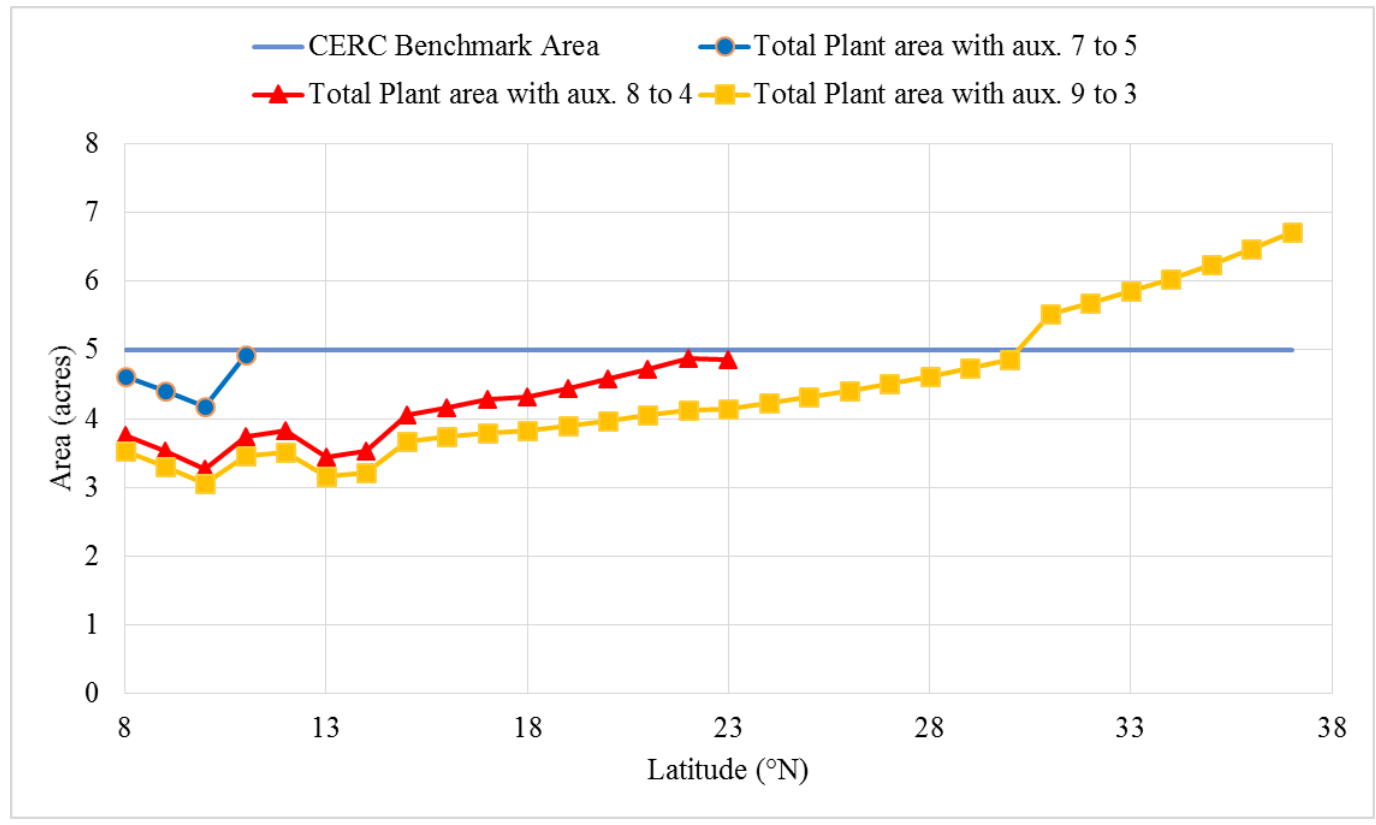

Figure 16: Total plant area including auxiliary area requirements for $1 M W p$ plant across time windows

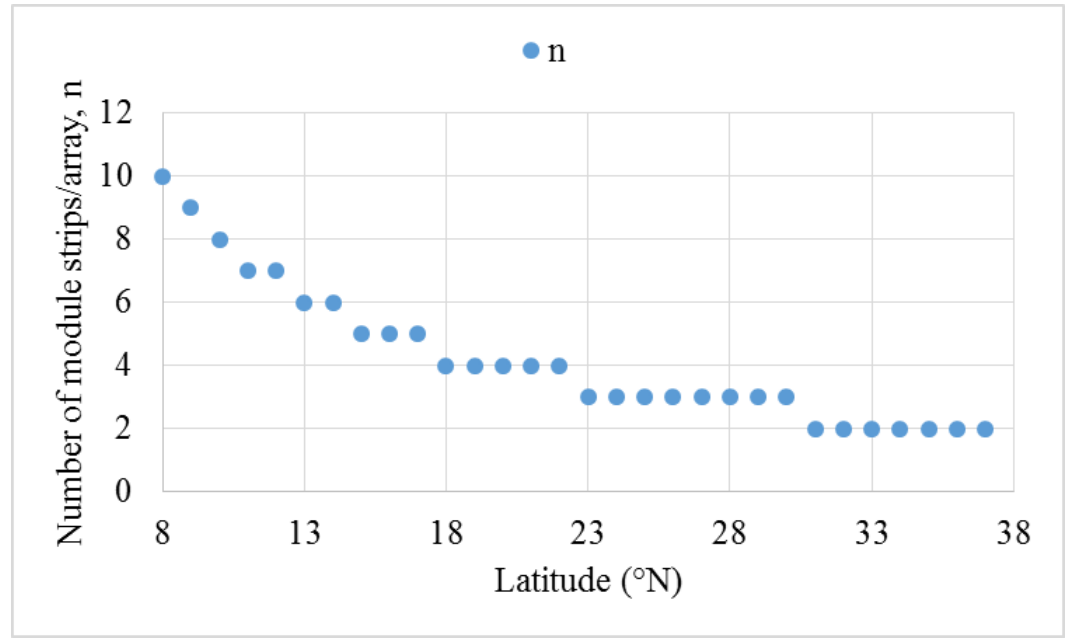

Figure 17: Variation of ' $n$ ' across latitude 


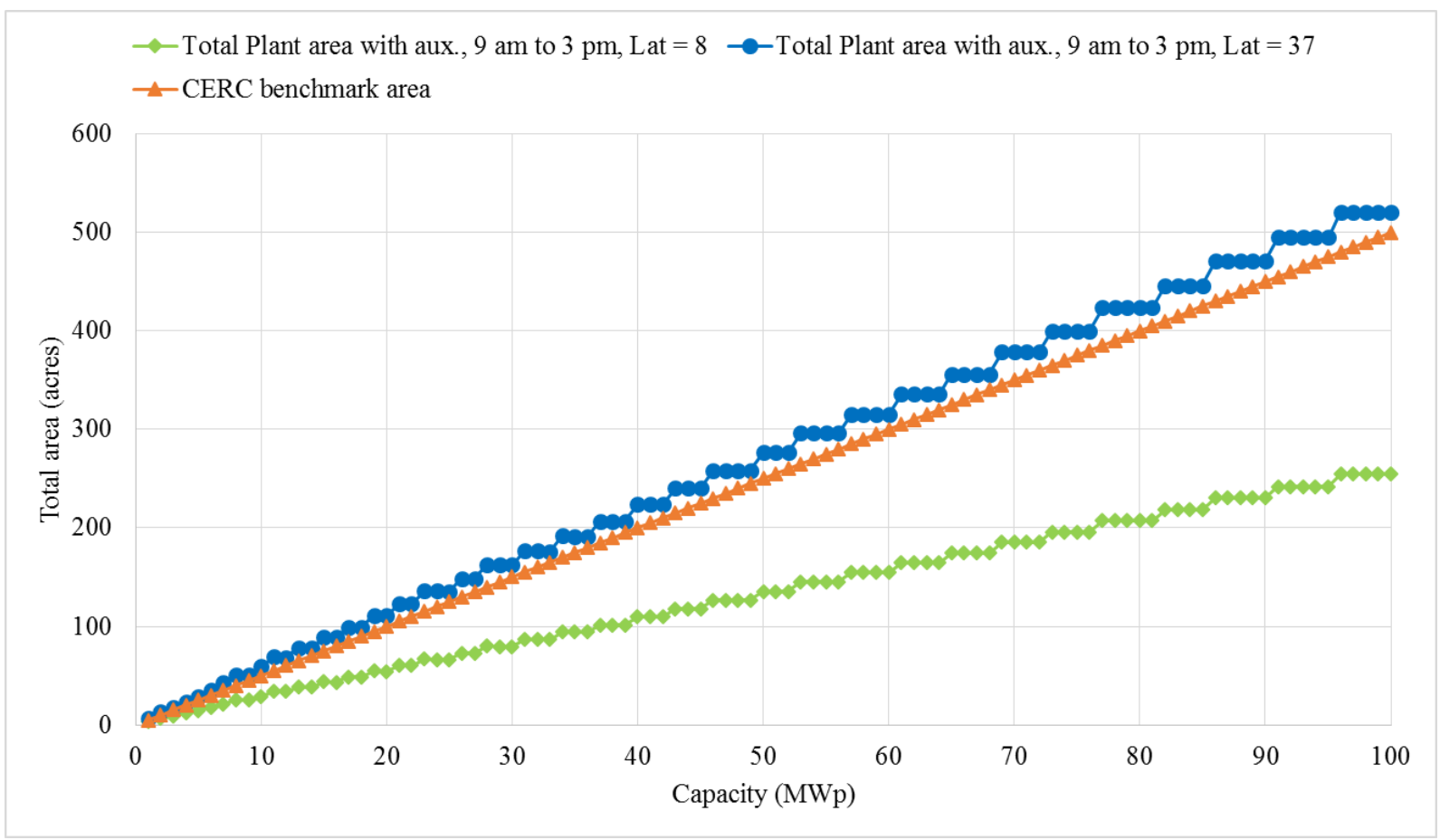

Figure 18: Capacity wise Total plant area (including auxiliary area) for 9 am to 3 pm window for latitudes 8 and $37 \stackrel{\circ}{N}$ 


\section{Estimating the Solar Power Potential for India}

In this report, so far we have presented a method for estimating land area requirements of a solar PV plant factoring various design considerations. Further, we presented results of a hypothetical case comparing different module technologies. To check the robustness of the approach we compared the estimated area requirements from the method to the reported area of currently operational plants. The basis for the deviations was ascertained. In this context, we now aim to assess the solar PV potential in India using the land data from 2011-12 provided in the 'Bhuvan - Geo platform' by the Indian Space Research Organisation (ISRO, 2014)

The total land cover of India is about 3.287 Million $\mathrm{km}^{2}$ and the percentage share of the various land types is indicated in Figure 19. Typically wastelands are considered for installation of RE plants. The wastelands constitute to about $12.10 \%$ of the total land cover, this translates to 0.34 Million $\mathrm{km}^{2}$. The percentage share of these wastelands is indicated in Figure 20. The definition of land use land cover categories considered for this analysis is as defined by ISRO (ISRO, NRSC, RSAA, LRUMG, \& LUCMD, 2014).

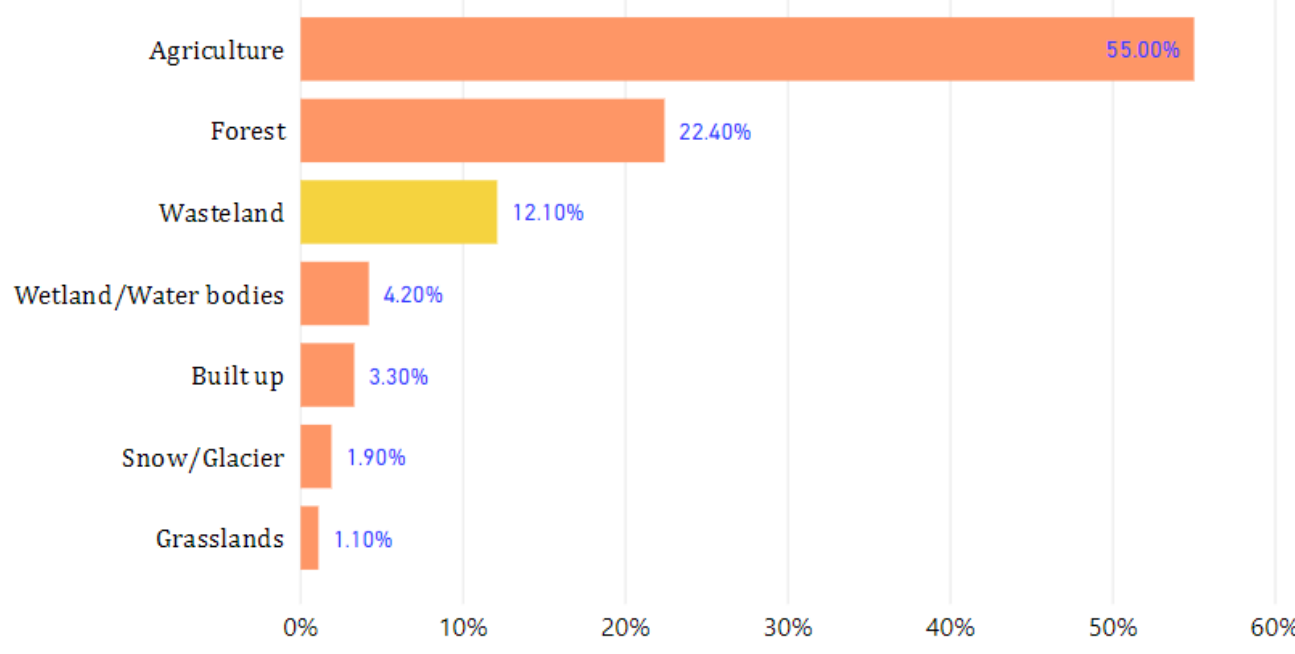

Figure 19: Percentage share of land categories for India

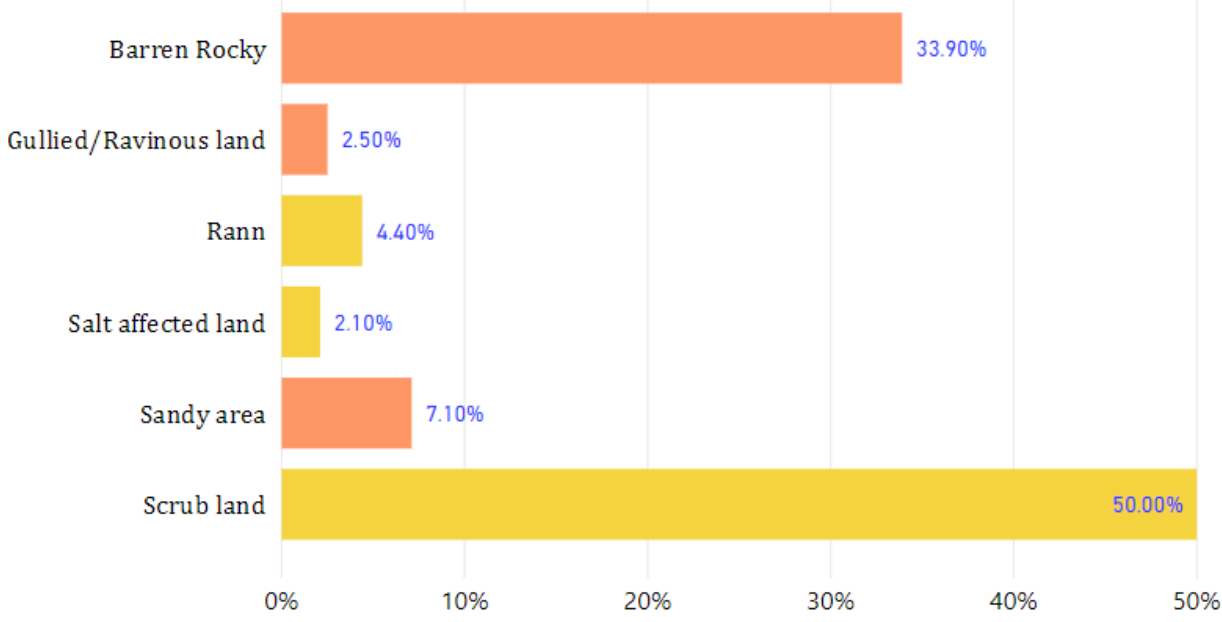

Figure 20: Percentage share of wasteland categories in India 
Communications with sector experts reveal that, in context of installing utility scale ground mounted solar plants, rocky areas, gullied/ravenous land and sandy areas are not preferred due to loose and unstable soil cover. In this context, the aggregate of the remaining categories (Rann, Salt affected land and scrub land) which are suitable for RE installation translates to about 0.22 million $\mathrm{km}^{2}$. It has to be acknowledged that each state has a distinct mix of land area and wasteland share. Figure 21 gives a perspective of state-wise land share, the supplementary material (excel sheet) provides the associated data. The idea of land availability has been sieved through in terms of total wasteland and 'Tappable' wasteland. Due to the unique mix of land cover of each state, the three maps in Figure 21 presents some interesting insights. Majority of the eastern states have relatively less available area for setting up solar plants. Jammu and Kashmir presents an interesting case, the scale of available wasteland significantly reduces when the rocky land component is not considered. The percentage of available land area in Gujarat, Madhya, Andhra Pradesh, Telangana and Maharashtra is slightly higher in the select wasteland set.

Our next step is to translate the available land area to potential solar plant capacity. In an exercise conducted by the National Institute of Solar Energy (NISE), they had estimated the national solar power potential to be about $750 \mathrm{GW}$ (NISE \& MNRE, 2014). This includes both utility scale and roof top installation. The assumptions considered for estimating ground mounted solar power plant potential is as follows:

- About $3 \%$ of wasteland in the state is used

- In $1 \mathrm{~km}^{2}$ of wasteland, $50 \mathrm{MWp}$ of solar PV power plant can be installed. This translates to about 4.95 acres/MWp

- The average solar PV module efficiency is assumed to be $15 \%$

We recollect that CERC has a norm of 5 acres/MWp, which is an approximated version of the above assumption. Considering the latitudinal spread of the country, the area requirements for solar PV plants across this spread has been illustrated in section 3.3. To take this idea further, we applied the proposed method to estimate state-wise benchmarks for land area requirements. To estimate this we simulate the area requirements for a $1 \mathrm{MWp}$ solar PV plant at a $0.01^{\circ}$ latitudinal resolution (indicated in Figure 23).The kinks in the curve are due to variations in ' $n$ ' as explained in section 3.3. We next consider the latitudinal spread of each state and arrive at the average area requirement for a $1 \mathrm{MWp}$ plant. Here we consider the same system configuration as indicated in section 3.3. A visual representation of this is presented in Figure 22 and the estimated data is presented in the supplementary material. From Figure 22, it can be noted that only five states have a benchmark area greater than 5 acres/MWp. The national average benchmark area works out to be 4.29 acres/MWp. Figure 24 and Figure 25 provides a summary of the estimated capacity as per assumptions considered by NISE (PM refers to considering state-wise estimates as per proposed method). The supplementary material provides the details of the state-wise estimated potentials. From Figure 24, it can be seen that by considering select wasteland categories the estimates based on CERC and NISE are reduced by about $35 \%$ and those based on PM are reduced by $31 \%$. Due to the considerations of PM, the potential solar capacity is estimated to be about $20 \%$ and $19 \%$ higher that estimated by the CERC and NISE norms respectively. From Figure 25, it can be seen that the scrub lands contribute to about $88 \%$ of the estimated potential, salt affected areas and areas under rann contribute to the remaining 12\%. Figure 26 (based on PM) it can be inferred that Rajasthan, Gujarat, Madhya Pradesh and Maharashtra constitute to about 56\% and the seven union territories contribute to a meagre $0.06 \%$.When we shift our consideration from all wastelands to select wasteland categories some states see significant dip estimates. Dip in potentials of Jammu and Kashmir, Himachal Pradesh and Uttarakhand can be attributed to discarding rocky areas for consideration and those of Rajasthan is attributed due to discarding both rocky and sandy land areas. The supplementary material provides relevant raw data. 

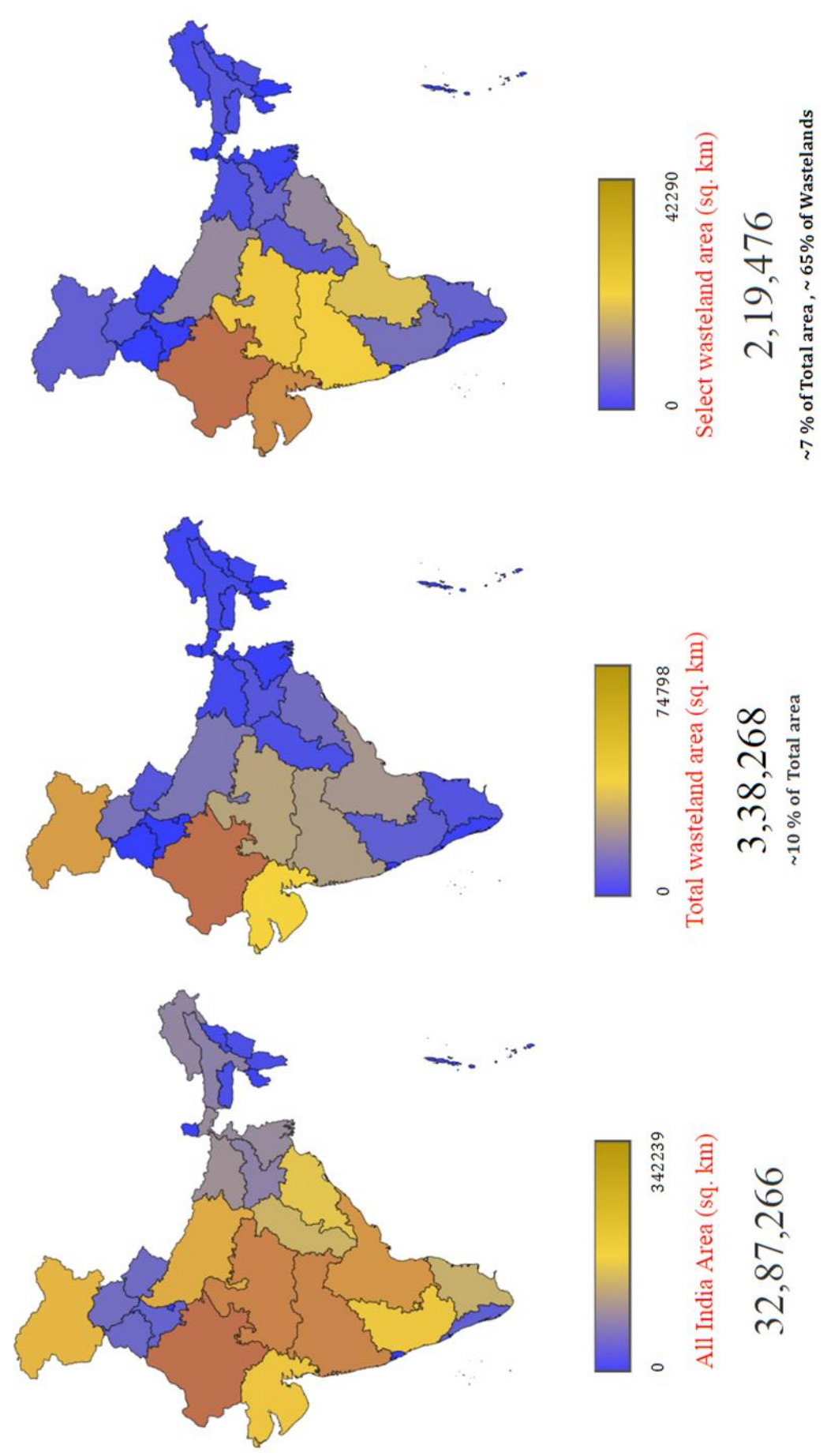

Figure 21: State-wise land share in India 


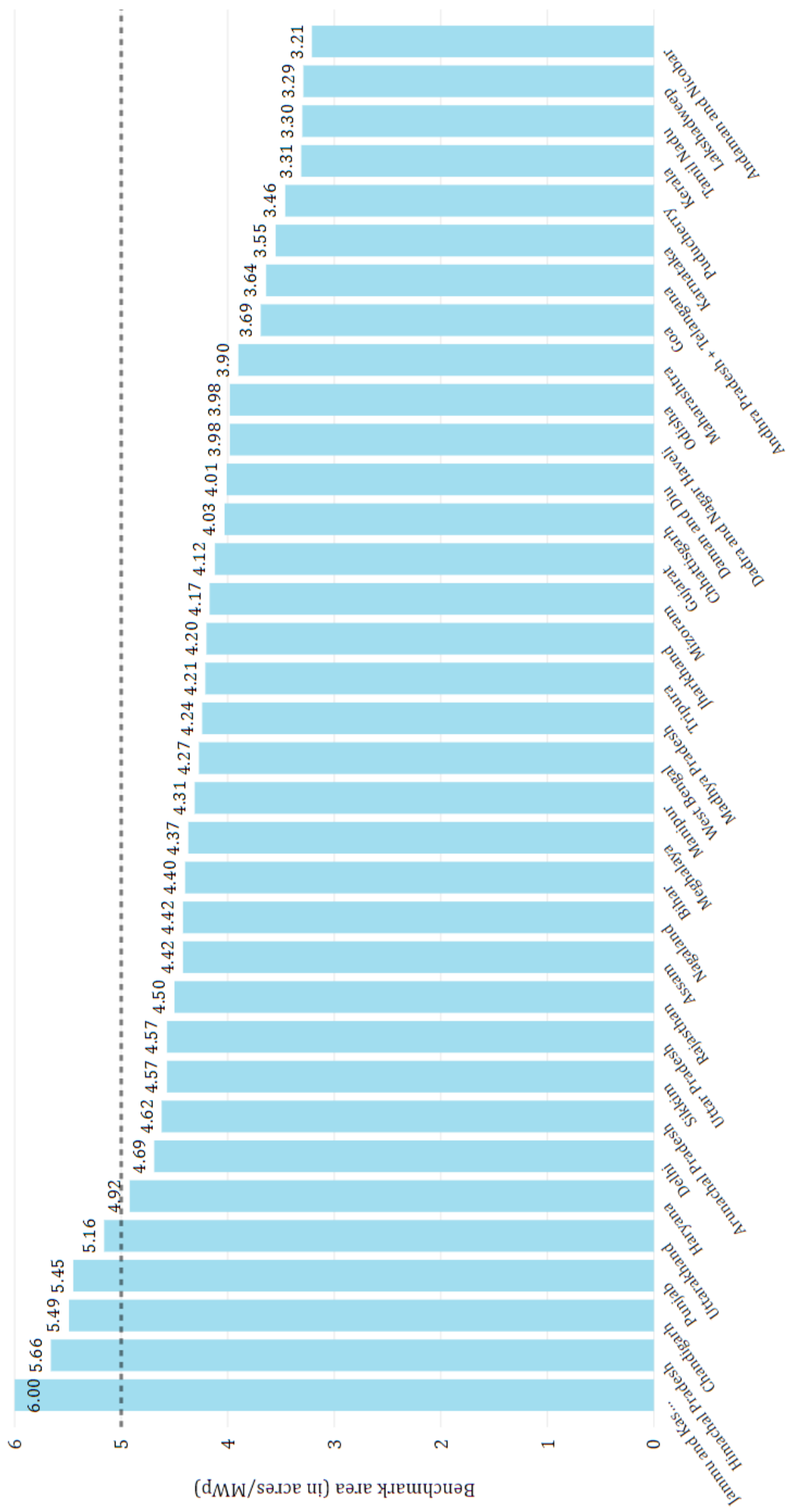

Figure 22: State-wise benchmark area for 1 MWp plant considering the Proposed Method (PM) 


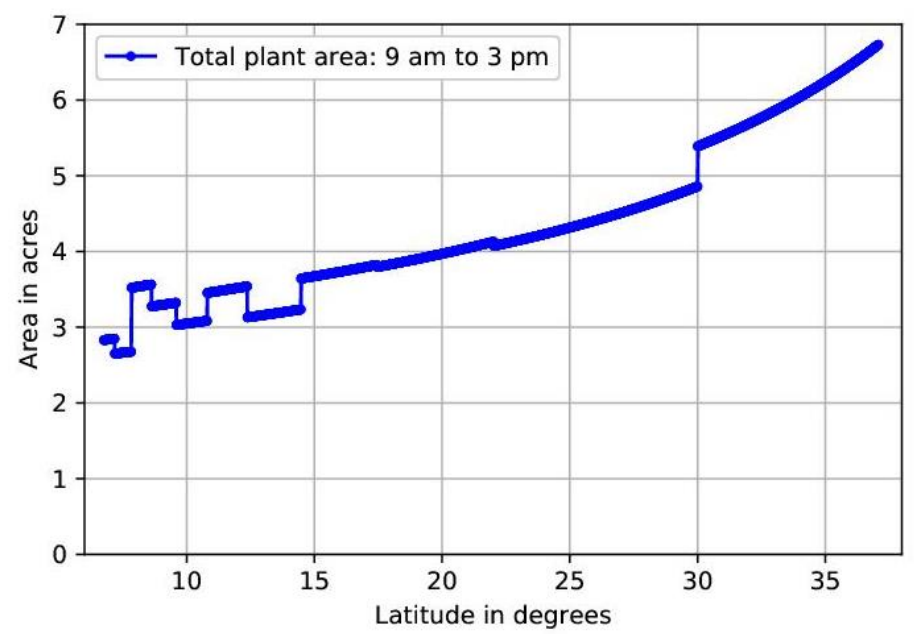

Figure 23: Latitude wise estimate of $1 \mathrm{MWp}$ PV plant area for a time window of 9 am to 3 pm using the proposed method

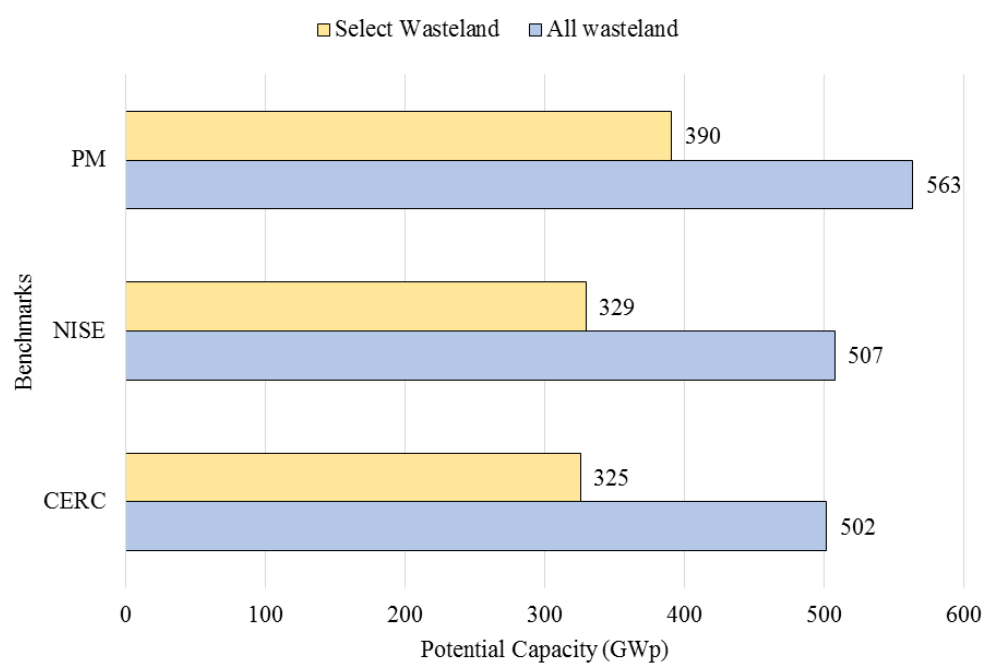

Figure 24: Estimated solar potential for 3\% of all wasteland and select wasteland areas

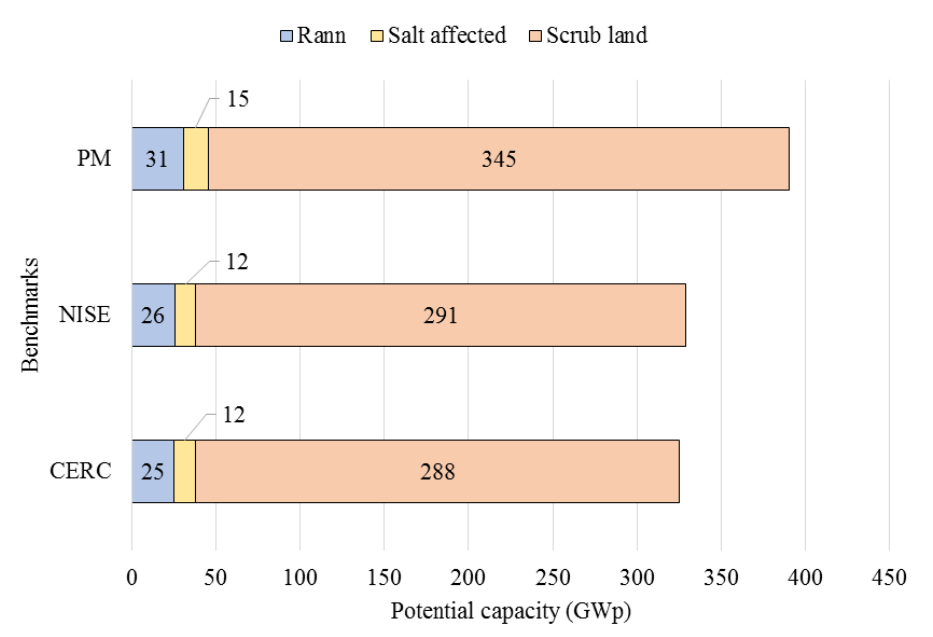

Figure 25: Category wise potential for 3\% of select wasteland areas 


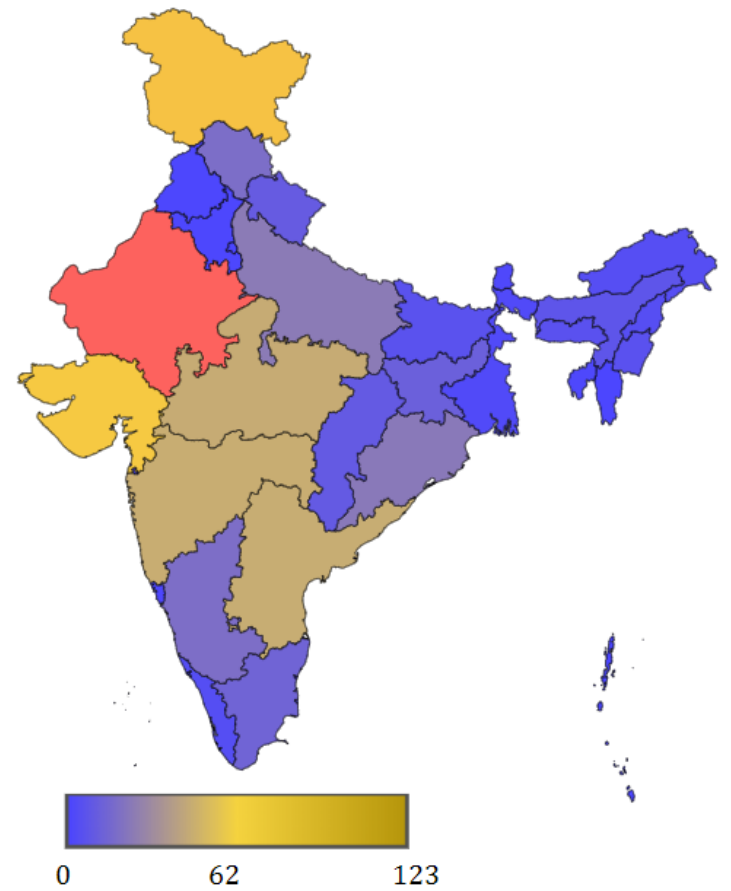

563

Potential (in GWp) as per statewise benchmark for $3 \%$ of all wastelands

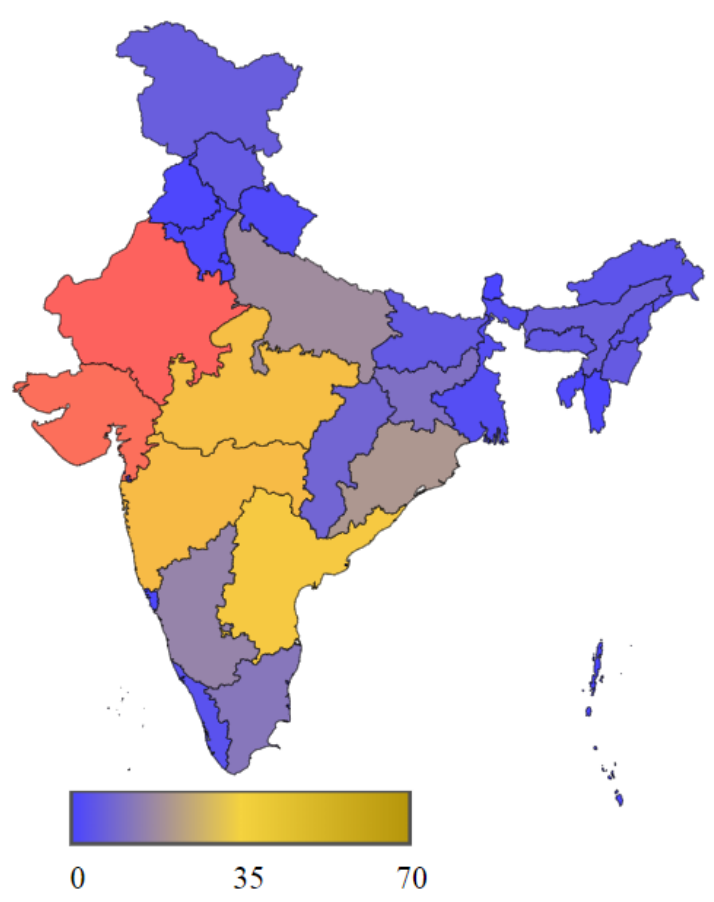

390

Potential (GWp) as per statewise benchmark for $3 \%$ of select wasteland

Figure 26: State-wise solar power plant potential estimated based on the proposed method 


\section{Conclusions and Policy Implications}

Land availability is one of the critical aspects of interest for pursuing a high RE based electricity system. The approach proposed here provides a theoretical means to arrive at the optimal land area requirement for setting up a utility scale PV plant. This method factors the electrical, maintenance, and shading aspects and provides a generic approach to estimate plant area for a given location, capacity, and PV technology. The proposed approach would help in better planning, considering the land resource requirements for large scale deployment of solar PV plants. The land area estimates using this approach have been compared with declared land area of select existing plants and have found to be within an acceptable margin of deviation for planning purpose. To assess the impact of the proposed approach, it was observed that the CERC benchmark tends to overestimate land area requirements for latitudes less than $30^{\circ} \mathrm{N}$. The proposed method can be used as a generic reference for estimating land area requirements for setting future utility scale solar PV plants across the country.

An area of refinement in the model for future work would be to create a revised basis for auxiliary area considerations factoring the terrain undulations. Another aspect would be the inclusion of optimal tilt and surface azimuth angle for a given location. Also, the mesh/grid created by this approach can be intersected with irregularly shaped land area contours to design module area cover for a prospective plant.

To summarise the policy commentary: the total wasteland area in India constitutes to about $12.10 \%$ of the total land cover. Out of this, $56.5 \%$ constitute the select wasteland area suitable for installing ground mounted solar plants. We apply the proposed method for area estimation to arrive at state-wise benchmark area for a $1 \mathrm{MWp}$ plant. It was found that national average land area requirement is about 4.29 acres/MWp which is less than the CERC norms of 5 acres/MWp. Further, the tappable ground mounted utility scale solar power potential for India when considering select wasteland categories is estimated to be about $\sim 391 \mathrm{GWp}$ as per the proposed method and $\sim 330 \mathrm{GWp}$ and $\sim 326 \mathrm{GWp}$ when considering the NISE and CERC benchmarks respectively. The $20 \%$ gain in solar potential can be attributed to better land utilisation. This approach also emphasises the importance of considering state-wise benchmark areas.

In conclusion the proposed method is robust enough to accommodate and aid in informing policy related implications for aspects such as improved module efficiency and locational specific land area utilisation for setting up future solar plants. The refined land area estimates could lead to better use of the finite land resource available. 


\section{References}

Adani Solar. (n.d.). Datasheet: Mono crystalline solar photovoltaic module ASM - PERC - 350. Adani Solar. Retrieved from https://cdn.enfsolar.com/Product/pdf/Crystalline/59f83b699c434.pdf

Anderson, N., \& Hong, J. (2013). Visually Extracting Data Records from Query Result Pages. In Z. shikawa, Y., Li, J., Wang, W., Zhang, R. (Ed.), Web Technologies and Applications 15th AsiaPacific Web Conference. Sydney: Springer. Retrieved from https://link.springer.com/chapter/10.1007/978-3-642-37401-2_40\#citeas

Cattani, C. (2011). On the existence of wavelet symmetries in Archaea DNA. Computational and Mathematical Methods in Medicine, 2012. https://doi.org/http://dx.doi.org/10.1155/2012/673934

CEA. (2019). All India Installed Capacity of Power Stations (as on 31.01.2019). New Delhi. Retrieved from http://cea.nic.in/reports/monthly/installedcapacity/2019/installed_capacity-01.pdf

CERC. (2014). Determination of Benchmark Capital Cost Norm for Solar PV power projects and Solar Thermal power projects applicable during FY 2014-15. New Delhi: CERC. Retrieved from http://www.cercind.gov.in/2014/orders/S0353.pdf

Duffie, J. A., \& Beckman, W. A. (2013). Solar Engineering of Thermal Processes: Fourth Edition. Solar Engineering of Thermal Processes: Fourth Edition. https://doi.org/10.1002/9781118671603

Eaton. (2015). Datasheet Power Xpert Solar 250 kW Inverter. Eaton.

Gardener, M. (1971). Martin Gardener's Sixth book of Mathematical Diversions from Scientific American. University of Chicago Press.

IREDA. (n.d.). Atlas of Potential Land for Renewable Energy Projects in India - Executive Summary. New Delhi: Indian Renewable Energy Development Agency Ltd. Retrieved from http://www.ireda.in/writereaddata/AtlasPotentialLandRE/Data/Executive Summary.pdf

ISRO. (2014). Land use land cover (2011 - 12) Bhuvan Indian Geo Platform. Retrieved March 31, 2019, from https://bhuvan-app1.nrsc.gov.in/thematic/thematic/index.php\#

ISRO, NRSC, RSAA, LRUMG, \& LUCMD. (2014). Land Use / Land Cover database on 1:50,000 scale, Natural Resources Census Project. Hyderabad. Retrieved from https://bhuvanapp1.nrsc.gov.in/2dresources/thematic/2LULC/lulc1112.pdf

Kitano, H., Katsuhiko, H., Kakimoto, Y., Urakawa, T., \& Araki, O. (2015). Computation simulation: Local Inhibitory Synapses Activate Cortical Regions Around the Lesion. In International Symposium on Nonlinear Theory and its Applications. Kowloon, Hong Kong. Retrieved from http://www.ieice.org/nolta/symposium/archive/2015/articles/B2L-C5-6151.pdf

Kumar, A., \& Thapar, S. (2017). Addressing Land Issues for Utility Scale Renewable Energy Deployment in India. New Delhi. Retrieved from

https://shaktifoundation.in/report/addressing-land-issues-for-utility-scale-renewableenergy-deployment-in-india/

Mitavachan, H; Srinivasan, J; Gokhale, A. (2011). A case study of 3 MW scale grid connected solar photovoltaic power plant at Kolar, Karnataka - Performance assessment \& recommendations. Bengaluru. Retrieved from http://www.dccc.iisc.ernet.in/3MWPV_Plant.pdf

Mitavachan, H; Srinivasan, J. (2012). Is land really a constraint for the utilization of solar energy in India? Current Science, 103(2). 
MNRE. (2015). Tentative State-wise break-up of Renewable Power target to be achieved by the year 2022 so that the cumulative achievement is 1,75,000 MW. Retrieved February 14, 2019, from https://mnre.gov.in/file-manager/UserFiles/Tentative-State-wise-break-upof-Renewable-Power-by-2022.pdf

Moserbaer Solar. (2010). Datasheet: Thin film solar photovoltaic module - FS Series A - Si. Moserbaer Solar. Retrieved from https://cdn.enfsolar.com/Product/pdf/Thin film/502858e0a3b74.pdf

NISE, \& MNRE. (2014). State Wise Estimated Solar Power Potential in the Country. Retrieved February 12, 2019, from https://mnre.gov.in/file-manager/UserFiles/Statewise-SolarPotential-NISE.pdf\%0A

NITI Aayog. (2016). Report of the expert group on 175 GW RE by 2022. New Delhi. Retrieved from http://niti.gov.in/writereaddata/files/writereaddata/files/document_publication/report175-GW-RE.pdf

NITI Aayog, CII, SSEF, \& RAP. (2015). Report on India's Renewable Electricity Roadmap 2030. New Delhi. Retrieved from http://niti.gov.in/writereaddata/files/document_publication/Report_on_India\%27s_RE_R oadmap_2030-full_report-web.pdf

NIWE. (2015). Indian Wind Atlas: Online GIS Wind Energy Resource Map of India @ 100m AGL. Chennai: National Institute of Wind Energy (NIWE). Retrieved from https://niwe.res.in/assets/Docu/Wra_100m agl map.pdf

Noone, C. J., Torrilhon, M., \& Mitsos, A. (2011). Heliostat field optimization: A new computationally efficient model and biomimetic layout. Solar Energy, 86, 792-823.

REC Solar. (n.d.). Datasheet: Multi crystalline solar photovoltaic module REC - 350 - TP2S72 PERC. REC Solar. Retrieved from https://www.recgroup.com/sites/default/files/documents/ds_rec_twinpeak_2s_72_series _rev_b2_eng.pdf

Stein, M. ., Ulam, S. ., \& Wells, M. . (1964, May). A Visual Display of Some Properties of the Distribution of Primes. Mathematical Association of America Stable, 71(5), 516-520. https://doi.org/10.2307/2312588

Sukhatme, S. P. (2011). Meeting India's Future Needs of electricity through renewable energy sources. Current Science, 101(5).

Sukhatme, S. P. (2012). Can India's future needs of electricity be met by renewable energy sources? A revised assessment. Current Science, 103(10).

Tata Power Solar. (2014). Datasheet: Multi crystalline solar photovoltaic module TS235. Tata Power Solar.

UNFCCC - CDM. (2011). Project Design Document - Grid connected 3 MWp Solar PV power plant in Belgaum District of Karnataka State, India. https://doi.org/Project 5906

UNFCCC - CDM. (2012a). Project Design Document - 15 MW Solar Photovoltaic Power Plant in Gujarat. https://doi.org/Project 6231

UNFCCC - CDM. (2012b). Project Design Document - 5 MW Solar PV Power Project at Port Blair (A $\& N)$. https://doi.org/Project 9524

UNFCCC - CDM. (2012c). Project Design Document - Grid Connected solar PV based power generation at Naini, Allahabad, India. https://doi.org/Project 7899

UNFCCC - CDM. (2014). Project Design Document - 5 MW Solar PV Power Project at NTPC 
Faridabad. https://doi.org/Project 9964

Vogel, H. (1979). A better way to construct the sunflower head. Mathermatical Biosciences, 44(3-4), 179-189. https://doi.org/https://doi.org/10.1016/0025-5564(79)90080-4 


\section{Appendices}




\section{Appendix A}

\section{Nomenclature}

$\underline{\text { Model related details }}$

Table A.1: List of symbols and conventions

\begin{tabular}{|c|c|}
\hline Symbol & Description \\
\hline $\mathrm{a}$ & Boundary spacing along N-S direction (m) \\
\hline $\mathrm{b}$ & Boundary spacing along E-W direction (m) \\
\hline$B_{\bmod }$ & Breadth of the module (m) \\
\hline DayHour & An array which indicates hour values ranging from 1 to $24^{\text {th }}$ hours of the day \\
\hline $\mathrm{D}_{\mathrm{c}}$ & Inter-column spacing set (three elements of $\mathrm{D}_{\mathrm{col}}$, one for each time window) (m) \\
\hline $\mathrm{D}_{\text {col }}$ & $\begin{array}{l}\text { Inter-column spacing between } 2 \text { array strips (E-W direction) for a given time } \\
\text { window }(\mathrm{m})\end{array}$ \\
\hline Dr & Inter-row spacing set (three element of Drow, one for each time window) (m) \\
\hline $\mathrm{D}_{\text {row }}$ & $\begin{array}{l}\text { Inter-row spacing between } 2 \text { array strips (N-S direction) for a given time } \\
\text { window }(\mathrm{m})\end{array}$ \\
\hline $\mathrm{h}$ & Array height not factoring ground clearance $(\mathrm{m})$ \\
\hline Imid & Current at $V_{\text {mid }}$ to provide the rated PCU power (A) \\
\hline $\mathrm{I}_{\mathrm{mp}}$ & $\begin{array}{l}\text { Current at maximum module power under Standard Testing Conditions - STC } \\
\text { (A) }\end{array}$ \\
\hline $\mathrm{L}_{\mathrm{col}}$ & Hourly Inter-column spacing between 2 array strips (E-W direction) (A) \\
\hline Lmod & Length of the module $(\mathrm{m})$ \\
\hline Lrow & Hourly Inter-row spacing between 2 array strips (NS direction) (m) \\
\hline $\mathrm{m}$ & No. of panels in series (for Voltage addition) $=1$ module string \\
\hline $\mathrm{N}$ & Day number as per Julian calendar \\
\hline $\mathrm{n}$ & No. of module strings in parallel (for Current addition) in 1 array \\
\hline$N_{\bmod }$ & Total number of modules in the plant \\
\hline $\mathrm{N}_{\mathrm{PCU}}$ & Number of PCUs/inverter in the plant \\
\hline$P_{\bmod }$ & Module power rating under STC (Wp) \\
\hline PnomDC & Nominal DC power rating of the PCU $(\mathrm{kW})$ \\
\hline Pplant & Designed plant capacity (MWp) \\
\hline Pplant-target & Desired plant capacity to be designed (MWp) \\
\hline $\mathrm{V}_{\operatorname{maxDC}}$ & Maximum DC voltage limit of the PCU (V) \\
\hline$V_{\text {mid }}$ & Midpoint of maximum power point (MPP) voltage range of the PCU (V) \\
\hline$V_{\mathrm{mp}}$ & Voltage at maximum module power at STC (V) \\
\hline $\mathrm{V}_{\operatorname{mppmax}}$ & Maximum MPP voltage limit of PCU (V) \\
\hline$V_{\text {mppmin }}$ & Minimum MPP voltage limit of PCU (V) \\
\hline $\mathrm{V}_{\text {start }}$ & Start-up voltage of PCU (V) \\
\hline $\mathrm{y}$ & No. of arrays in parallel (for Current addition) \\
\hline$\alpha_{s}$ & 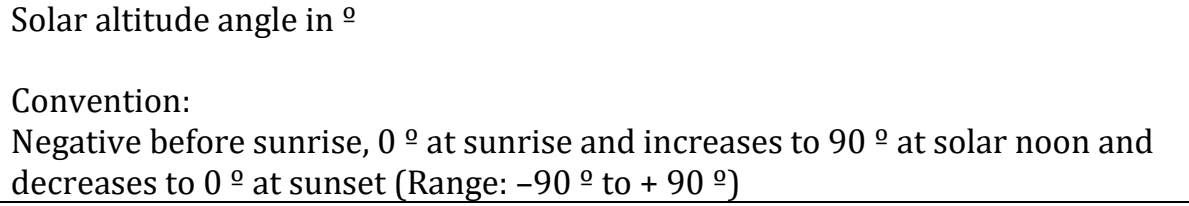 \\
\hline$\beta$ & $\begin{array}{l}\text { Tilt of the module in } \underline{ } \\
\text { Convention: Always positive (Range: } 00 \text { to } 90^{\circ} \text { ) }\end{array}$ \\
\hline$\gamma$ & 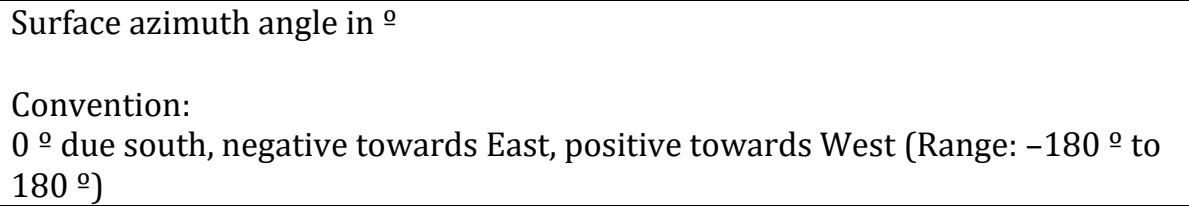 \\
\hline$\gamma_{\mathrm{s}}$ & Solar azimuth angle in $\underline{0}$ \\
\hline
\end{tabular}




\begin{tabular}{|c|c|}
\hline & 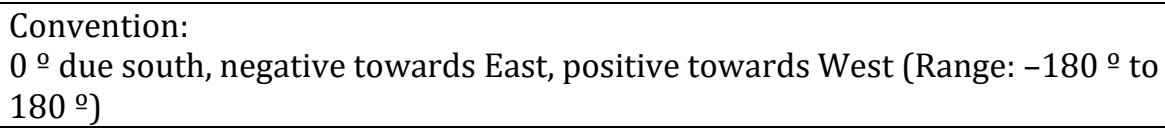 \\
\hline$\delta$ & 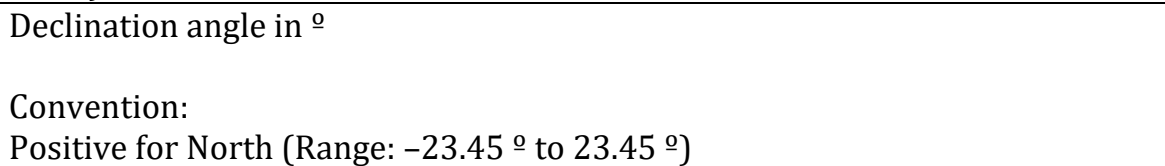 \\
\hline$\theta$ & 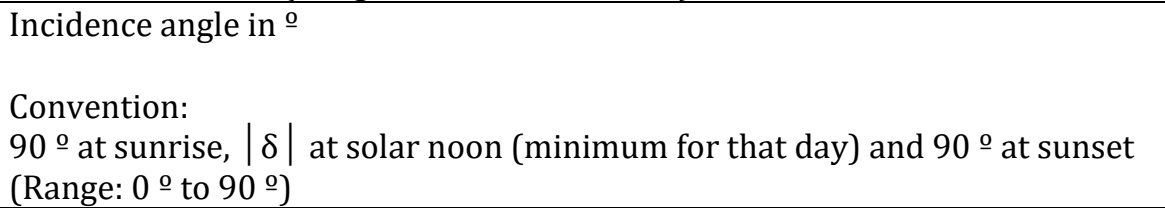 \\
\hline$\theta_{\mathrm{z}}$ & 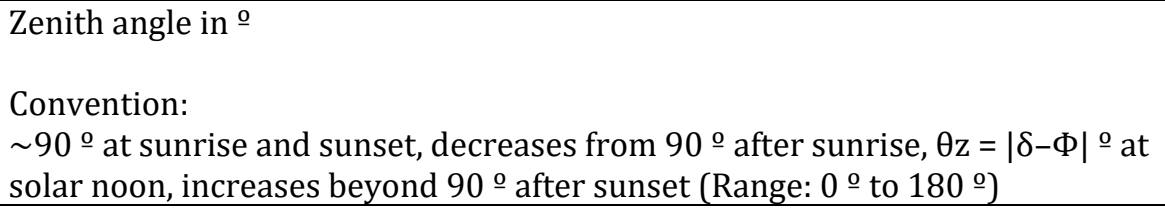 \\
\hline$\varphi$ & 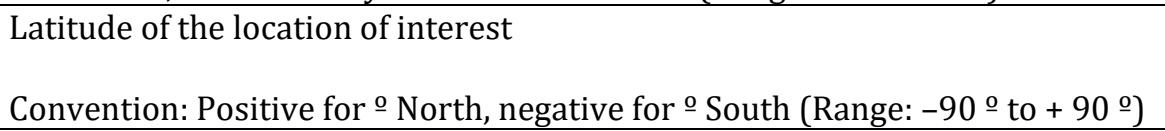 \\
\hline$\omega$ & $\begin{array}{l}\text { Hour angle in } \cong \\
\text { Convention: } \\
-90 \cong \text { at sunrise, } 0 \cong \text { at solar noon, } 90 \cong \text { at sunset (Range: }-180 \cong \text { to } 180 \stackrel{\circ}{\text { ) }}\end{array}$ \\
\hline
\end{tabular}

Table A.2: Nomenclature used in generic spiral application algorithm

\begin{tabular}{|l|l|}
\hline Symbol & Description \\
\hline A_BDr & $\begin{array}{l}\text { Counter for tracing the area component of a unit due to its breadth and inter- } \\
\text { row spacing, B } \times \text { Dr }\end{array}$ \\
\hline A_BDr_temp & Counter for tracing the B $\times$ Dr area components of the transition set \\
\hline Ablock & $\begin{array}{l}\text { Area for a generic set of X units arranged in spiral, representing sum of area } \\
\text { due to enclosed and outlying set }\end{array}$ \\
\hline A_LB & Counter for tracing the Area component of a unit due to its dimensions L $\times$ B \\
\hline A_LDc & $\begin{array}{l}\text { Counter for tracing the Area component of a unit due to its length and inter- } \\
\text { column spacing, } \times \text { } \times \text { Dc }\end{array}$ \\
\hline A_LDc_temp & Counter for tracing the $\mathrm{L} \times$ Dc area components of the transition set \\
\hline Ae & Area of the enclosed set \\
\hline A & Area of the outlying set \\
\hline Area_BS_along_length & Area of the boundary spacing component along length \\
\hline Area_BS_along_breadth & Area of the boundary spacing component along breadth \\
\hline Aunit & Area of the generic unit \\
\hline Auxland & Auxiliary land area requirements \\
\hline B & Breadth of a generic unit \\
\hline B_arraye/o & Breadth of the array units for the enclosed or outlying set \\
\hline B_flag & Flag to trace the addition of outlying set along breadth \\
\hline B_PCUe/o & Breadth of the PCU block for the enclosed or outlying set \\
\hline BDrow & $\begin{array}{l}\text { Consolidated coefficient accounting for contribution due to B } \times \text { Drow area } \\
\text { component for all units }\end{array}$ \\
\hline BpCU & Effective breadth of the PCU block \\
\hline Bplant & Breadth of the area constituting the effective plant area \\
\hline count & Counter to trace if the first element of the transition set is reached \\
\hline DrowDcol & $\begin{array}{l}\text { Consolidated coefficient accounting for contribution due to Drow } \times \text { Dcol area } \\
\text { component for all units }\end{array}$ \\
\hline Effective_PCU_area & Effective area of the PCU block \\
\hline Effective_Plant_Area & Effective area of the plant not including boundary spacing and auxiliary area \\
\hline & \\
\hline
\end{tabular}




\begin{tabular}{|c|c|}
\hline $\mathrm{L}$ & Length of a generic unit \\
\hline L_arraye/o & Length of the array units for the enclosed or outlying set \\
\hline L_flag & Flag to trace the addition of outlying set along length \\
\hline $\mathrm{L}_{-} \mathrm{PCU}_{\mathrm{e} / \mathrm{o}}$ & Length of the PCU block for the enclosed or outlying set \\
\hline LPlant & Length of the area constituting the effective plant area \\
\hline LB & $\begin{array}{l}\text { Consolidated coefficient accounting for contribution due to } \mathrm{L} \times \mathrm{B} \text { area } \\
\text { component for all units }\end{array}$ \\
\hline LDcol & $\begin{array}{l}\text { Consolidated coefficient accounting for contribution due to } \mathrm{L} \times \text { Dcol area } \\
\text { component for all units }\end{array}$ \\
\hline LPCU & Effective length of the PCU block \\
\hline Net_Area_PCU & Net area of the PCU block \\
\hline $\mathrm{N}_{\mathrm{B}}$ & Number of generic units along breadth for $\mathrm{X}$ units \\
\hline $\mathrm{N}_{\mathrm{Be}}$ & Number of units along breadth contributing to enclosed set \\
\hline $\mathrm{N}_{\text {Bo }}$ & Number of units along breadth contributing to outlying set \\
\hline $\mathrm{N}_{\mathrm{Ce}}$ & $\begin{array}{l}\text { Number of inter-column spacing sections along breadth contributing to } \\
\text { enclosed set }\end{array}$ \\
\hline $\mathrm{N}_{\text {Co }}$ & $\begin{array}{l}\text { Number of inter-column spacing sections along breadth contributing to } \\
\text { outlying set }\end{array}$ \\
\hline $\mathrm{N}_{\mathrm{L}}$ & Number of generic units along length for $\mathrm{X}$ units \\
\hline $\mathrm{N}_{\mathrm{Le}}$ & Number of units along length contributing to enclosed set \\
\hline $\mathrm{N}_{\text {Lo }}$ & Number of units along length contributing to outlying set \\
\hline $\mathrm{N}_{\mathrm{o}}$ & Number of outlying units \\
\hline $\mathrm{N}_{\mathrm{Re}}$ & $\begin{array}{l}\text { Number of inter-row spacing sections along length contributing to enclosed } \\
\text { set }\end{array}$ \\
\hline $\mathrm{N}_{\mathrm{Ro}}$ & $\begin{array}{l}\text { Number of inter-row spacing sections along length contributing to outlying } \\
\text { set }\end{array}$ \\
\hline $\mathrm{R}$ & $\begin{array}{l}\text { Counter to trace the growth of units along length ( } y \text { - axis) and rectangular } \\
\text { matrix formation, by default unit is assumed to be a rectangular matrix }\end{array}$ \\
\hline $\mathrm{S}$ & $\begin{array}{l}\text { Counter to trace the growth of units along breadth }(\mathrm{x} \text { - axis) and square } \\
\text { matrix formation }\end{array}$ \\
\hline Total_Plant_Area & Total plant area not including auxiliary area \\
\hline $\mathrm{X}$ & Number of blocks/units \\
\hline
\end{tabular}




\section{Appendix B}

\section{Assumptions}

The broad assumptions for the model are listed as follows:

1. The time period of reference is based on solar time

2. PV modules are of fixed-tilt configuration. It is also a general practice to consider the tilt of the module (and hence array) $\beta$, to be equal to the latitude of the location $\varphi$. Further, the arrays are considered to face due south in case of northern hemisphere and due north in case of the southern hemisphere (Antonio and Hegedus, 2003; Markvart and Castaner, 2013), this makes the surface azimuth angle, $\gamma=0^{\circ}$.

3. The maximum allowable height of the array structure is limited to $2 \mathrm{~m}(\sim 6.5$ feet $)$. This is to accommodate the ease of maintenance and upkeep of the arrays. Also, a $0.5 \mathrm{~m}(1.64$ feet) ground clearance is provided to protect the panels from effects of soiling.

4. The initial land area available is an infinite plane with no undulations and has a flat terrain profile.

5. The auxiliary area requirement factors the need for additional land area for placement of the inverter/PCU, office buildings and extended pathways inside plant. These have been considered based on consultation with sector experts. To account for this in the model, a curve fit equation is generated to estimate the auxiliary land area requirement as a function the capacity of the plant (MWp)

6. A boundary spacing of $10 \mathrm{~m}$ is considered between the plant inner periphery and the outer plant boundary.

7. An important consideration while performing the electrical sizing of the system is that:

a. The combined voltage of modules in series should not exceed the maximum tolerable Direct Current (DC) voltage of the inverter

b. The combined current of the module arrays in parallel should not exceed the maximum rated DC current of the inverter

These considerations are fundamental to deciding the system design point for the PCU (Antonio and Hegedus, 2003). In this model we consider the midpoint voltage in the Maximum Power Point (MPP) range and the corresponding current to achieve the rated PCU power rating. 


\section{Appendix C}

\section{Solar Angles}

Formulae relevant to various solar angles computation:

$\mathrm{B}=(\mathrm{N}-1) \times 360 / 365$

$\omega=-15\left(12-\right.$ Day $\left._{\text {hour }}\right)$

$\delta=\frac{180}{\pi} \times(0.006918-0.399912 \times \cos (\mathrm{B})+0.070257 \times \sin (\mathrm{B})-0.006758 \times$

$\cos (2 \mathrm{~B})+0.000907 \times \sin (2 \mathrm{~B})-0.002697 \times \cos (3 \mathrm{~B})+0.00148 \times \sin (3 \mathrm{~B}))$

$\theta=\cos ^{-1}(\sin \delta \times \sin \Phi \times \cos \beta-\sin \delta \times \cos \Phi \times \sin \beta \times \cos \gamma+\cos \delta \times \cos \Phi \times \cos \beta \times$ $\cos \omega+\cos \delta \times \sin \Phi \times \sin \beta \times \cos \gamma \times \cos \omega+\cos \delta \times \sin \beta \times \sin \gamma \times \sin \omega)$

$\theta_{\mathrm{z}}=\cos ^{-1}(\cos \Phi \times \cos \omega \times \cos \delta+\sin \Phi \times \sin \delta)$

$\alpha_{\mathrm{s}}=90-\theta_{\mathrm{z}}$

$\gamma_{\mathrm{s}}=\operatorname{sign}(\omega) \times\left|\cos ^{-1}\left(\frac{\cos \theta_{\mathrm{z}} \cdot \sin \Phi-\sin \delta}{\sin \theta_{\mathrm{z}} \cdot \cos \Phi}\right)\right|$ 


\section{Appendix D}

\section{Generic equation for plant area}

A more generic representation of the plant in terms of a single variable for each of the area components:

$\left(\mathrm{L} \times \mathrm{B}, \mathrm{L} \times \mathrm{D}_{\mathrm{c}}, \mathrm{B} \times \mathrm{D}_{\mathrm{r}}\right.$, and $\left.\mathrm{D}_{\mathrm{r}} \times \mathrm{D}_{\mathrm{c}}\right)$ can be illustrated as follows:

$A_{\text {plant }}$ (sq. m) $=p \times L \times B+q \times B \times D_{r}+r \times D_{c} \times L+s \times D_{r} \times D_{c}$

Here,

$\mathrm{p}=\mathrm{N}_{\mathrm{Le}} \times \mathrm{N}_{\mathrm{Be}}+\mathrm{N}_{\mathrm{Lo}} \times \mathrm{N}_{\mathrm{Bo}}$

$q=N_{R e} \times N_{B e}+N_{R o} \times N_{B o}$

$\mathrm{r}=\mathrm{N}_{\mathrm{Le}} \times \mathrm{N}_{\mathrm{Ce}}+\mathrm{N}_{\mathrm{Lo}} \times \mathrm{N}_{\mathrm{Co}}$

$\mathrm{s}=\mathrm{N}_{\mathrm{Re}} \times \mathrm{N}_{\mathrm{Ce}}+\mathrm{N}_{\mathrm{Ro}} \times \mathrm{N}_{\mathrm{Co}}$

By logic it could be stated that the coefficient of $L \times B$ term would be equal to number of units $X$, as in terms of area computation every block would contribute $\mathrm{p}=\mathrm{X}$ 


\section{Appendix E}

\section{Auxiliary area requirements}

The auxiliary area requirements accounts for land imperfections, additional spacing requirements for support infrastructure, etc. Since there is no standardised way for allocating land area for PCUs, administrative and monitoring building, power substation, and extended pathways etc. as needed in the plant; a criteria for auxiliary area requirement has been considered in consultation with sector experts. It has been conveyed by sector experts that for a $1 \mathrm{MWp}$ plant, roughly $15 \%$ of the net plant area is required for auxiliary infrastructure and it decreases to $1 \%$ for a $100 \mathrm{MWp}$ plant. A mathematical curve fit was adopted to capture this decreasing trend, and is illustrated by the following equations:

$$
\begin{array}{ll}
\operatorname{Aux}_{\text {land }}=0.165 \times \text { Total_Plant_Area } & \left(P_{\text {plant }}<1 \mathrm{MW}\right) \\
\text { Aux }_{\text {land }}=16.723 \times \mathrm{e}^{-0.027 *\left(\mathrm{P}_{\text {plant }}\right)} \times \text { Total_Plant_Area } & \left(P_{\text {plant }}=1 \text { to } 100 \mathrm{MW}\right) \\
\operatorname{Aux}_{\text {land }}=0.01 \times \text { Total_Plant_Area } & \left(P_{\text {plant }}>100 \mathrm{MW}\right)
\end{array}
$$

Total_Plant_Area_with_Aux $\left(\right.$ in $\left.\mathrm{m}^{2}\right)=$ Total_Plant_Area + Aux land

It is required to trace plant design with asymmetric sizing parameters and apply an area correction so as to avoid excess auxiliary area assignment. If the difference between effective plant area (Effective_Plant_Area) and Total plant area (Total_Plant_Area) is greater than the auxiliary area (Aux land), then there would be no need for any auxiliary area consideration. However, if the difference is less, the auxiliary area would be considered for evaluating the total area requirements. 


\section{Appendix F}

\section{Case details for technology comparison}

Spiral related parameters for the case are indicated in Table F.1 and Table F.2

Table F.1: Area related parameters for arranging 'y' arrays in spiral

\begin{tabular}{|l|c|c|c|}
\hline $\begin{array}{l}\text { Parameters } \\
\downarrow / \text { Technology } \rightarrow\end{array}$ & $\begin{array}{l}\text { Mono- } \\
\text { crystalline }\end{array}$ & $\begin{array}{l}\text { Multi- } \\
\text { crystalline }\end{array}$ & $\begin{array}{l}\text { Thin-Film (Amorphous } \\
\text { Silicon) }\end{array}$ \\
\hline $\mathrm{Y}$ & 79 & 11 & 11 \\
\hline $\mathrm{N}_{\mathrm{Le}}$ & 9 & 3 & 3 \\
\hline $\mathrm{N}_{\mathrm{Be}}$ & 8 & 3 & 1 \\
\hline $\mathrm{N}_{\mathrm{Lo}}$ & 7 & 1 & 2 \\
\hline $\mathrm{N}_{\mathrm{Bo}}$ & 1 & 2 & 2 \\
\hline $\mathrm{N}_{\mathrm{re}}$ & 7 & 2 & 2 \\
\hline $\mathrm{N}_{\mathrm{ce}}$ & 6 & 2 & 1 \\
\hline $\mathrm{N}_{\mathrm{ro}}$ & 1 & 1 & 1 \\
\hline $\mathrm{N}_{\mathrm{co}}$ & 1 & 1 & 0 \\
\hline $\mathrm{L}_{-}$flag & 0 & 0 & 1 \\
\hline $\mathrm{B}_{-}$flag & & 1 & \\
\hline
\end{tabular}

Table F.2: Area related parameters for arranging ' $N_{P C U}$ ' inverters in spiral

\begin{tabular}{|l|c|c|c|}
\hline $\begin{array}{l}\text { Parameters } \\
\downarrow / \text { Technology } \rightarrow\end{array}$ & $\begin{array}{l}\text { Mono- } \\
\text { crystalline }\end{array}$ & $\begin{array}{l}\text { Multi- } \\
\text { crystalline }\end{array}$ & $\begin{array}{l}\text { Thin-Film (Amorphous } \\
\text { Silicon) }\end{array}$ \\
\hline $\mathrm{N}_{\mathrm{PCU}}$ & 4 & 4 & 4 \\
\hline $\mathrm{N}_{\mathrm{Le}}$ & 2 & 2 & 2 \\
\hline $\mathrm{N}_{\mathrm{Be}}$ & 2 & 2 & 2 \\
\hline $\mathrm{N}_{\mathrm{Lo}}$ & 0 & 0 & 0 \\
\hline $\mathrm{N}_{\mathrm{Bo}}$ & 1 & 0 & 1 \\
\hline $\mathrm{N}_{\mathrm{re}}$ & 1 & 1 & 1 \\
\hline $\mathrm{N}_{\mathrm{ce}}$ & 0 & 1 & 0 \\
\hline $\mathrm{N}_{\mathrm{ro}}$ & 0 & 0 & 0 \\
\hline $\mathrm{N}_{\mathrm{co}}$ & 0 & 0 & 0 \\
\hline $\mathrm{L}_{-}$flag & 0 & 0 & 0 \\
\hline $\mathrm{B}_{-}$flag & & & \\
\hline
\end{tabular}




\section{Appendix G}

\section{Comparison of plant area with select existing plants}

This section aims to estimate the area requirements of select operational plants and compare it with their reported land area coverage. The plants for the case study (listed Table G.1) were chosen such that they are spread across the country so as to get wide latitudinal spread. In order to have uniformity in design, same design considerations have been applied for all plants. Only plants which had reported the total land area covered were considered. The image of each plant is attached in the end of Appendix G for reference.

Table G.1: Plant details

\begin{tabular}{|c|c|c|c|c|c|}
\hline $\begin{array}{l}\text { Plant } \\
\text { no. }\end{array}$ & Plant & $\begin{array}{l}\text { Promoter / } \\
\text { Developer }\end{array}$ & Location & $\begin{array}{c}\text { Coordinates } \\
\text { (declared / As per } \\
\text { google maps) } \\
\end{array}$ & $\begin{array}{c}\text { Declared } \\
\text { Land area } \\
\text { (Acres) }\end{array}$ \\
\hline \multirow{2}{*}{1} & \multirow{2}{*}{$\begin{array}{l}\text { Grid connected } 3 \mathrm{MWp} \\
\text { Solar PV power plant } \\
\text { (UNFCCC - CDM, 2011) }\end{array}$} & \multirow{2}{*}{$\begin{array}{l}\text { Karnataka } \\
\text { Power } \\
\text { Corporation } \\
\text { Ltd. (KPCL) }\end{array}$} & \multirow{2}{*}{$\begin{array}{l}\text { Itnal, } \\
\text { Belgaum, } \\
\text { Karnataka }\end{array}$} & $\begin{array}{c}16^{\circ} 26^{\prime} 06^{\prime \prime} \mathrm{N}, 74^{\circ} \\
40^{\prime} 30^{\prime \prime} \mathrm{E}\end{array}$ & \multirow{2}{*}{15} \\
\hline & & & & $\begin{array}{c}16^{\circ} 24^{\prime} 03^{\prime \prime} \mathrm{N}, 74^{\circ} \\
39^{\prime} 48^{\prime \prime} \mathrm{E}\end{array}$ & \\
\hline \multirow[b]{2}{*}{2} & \multirow{2}{*}{$\begin{array}{l}5 \text { MW Solar PV Power } \\
\text { Project at NTPC Faridabad } \\
\text { (UNFCCC - CDM, 2014) }\end{array}$} & \multirow{2}{*}{$\begin{array}{l}\text { National } \\
\text { Thermal } \\
\text { Power } \\
\text { Corporation } \\
\text { (NTPC) Ltd. }\end{array}$} & \multirow{2}{*}{$\begin{array}{l}\text { Jajru, } \\
\text { Faridabad, } \\
\text { Haryana }\end{array}$} & $\begin{array}{c}28^{\circ} 17^{\prime} 08^{\prime \prime} \mathrm{N}, 77^{\circ} \\
19^{\prime} 04^{\prime \prime} \mathrm{E}\end{array}$ & \multirow[b]{2}{*}{20} \\
\hline & & & & $\begin{array}{l}28^{\circ} 17^{\prime} 08^{\prime \prime} \mathrm{N}, 77^{\circ} \\
19^{\prime} 02^{\prime \prime} \mathrm{E}\end{array}$ & \\
\hline \multirow[b]{2}{*}{3} & \multirow{2}{*}{$\begin{array}{l}5 \text { MW Solar PV Power } \\
\text { Project at Port Blair (A\&N) } \\
\text { (UNFCCC - CDM, 2012a) }\end{array}$} & \multirow[b]{2}{*}{ NTPC Ltd. } & \multirow{2}{*}{$\begin{array}{l}\text { Garachar } \\
\text { ma, } \\
\text { Captain } \\
\text { Town, } \\
\text { Port Blair, } \\
\text { Andaman } \\
\text { Islands }\end{array}$} & $\begin{array}{l}11^{\circ} 36^{\prime} 00^{\prime \prime} \mathrm{N}, \\
92^{\circ} 42^{\prime} 00^{\prime \prime} \mathrm{E}\end{array}$ & \multirow[b]{2}{*}{24.71} \\
\hline & & & & $\begin{array}{c}11^{\circ} 36^{\prime} 40^{\prime \prime} \mathrm{N}, 92^{\circ} \\
42^{\prime} 36^{\prime \prime} \mathrm{E}\end{array}$ & \\
\hline \multirow{2}{*}{4} & \multirow{2}{*}{$\begin{array}{l}15 \text { MW Solar Photovoltaic } \\
\text { Power Plant in Gujarat } \\
\text { (UNFCCC - CDM, 2012b) }\end{array}$} & \multirow{2}{*}{$\begin{array}{l}\text { Welspun Urja } \\
\text { Gujarat Pvt. } \\
\text { Ltd. }\end{array}$} & \multirow{2}{*}{$\begin{array}{l}\text { Khisura, } \\
\text { Anjar, } \\
\text { Kutch, } \\
\text { Gujarat }\end{array}$} & $\begin{array}{l}23^{\circ} 21^{\prime} 37^{\prime \prime} \mathrm{N} \\
70^{\circ} 03^{\prime} 15^{\prime \prime} \mathrm{E}\end{array}$ & \multirow{2}{*}{106} \\
\hline & & & & $\begin{array}{c}23^{\circ} 21^{\prime} 37^{\prime \prime} \mathrm{N}, 70^{\circ} \\
03^{\prime} 15^{\prime \prime} \mathrm{E}\end{array}$ & \\
\hline \multirow[b]{2}{*}{5} & \multirow{2}{*}{$\begin{array}{l}5 \mathrm{MW} \text { AC }(\sim 5.75 \mathrm{MWp}) \text { Grid } \\
\text { Connected Solar PV based } \\
\text { power generation at Naini, } \\
\text { Allahabad (UNFCCC - CDM, } \\
2012 \mathrm{c} \text { ) }\end{array}$} & \multirow[b]{2}{*}{ EMC Ltd. } & \multirow{2}{*}{$\begin{array}{l}\text { Naini, } \\
\text { Allahabad, } \\
\text { Uttar } \\
\text { Pradesh }\end{array}$} & $\begin{array}{l}25^{\circ} 22^{\prime} 00^{\prime \prime} \mathrm{N} \\
81^{\circ} 51^{\prime} 00^{\prime \prime} \mathrm{E}\end{array}$ & \multirow[b]{2}{*}{27} \\
\hline & & & & $\begin{array}{c}25^{\circ} 22^{\prime} 22^{\prime \prime} \mathrm{N}, 81^{\circ} \\
52^{\prime} 18^{\prime \prime} \mathrm{E}\end{array}$ & \\
\hline
\end{tabular}

Table G.2 indicates the details provided for module and PCU for this plant. Further, some plants indicated the number of modules, number of modules/string, and also the number of inverters. This is indicated in Table G.3. 
Table G.2: Module and PCU details

\begin{tabular}{|l|l|l|l|}
\hline $\begin{array}{l}\text { Plan } \\
\text { t no. }\end{array}$ & $\begin{array}{c}\text { Installed } \\
\text { Capacity as per } \\
\text { no of panels }\end{array}$ & \multicolumn{1}{|c|}{ Panel info } & \multicolumn{1}{c|}{ PCU info } \\
\hline 1 & 2.99993 & $\begin{array}{l}\text { Titan Energy Systems Mono } \\
\text { Crystalline, 225 Wp, Titan S6 - 60 } \\
\text { (Titan Energy Systems, n.d.) }\end{array}$ & $\begin{array}{l}\text { Details Unavailable - 250 kW, } \\
\text { Assuming Eaton 250 kW (Eaton, } \\
2015)\end{array}$ \\
\hline 2 & 5.00112 & $\begin{array}{l}\text { Emmvee solar, poly crystalline, 230 } \\
\text { Wp (Emmvee Photovoltaic Power } \\
\text { Pvt. Ltd., 2012) }\end{array}$ & $\begin{array}{l}\text { AEG 630 kW (AEG Power Solutions, } \\
\text { n.d.) }\end{array}$ \\
\hline 3 & 5.00832 & $\begin{array}{l}\text { Photon Energy Systems Ltd 235 Wp } \\
\text { C-Si, PMM0235 (Photon Energy } \\
\text { Systems Limited, 2014) }\end{array}$ & $\begin{array}{l}\text { SMA -Sunny Central 800 CP, 800 kW } \\
\text { (SMA Solar Technology, n.d.) }\end{array}$ \\
\hline 4 & 14.99232 & $\begin{array}{l}\text { First Solar - Thin Film (CdTe) 80 } \\
\text { Wp, FS380 (First Solar Inc., 2012) }\end{array}$ & $\begin{array}{l}\text { SMA - 800 kW (SMA Solar } \\
\text { Technology, n.d.) }\end{array}$ \\
\hline 5 & 5.76455 & $\begin{array}{l}\text { Unknown - Multi Crystalline - 235 } \\
\text { Wp, Assuming TS235 Tata power } \\
\text { module (Tata Power Solar, 2014) }\end{array}$ & $\begin{array}{l}\text { unknown - 500 kW x 2 for each 1.15 } \\
\text { MWp, Assuming ABB 500 kW, (ABB, } \\
\text { 2014) }\end{array}$ \\
\hline
\end{tabular}

Table G.3: Additional details of plant as provided in reports

\begin{tabular}{|l|l|l|l|l|l|l|l|l|}
\hline $\begin{array}{l}\text { Plan } \\
\text { t no. }\end{array}$ & $\begin{array}{c}\text { Latitude } \\
\mathbf{f} \text { tilt }\end{array}$ & $\begin{array}{c}\text { Module } \\
\text { Rating } \\
\mathbf{( W p )}\end{array}$ & $\begin{array}{c}\text { Lmod } \\
\mathbf{( m )}\end{array}$ & $\begin{array}{c}\text { Bmod } \\
\mathbf{( m )}\end{array}$ & $\begin{array}{c}\text { Inverter } \\
\text { Rating } \\
\mathbf{( k W )}\end{array}$ & $\begin{array}{c}\text { No. of } \\
\text { modules }\end{array}$ & $\begin{array}{c}\text { No. of } \\
\text { modules/String }\end{array}$ & $\begin{array}{c}\text { No. of } \\
\text { PCU }\end{array}$ \\
\hline 1 & 16.40 & 3 & 225 & 28.63 & 7.93 & 13333 & 24 & 12 \\
\hline 2 & 28.29 & 5 & 230 & 29.53 & 7.79 & 21744 & 24 & 8 \\
\hline 3 & 11.61 & 5 & 235 & 29.6 & 8.06 & 21312 & 24 & - \\
\hline 4 & 23.36 & 15 & 80 & 48.5 & 1.65 & 187404 & 14 & 16 \\
\hline 5 & 25.37 & 5.75 & 235 & 29.6 & 7.95 & 24530 & 22 & 10 \\
\hline
\end{tabular}

The possible combinations that can be considered while sizing the plant, are illustrated in Figure G.1, as the exact design point of each plant is not known. Considering all four permissible configurations, the number of modules at different levels were estimated (Table G.4) and the combination which gave the lowest deviation in terms of total number of modules relative to declared number of modules (Table G.5) was finalised for area estimation (marked in bold).

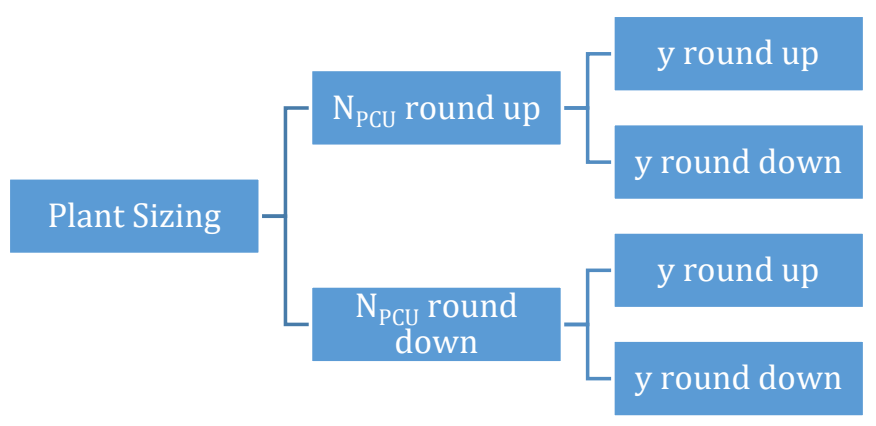

Figure G.1: Combinations of $N_{P C U}$ and $y$ 


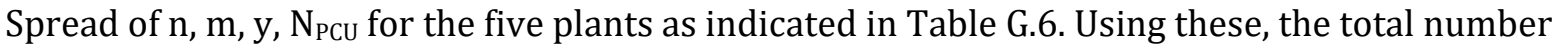
of modules and hence the effective MWp rating of the plant for each combination is calculated and is indicated Table G.4.

Table G.4: Estimated number of modules and plant capacity

\begin{tabular}{|c|c|c|c|c|c|c|c|c|c|c|c|}
\hline \multirow{2}{*}{$\begin{array}{c}\text { Plant } \\
\text { no. }\end{array}$} & \multirow{2}{*}{$\begin{array}{l}\text { Mod. } \\
\text { Rating } \\
\text { (Wp) }\end{array}$} & \multicolumn{2}{|c|}{ Declared } & \multicolumn{4}{|c|}{ NPCU $_{\text {round down }}$} & \multicolumn{4}{|c|}{$\mathrm{N}_{\mathrm{PCU}}$ round up } \\
\hline & & $\begin{array}{c}\text { No of } \\
\text { Module } \\
\quad \text { s }\end{array}$ & $\begin{array}{c}\text { Plant } \\
\text { Capacit } \\
y\end{array}$ & $\begin{array}{c}\text { No of } \\
\text { module } \\
s(y) \\
\text { round } \\
\text { up }\end{array}$ & $\begin{array}{c}\text { Plant } \\
\text { Capac } \\
\text { ity }\end{array}$ & $\begin{array}{c}\text { No of } \\
\text { modules } \\
(y) \\
\text { round } \\
\text { down }\end{array}$ & $\begin{array}{c}\text { Plant } \\
\text { Capac } \\
\text { ity }\end{array}$ & $\begin{array}{c}\text { No of } \\
\text { module } \\
s(y) \\
\text { round } \\
\text { up }\end{array}$ & $\begin{array}{c}\text { Plant } \\
\text { Capac } \\
\text { ity }\end{array}$ & $\begin{array}{c}\text { No of } \\
\text { modules - } \\
\text { (y) round } \\
\text { down }\end{array}$ & $\begin{array}{c}\text { Plant } \\
\text { Capa } \\
\text { city }\end{array}$ \\
\hline 1 & 225 & 13333 & 3.00 & 14400 & 3.24 & 12960 & 2.92 & 14400 & 3.24 & 12960 & 2.92 \\
\hline 2 & 230 & 21744 & 5.00 & 20160 & 4.64 & 19656 & 4.52 & 23040 & 5.30 & 22464 & 5.17 \\
\hline 3 & 235 & 21312 & 5.01 & 21168 & 4.97 & 20160 & 4.74 & 24696 & 5.80 & 23520 & 5.53 \\
\hline 4 & 80 & 187404 & 14.99 & 189540 & 15.16 & 187920 & 15.03 & 200070 & 16.01 & 198360 & 15.87 \\
\hline 5 & 235 & 24530 & 5.76 & 23958 & 5.63 & 23232 & 5.46 & 26136 & 6.14 & 25344 & 5.96 \\
\hline
\end{tabular}

Table G.5: deviations with respect to total number of modules and final choice

\begin{tabular}{|l|l|l|l|l|}
\hline \multirow{2}{*}{$\begin{array}{c}\text { Plant } \\
\text { no. }\end{array}$} & \multicolumn{2}{|c|}{ Round down NPCu } & \multicolumn{2}{c|}{ Round up N PCu } \\
\cline { 2 - 5 } & $\mathbf{y}$ - round up & $\begin{array}{c}\text { y- round } \\
\text { down }\end{array}$ & y - round up & y-round down \\
\hline 1 & $8.00 \%$ & $-\mathbf{- 2 . 8 0 \%}$ & $8.00 \%$ & $-2.80 \%$ \\
\hline 2 & $-7.28 \%$ & $-9.60 \%$ & $5.96 \%$ & $\mathbf{3 . 3 1 \%}$ \\
\hline 3 & $\mathbf{- 0 . 6 8 \%}$ & $-5.41 \%$ & $15.88 \%$ & $10.36 \%$ \\
\hline 4 & $1.14 \%$ & $\mathbf{0 . 2 8 \%}$ & $6.76 \%$ & $5.85 \%$ \\
\hline 5 & $-\mathbf{2 . 3 3 \%}$ & $-5.29 \%$ & $6.55 \%$ & $3.32 \%$ \\
\hline
\end{tabular}

Table G.6: Spread of $n, m, y$ and $N_{P C U}$

\begin{tabular}{|l|l|l|l|l|l|l|}
\hline Plant no & $\mathbf{n}$ & $\mathbf{m}$ & $\begin{array}{c}\text { y-round } \\
\text { up }\end{array}$ & $\begin{array}{c}\text { y - round } \\
\text { down }\end{array}$ & $\begin{array}{c}\text { NPCu round } \\
\text { down }\end{array}$ & NPcu round up \\
\hline 1 & 5 & 24 & 10 & 9 & 12 & 12 \\
\hline 2 & 3 & 24 & 40 & 39 & 7 & 8 \\
\hline 3 & 7 & 24 & 21 & 20 & 6 & 7 \\
\hline 4 & 6 & 15 & 117 & 116 & 18 & 19 \\
\hline 5 & 3 & 22 & 33 & 32 & 11 & 12 \\
\hline
\end{tabular}

Based on the deviation indicated table G.5, the most suitable combination of module sizing parameters is indicated in the following Table G.7.

Table G.7: Suitable plant sizing parameters

\begin{tabular}{|l|l|l|l|l|l|l|l|}
\hline $\begin{array}{c}\text { Plant } \\
\text { no. }\end{array}$ & $\begin{array}{c}\text { Target Plant } \\
\text { Capacity (MWp) }\end{array}$ & NPCU & $\begin{array}{c}\text { Plant rating as } \\
\text { per PCU (MW) }\end{array}$ & $\mathbf{n}$ & $\mathbf{m}$ & $\mathbf{y}$ & $\begin{array}{c}\text { Plant } \\
\text { Rating } \\
\text { (MWp) }\end{array}$ \\
\hline 1 & 3 & 12 & 3 & 5 & 24 & 9 & 2.92 \\
\hline 2 & 5 & 8 & 5.04 & 3 & 24 & 39 & 5.17 \\
\hline 3 & 5 & 6 & 4.8 & 7 & 24 & 21 & 4.97 \\
\hline
\end{tabular}




\begin{tabular}{|l|l|l|l|l|l|l|l|}
\hline 4 & 15 & 18 & 14.4 & 6 & 15 & 116 & 15.03 \\
\hline 5 & 5.75 & 11 & 5.5 & 3 & 22 & 33 & 5.63 \\
\hline
\end{tabular}

Considering different time window of operations, the inter-row and inter-column spacing required for tilt of the module (equal to latitude), is indicated in Table G.8.

Table G.8: Time window wise inter-row and inter-column spacing

\begin{tabular}{|c|c|c|c|c|c|c|c|}
\hline \multirow[t]{2}{*}{ Plant no. } & \multirow{2}{*}{$\begin{array}{l}\text { Module tilt } \\
(\stackrel{\circ}{)})\end{array}$} & \multicolumn{2}{|c|}{7 am to $5 \mathrm{pm}$} & \multicolumn{2}{|c|}{8 am to $4 \mathrm{pm}$} & \multicolumn{2}{|c|}{9 am to $3 \mathrm{pm}$} \\
\hline & & $D_{\text {row }}(\mathrm{m})$ & $D_{\text {col }}(\mathrm{m})$ & $D_{\text {row }}(\mathrm{m})$ & $D_{\text {col }}(\mathrm{m})$ & $D_{\text {row }}(\mathrm{m})$ & $D_{\text {col }}(\mathrm{m})$ \\
\hline 1 & 16.40 & 5.41 & 10.69 & 2.17 & 3.38 & 1.54 & 1.77 \\
\hline 2 & 28.29 & 31.40 & 60.16 & 3.70 & 5.19 & 2.42 & 2.38 \\
\hline 3 & 11.61 & 4.00 & 8.10 & 1.82 & 3.00 & 1.31 & 1.63 \\
\hline 4 & 23.36 & 10.85 & 20.95 & 2.96 & 4.30 & 2.03 & 2.11 \\
\hline 5 & 25.37 & 13.40 & 25.77 & 2.93 & 4.18 & 1.97 & 2.01 \\
\hline
\end{tabular}

An indication of benchmark area for comparison provided in Table G.9.

Table G.9: Declared and benchmarked area for comparison

\begin{tabular}{|l|l|l|l|l|}
\hline $\begin{array}{c}\text { Plant } \\
\text { no. }\end{array}$ & \multicolumn{2}{|c|}{ Plant Rating } & \multicolumn{1}{c|}{ Area } & Area as per CERC benchmark \\
\cline { 2 - 5 } & Target (MWp) & Estimated (MWp) & $\begin{array}{c}\text { Declared } \\
\text { (acres) }\end{array}$ & $\begin{array}{c}\text { x 5 acre/MWp - Target } \\
\text { capacity }\end{array}$ \\
\hline 1 & 3 & 2.92 & 15 & 15 \\
\hline 2 & 5 & 5.17 & 20 & 25 \\
\hline 3 & 5 & 4.97 & 24.71 & 25 \\
\hline 4 & 15 & 15.03 & 106 & 75 \\
\hline 5 & 5.75 & 5.63 & 27 & 28.75 \\
\hline
\end{tabular}

The area estimated for all time windows is indicated in table G.10.

Table G.10: Estimated area for all time windows

\begin{tabular}{|c|c|c|c|c|c|c|}
\hline \multirow{2}{*}{$\begin{array}{l}\text { Plan } \\
\text { t no. }\end{array}$} & \multicolumn{3}{|c|}{ Effective Area (acres) } & \multicolumn{3}{|c|}{ Total Area (acres) } \\
\hline & $\begin{array}{c}7 \text { am to } 5 \\
\text { pm }\end{array}$ & $\begin{array}{c}8 \text { am to } 4 \\
\text { pm }\end{array}$ & $\begin{array}{c}9 \text { am to } 3 \\
\text { pm }\end{array}$ & $\begin{array}{c}7 \text { am to } 5 \\
\text { pm }\end{array}$ & $\begin{array}{c}8 \text { am to } 4 \\
\text { pm }\end{array}$ & $\begin{array}{c}9 \text { am to } 3 \\
\text { pm }\end{array}$ \\
\hline 1 & 12.74 & 7.68 & 6.78 & 15.61 & 10.08 & 9.09 \\
\hline 2 & 293.58 & 25.67 & 19.33 & 336.85 & 30.39 & 23.68 \\
\hline 3 & 18.37 & 13.38 & 12.26 & 21.58 & 16.21 & 14.99 \\
\hline 4 & 321.24 & 82.50 & 63.55 & 357.41 & 92.17 & 71.08 \\
\hline 5 & 101.29 & 23.92 & 18.93 & 116.48 & 28.28 & 23.01 \\
\hline
\end{tabular}

Although, the areas marked in bold indicate the closest area estimates to the declared area, it could be noted that, it is theoretically possible to set the same plant with area requirement lesser than that indicated by benchmark CERC norms. In this case, the area estimates for all plants in the 9 am to $3 \mathrm{pm}$ window fall below the requirements posed by the benchmark CERC 
norms. Of course, with consideration of a narrower time window, the shading losses during time period beyond the specific window could reduce the energy generation. This trade-off is to be considered by the developer while designing the plant.

The effective dimensions of the plant based on spacing with respect to each time window is indicated in Table G.11.

Table G.11: Effective dimensions of plant for each reference time window

\begin{tabular}{|l|l|l|l|l|l|l|}
\hline \multirow{2}{*}{$\begin{array}{c}\text { Plant } \\
\text { no }\end{array}$} & \multicolumn{3}{|c|}{ Effective Length (m) } & \multicolumn{3}{c|}{ Effective Breadth (m) } \\
\cline { 2 - 7 } & $\mathbf{7}$ am to 5 pm & $\mathbf{8}$ am to $\mathbf{~ p m}$ & $\mathbf{9}$ am to $\mathbf{~ p m}$ & $\mathbf{7}$ am to $\mathbf{~ p m}$ & $\mathbf{8}$ am to 4 pm & $\begin{array}{c}\mathbf{9} \text { am to 3 } \\
\text { pm }\end{array}$ \\
\hline 1 & 116.29 & 80.70 & 73.77 & 443.40 & 384.93 & 372.09 \\
\hline 2 & 682.92 & 129.01 & 103.25 & $1,739.77$ & 805.30 & 757.66 \\
\hline 3 & 157.77 & 127.29 & 120.10 & 471.30 & 425.41 & 413.06 \\
\hline 4 & 767.91 & 341.73 & 291.28 & $1,692.97$ & 977.08 & 882.92 \\
\hline 5 & 373.29 & 132.36 & 110.36 & $1,098.16$ & 731.25 & 694.23 \\
\hline
\end{tabular}

By visually inspecting images of the plants (Figures G.2 to G.6), it could be observed that the module cover area and total plant area differs significantly and total plant area is a function of the land terrain undulations. The auxiliary area allotted for each plant varies and is case specific. Plant 1 and 3 have a fair portion of land, which is free from PV module cover. Plant 4 and 5 exhibit case of a well-packed plant.

Plant 2, especially is a case of interest, as here hardly any auxiliary area or boundary spacing is used by the plant. Hence, it would be apt for it to be compared to only the effective land area estimate instead of the total land area with auxiliary area estimate. For all other plants the comparison is done with the total land area with auxiliary area estimate. Since the basis for the tilt angle and inter-row and inter-column spacing is not explained in the UNFCCC reports, an effort has been made to address this issue with the concept of solar time windows as discussed earlier. The time window which provides the closest estimate to the declared area is considered. The entries which are the closest to the declared area in absolute terms are marked in bold in Table G.10. This is the reference area chosen for comparison and is summarised in Table G.12.

Table G.12: Summary of comparison of declared area and estimated area

\begin{tabular}{|l|l|l|l|l|}
\hline $\begin{array}{l}\text { Plant } \\
\text { No. }\end{array}$ & $\begin{array}{l}\text { Declared area } \\
\text { (acres) }\end{array}$ & $\begin{array}{l}\text { Computed reference } \\
\text { area (acres) }\end{array}$ & Choice of area, time window & Deviation \\
\hline 1 & 15 & 15.61 & Total Area, 7 am to 5 pm & $4 \%$ \\
\hline 2 & 20 & 19.33 & Effective Area, 9 am to 3 pm & $-3 \%$ \\
\hline 3 & 24.71 & 21.58 & Total Area, 7 am to $5 \mathrm{pm}$ & $-13 \%$ \\
\hline 4 & 106 & 92.17 & Total Area, 8 am to 4 pm & $-13 \%$ \\
\hline 5 & 27 & 28.28 & Total Area, 8 am to 4 pm & $5 \%$ \\
\hline
\end{tabular}

The mismatch in the area could be attributed to applicability of assumptions for estimating the auxiliary area. This is a plant specific criteria, as it is a strong function of terrain undulations. Another factor, which could create variations in the estimate, is the tilt angle of the modules considered in design.

It has to be reiterated that the proposed method is a theoretical approach to estimate the lower end of the area requirements for a given set of conditions, for a given capacity, at a specified location. The comparison with real plants is an effort to look at the closeness of the assumptions 
considered in this approach, to that of the conditions factored by an operational plant. It could be noted that it is theoretically possible to set up the same plant with lesser land area, than the specified norm as indicated in Table G.13.

Table G.13: A comparison of declared area and estimated theoretical minimum area

\begin{tabular}{|l|l|l|l|l|}
\hline $\begin{array}{l}\text { Plant } \\
\text { No. }\end{array}$ & Estimated (MWp) & $\begin{array}{l}\text { Declared area } \\
\text { (acres) }\end{array}$ & $\begin{array}{l}\text { Minimum area } \\
\text { required (acres) }\end{array}$ & $\begin{array}{l}\text { Minimum } \\
\text { area } \\
\text { (acres/MWp) }\end{array}$ \\
\hline 1 & 2.92 & 15 & 9.09 & 3.12 \\
\hline 2 & 5.17 & 20 & 23.68 & 4.58 \\
\hline 3 & 4.97 & 24.71 & 14.99 & 3.01 \\
\hline 4 & 15.03 & 106 & 71.08 & 4.73 \\
\hline 5 & 5.63 & 27 & 23.01 & 4.09 \\
\hline
\end{tabular}




\section{Images of various plants:}

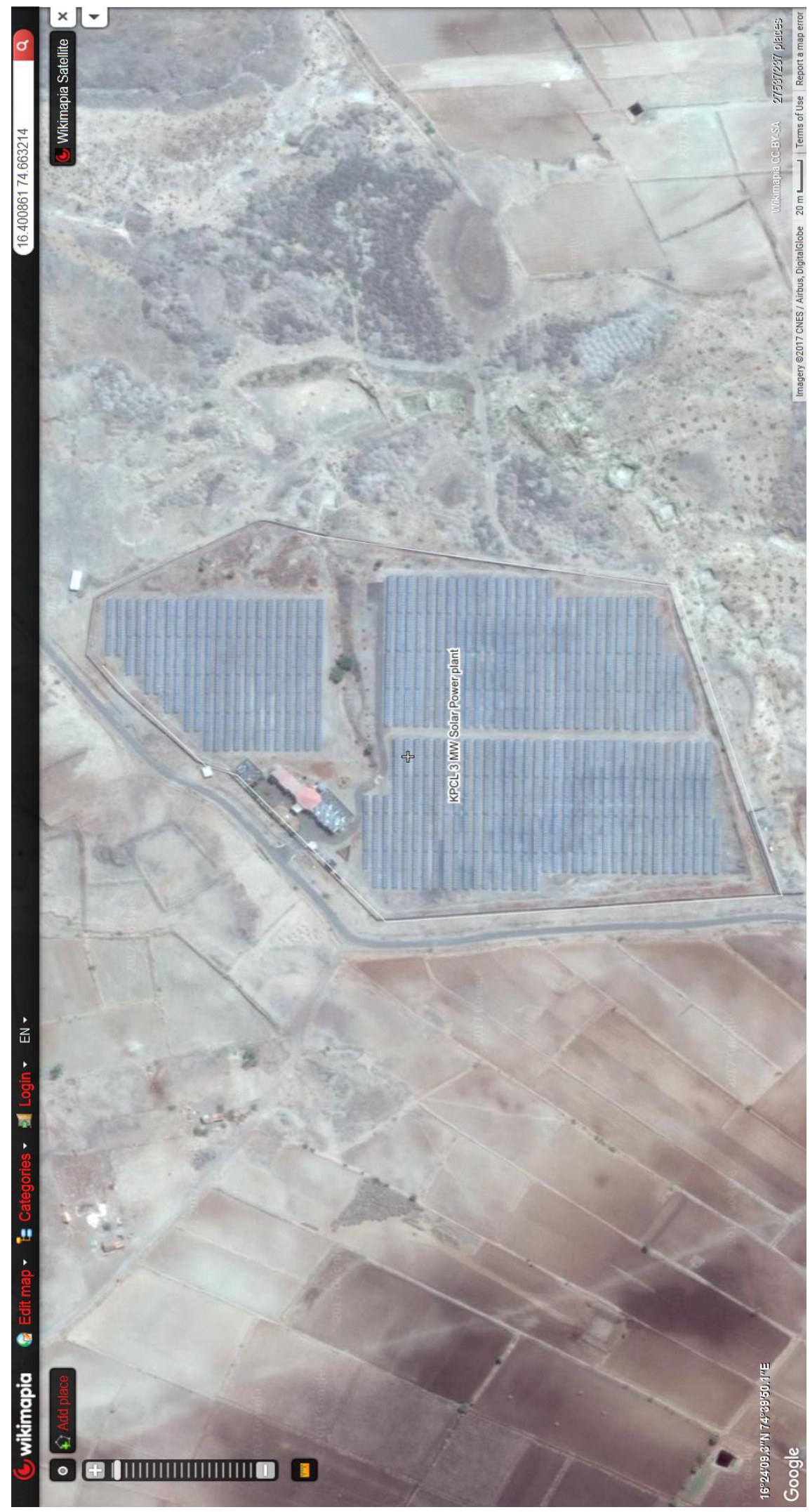

Figure G.2: Plant 1 - KPCL Belgaum plant 


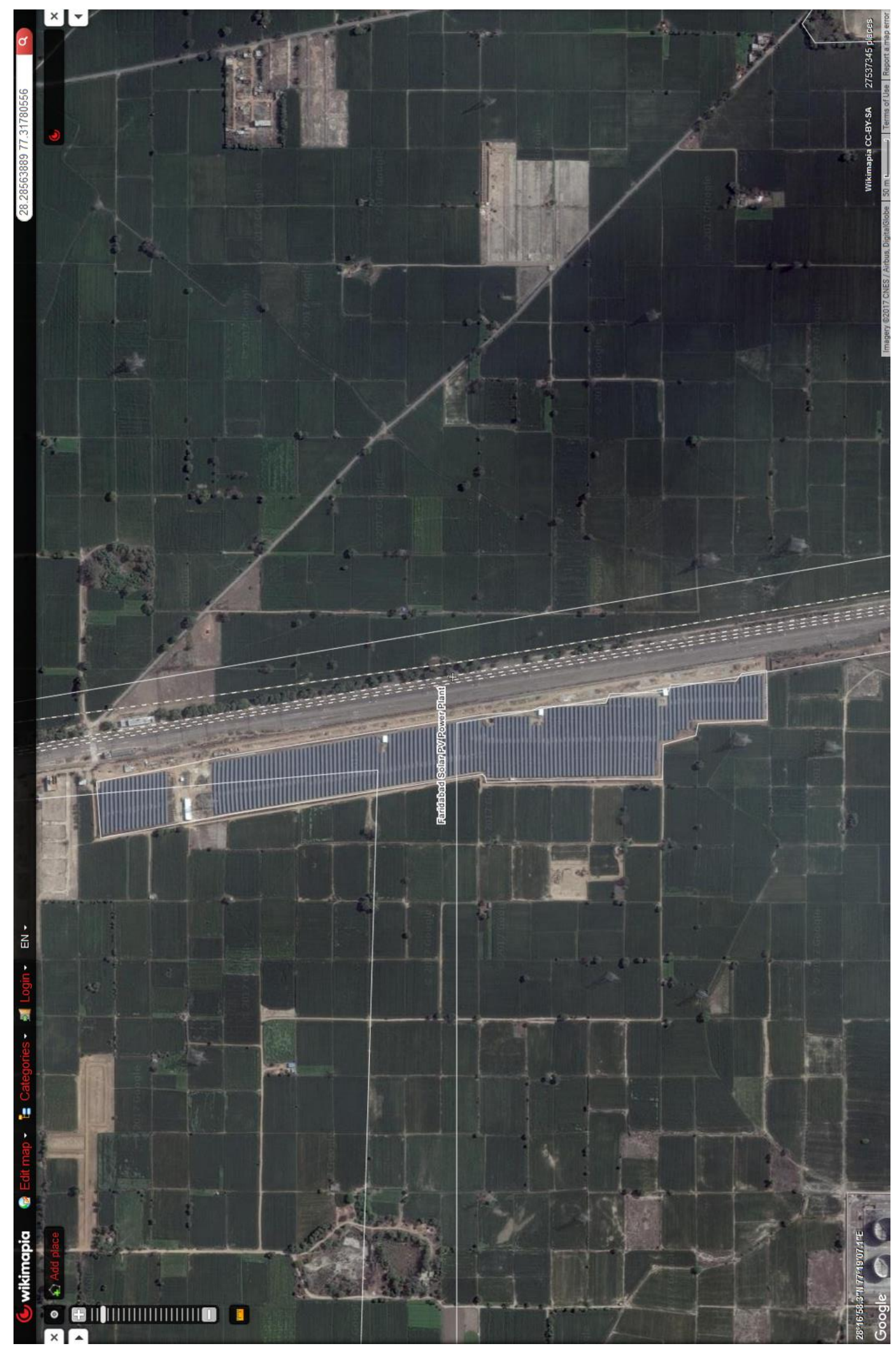

Figure G.3: Plant 2 - NTPC Faridabad plant 


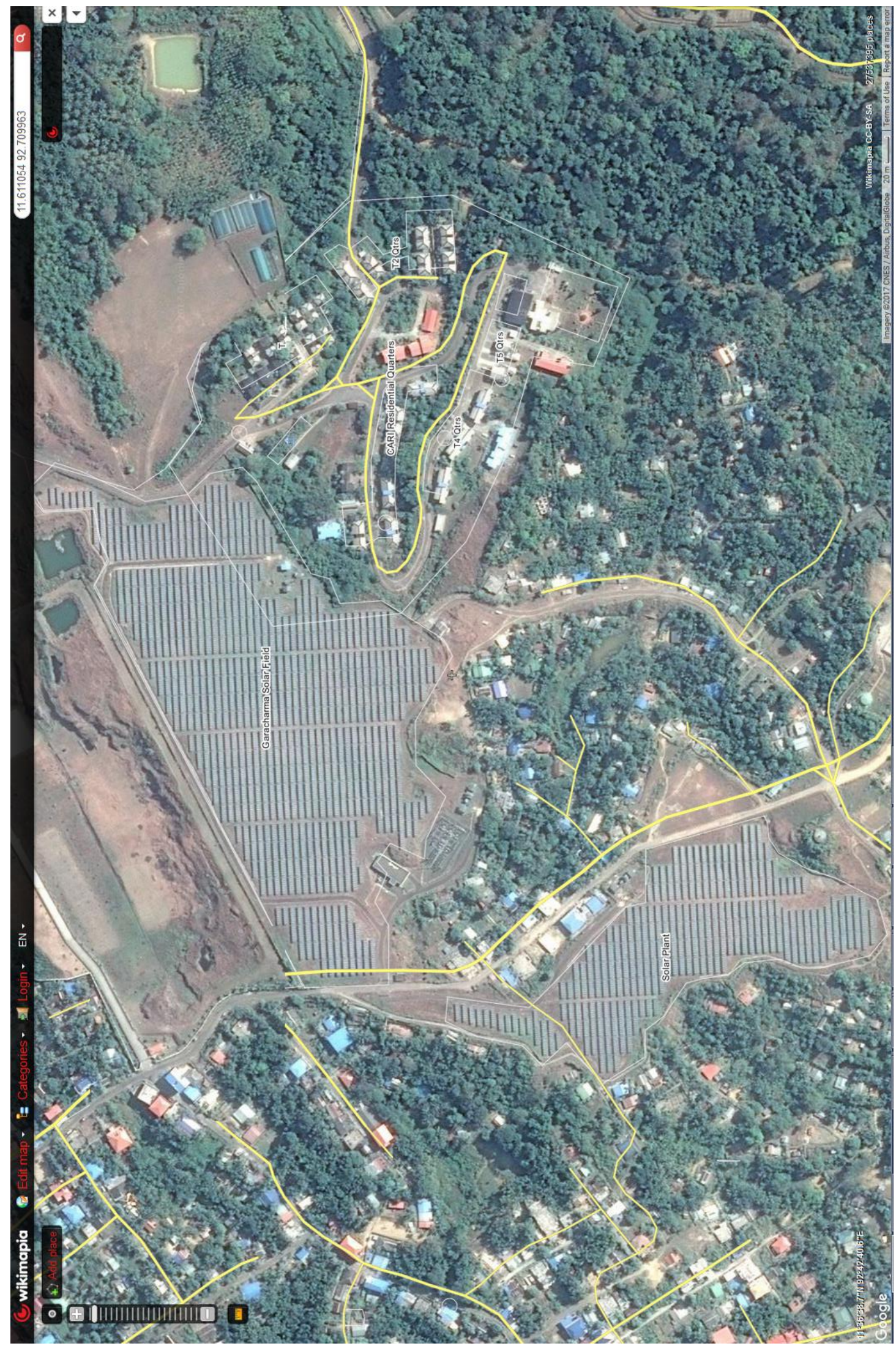

Figure G.4: Plant 3 - NTPC plant Port Blair 


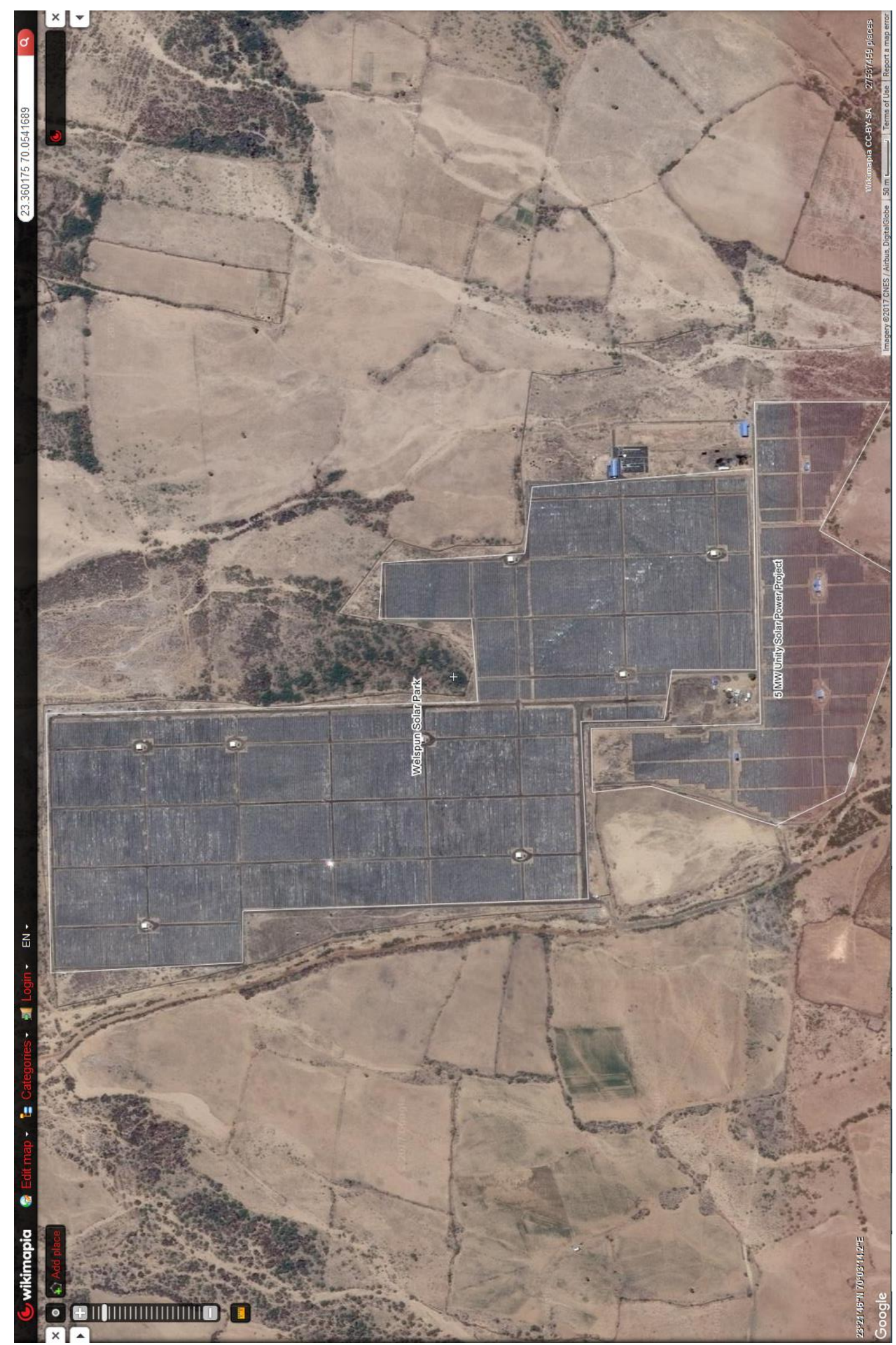

Figure G.5: Plant 4 - Welspun Urja plant 


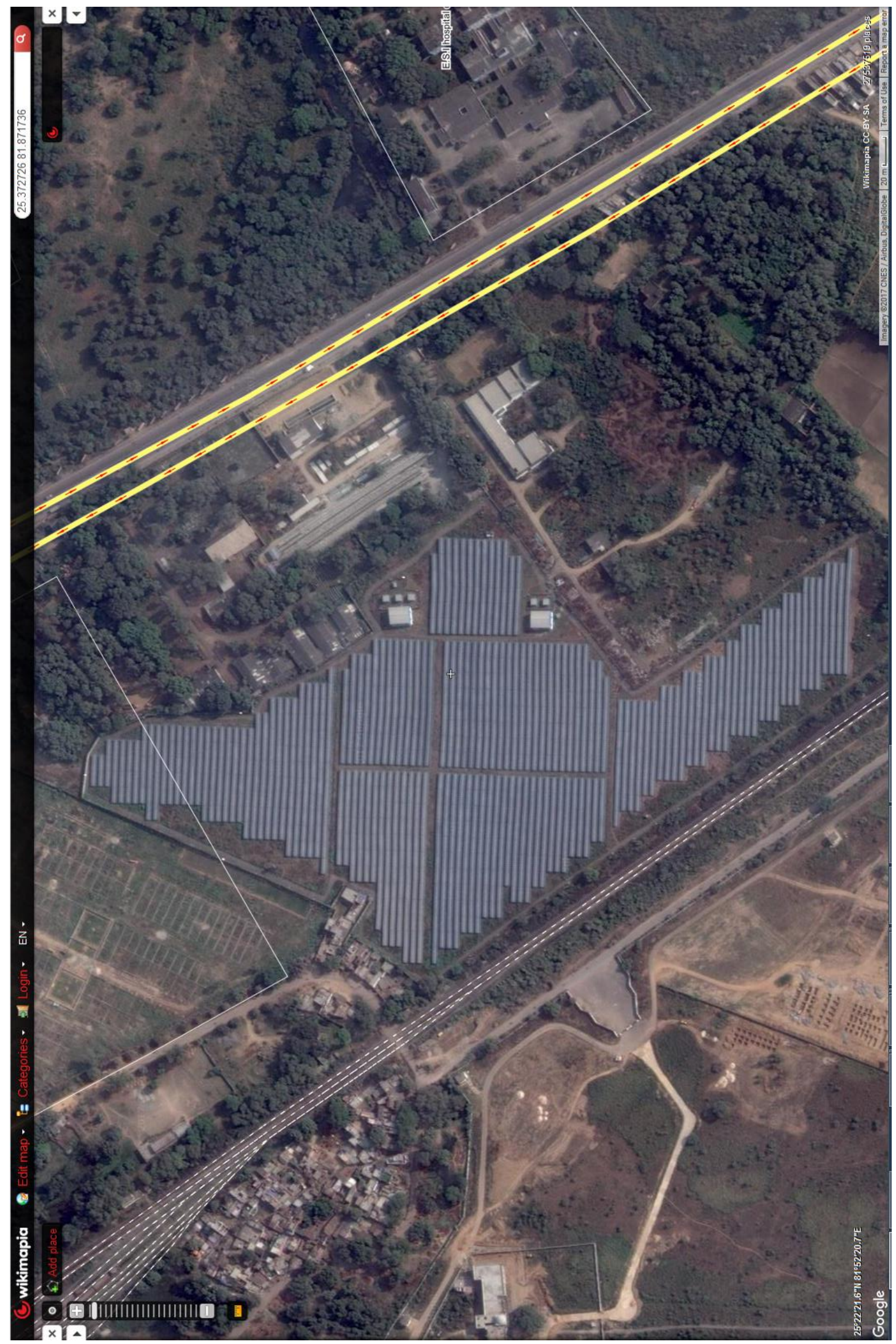

Figure G.6: Plant 5 - EMC plant at Naini 


\section{Appendix $\mathrm{H}$}

\section{Comparison of land area requirements for extreme latitudes in India}

Figure H.1 extends this technology comparison as illustrated in section 3.1 for the extreme latitudes ( $8^{\circ} \mathrm{N}$ and $37^{\circ} \mathrm{N}$ ) encompassing India. Here, we estimate the total plant area with auxiliary area considerations for the 9 am to $3 \mathrm{pm}$ window.

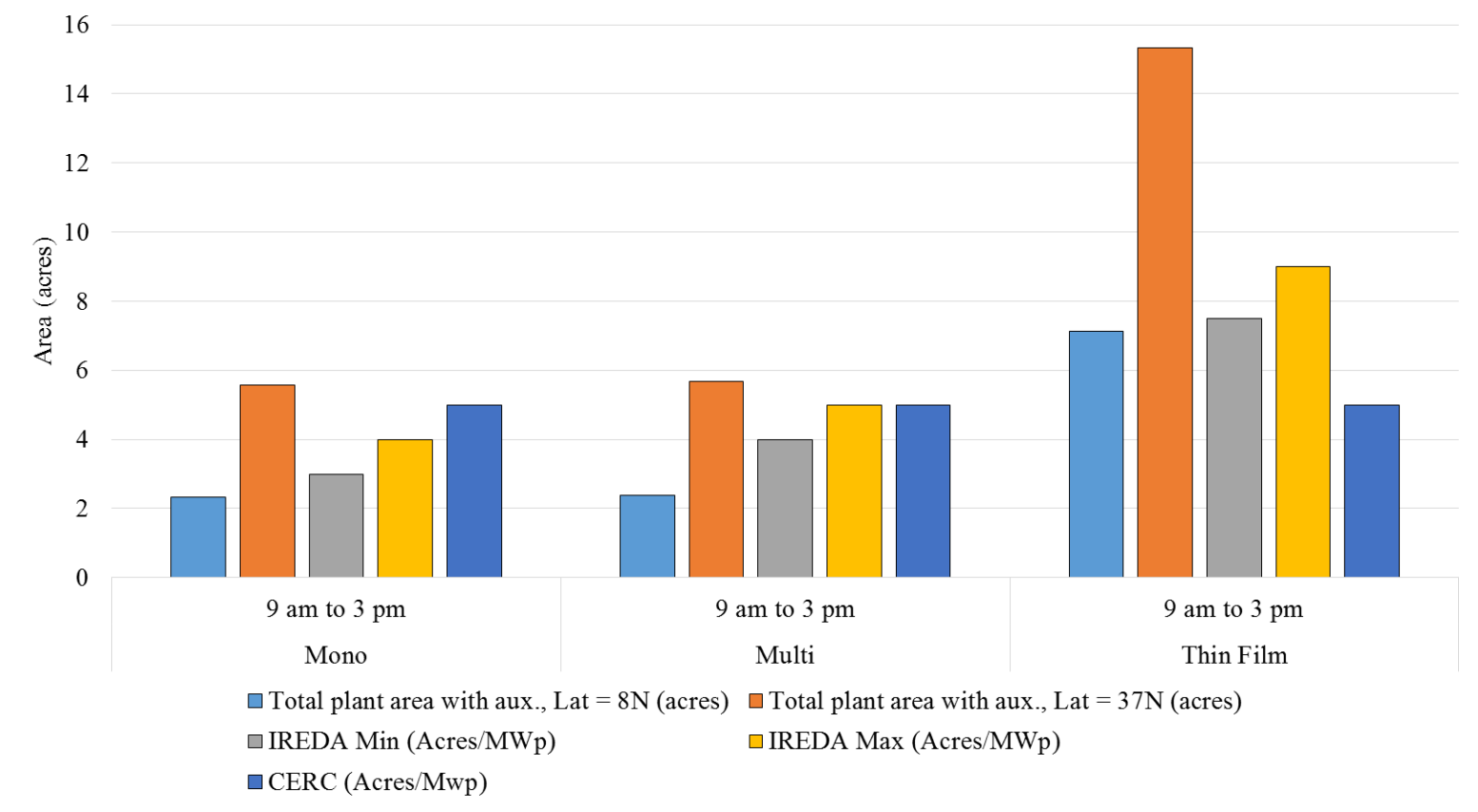

Figure H.1: Land area requirements for various technology options for $8^{\circ} \mathrm{N}$ and $37^{\circ} \mathrm{N}$ case

It can be seen that due to tilt angle considerations and plant sizing parameters (n, $m, y)$ there is a noticeable difference between the area of the plant across the extreme latitudes, and the IREDA and CERC benchmarks. This is particularly predominant for thin film based set up and is in accordance with our earlier observations in section 3.1. In all cases there is significant difference between the area estimates of the plant at $8^{\circ} \mathrm{N}$ and $37^{\circ} \mathrm{N}$. Further, it can be seen that the CERC benchmark over-estimates the land area requirement for lower latitudes for mono and multi-crystalline technologies. This reaffirms our inference from Figure 15 in section 3.3. 


\section{Reference for Appendices}

ABB, 2014. Datasheet: Central inverters PVS800.

AEG Power Solutions, n.d. Datasheet: Protect PV.630 630 kW Inverter.

Antonio, H., Hegedus, S., 2003. Handbook of photovoltaic science and engineering. https://doi.org/10.1002/9780470974704

Eaton, 2015. Datasheet Power Xpert Solar 250 kW Inverter.

Emmvee Photovoltaic Power Pvt. Ltd., 2012. Datasheet: Polycrystalline 230 Wp solar photovoltaic module.

First Solar Inc., 2012. Datasheet: Thin film solar photovoltaic module, FS380.

Markvart, T., Castaner, L., 2013. Practical Handbook of Photovoltaics Fundamentals and Applications. Elsevier Science Inc., USA.

Photon Energy Systems Limited, 2014. Datasheet: Monocrystalline solar photovoltaic modules PMM0225 - PMM0240 - 60.

SMA Solar Technology, n.d. Datasheet: Sunny Central 800CP XT/ 850CP XT/ 900CP XT Inverter.

Tata Power Solar, 2014. Datasheet: Multi crystalline solar photovoltaic module TS235.

Titan Energy Systems, n.d. Datasheet: Titan S6 - 60, Mono Crystalline solar photovoltaic modules.

UNFCCC - CDM, 2014. Project Design Document - 5 MW Solar PV Power Project at NTPC Faridabad. https://doi.org/Project 9964

UNFCCC - CDM, 2012a. Project Design Document - 5 MW Solar PV Power Project at Port Blair (A \& N). https://doi.org/Project 9524

UNFCCC - CDM, 2012b. Project Design Document - 15 MW Solar Photovoltaic Power Plant in Gujarat. https://doi.org/Project 6231

UNFCCC - CDM, 2012c. Project Design Document - Grid Connected solar PV based power generation at Naini, Allahabad, India. https://doi.org/Project 7899

UNFCCC - CDM, 2011. Project Design Document - Grid connected 3 MWp Solar PV power plant in Belgaum District of Karnataka State, India. https://doi.org/Project 5906 


\section{Supplementary Material}

\begin{tabular}{|c|c|c|c|c|c|c|c|}
\hline \multirow{2}{*}{ State / UT } & \multirow{2}{*}{ Total State area (sq.km) } & \multirow{2}{*}{ Total all wasteland (sq.km) } & \multicolumn{4}{|c|}{ Select Wastelands (sq.km) } & \multirow{2}{*}{\begin{tabular}{|l|} 
in acres/MWp \\
benchmark area \\
\end{tabular}} \\
\hline & & & Rann & Salt affected & Scrub land & Total (SWL) & \\
\hline Andaman and Nicobar & 8249 & 8.94 & 0 & 0 & \begin{tabular}{r|}
1.29 \\
\end{tabular} & \begin{tabular}{r|}
1.29 \\
\end{tabular} & 3.21 \\
\hline Andhra Pradesh + Telangana & 275068 & 22079.85 & 0 & 1608.74 & 16943.53 & 18552.27 & 3.64 \\
\hline Arunachal Pradesh & 83743 & 2489.9 & 0 & 0 & 2297 & 2297 & 4.62 \\
\hline Assam & 78438 & 4012.2 & 0 & 0 & 3780.27 & 3780.27 & 4.42 \\
\hline Bihar & 94171 & 3229.08 & 0 & 0 & 3015.81 & 3015.81 & 4.4 \\
\hline Chandigarh & 114 & 1.42 & 0 & 0 & 1.35 & 1.35 & 5.49 \\
\hline Chhattisgarh & 135194 & 4963.62 & 0 & 0.29 & 4292.13 & 4292.42 & 4.03 \\
\hline Daman and Diu & 112 & 8.99 & 0 & 0.85 & 7.72 & 8.57 & 4.01 \\
\hline Delhi & 1483 & 68.48 & 0 & 0.15 & 62.18 & 62.33 & 4.69 \\
\hline Goa & 3702 & 323.57 & 0 & 0 & 264.73 & 264.73 & 3.69 \\
\hline Gujarat & 196024 & 37393.71 & 16995.29 & 970.36 & 18593.18 & 36558.83 & 4.12 \\
\hline Haryana & 44212 & 507.17 & 0 & 27.64 & 378.1 & 405.74 & 4.92 \\
\hline Himachal Pradesh & 55673 & 13530.65 & 0 & 2.47 & 3913.33 & 3915.8 & 5.66 \\
\hline Jammu and Kashmir & 222236 & 57574.72 & 0 & 60.74 & 4937.85 & 4998.59 & 6 \\
\hline Jharkhand & 79706 & 6569.29 & 0 & 0 & 6027.87 & 6027.87 & 4.2 \\
\hline Lakshadweep & 32 & 0.62 & 0 & 0 & 0 & 0 & 3.29 \\
\hline Madhya Pradesh & 308252 & 25420.55 & 0 & 0 & 23534.51 & 23534.51 & 4.24 \\
\hline Maharashtra & 307690 & 23773.96 & 0 & 8.12 & 22175.08 & 22183.2 & 3.9 \\
\hline Manipur & 22330 & 3055.59 & 0 & 0 & 3055.59 & 3055.59 & 4.31 \\
\hline Meghalaya & 22429 & 3102.98 & 0 & 0 & 2835.55 & 2835.55 & 4.37 \\
\hline Mizoram & 21081 & 144.82 & 0 & 0 & 139.68 & 139.68 & 4.17 \\
\hline Nagaland & 16579 & 2356.43 & 0 & 0 & 2355.57 & 2355.57 & 4.42 \\
\hline Odisha & 155707 & 12057.93 & 0 & 15.52 & 10791.78 & 10807.3 & 3.98 \\
\hline Puducherry & 492 & 10.81 & 0 & 0.1 & 8.24 & 8.34 & 3.46 \\
\hline Punjab & 50362 & 547.46 & 0 & 25.64 & 357.53 & 383.17 & 5.45 \\
\hline Rajasthan & 342239 & 74798.18 & 196.2 & 799.15 & 41294.37 & 42289.72 & 4.5 \\
\hline Sikkim & 7096 & 842.08 & 0 & 0 & 19.71 & 19.71 & 4.57 \\
\hline Tamil Nadu & 130058 & 6011.41 & 0 & 530.59 & 4967.59 & 5498.18 & 3.3 \\
\hline Tripura & 10486 & 622.59 & 0 & 0 & 617.83 & 617.83 & 4.21 \\
\hline Uttar Pradesh & 240928 & 14369.43 & 0 & 3741.69 & 7052.3 & 10793.99 & 4.57 \\
\hline Uttarakhand & 53483 & 6744.36 & 0 & 0 & 695.67 & 695.67 & 5.16 \\
\hline West Bengal & 88752 & 1329 & 0 & 0.97 & 1235.16 & 1236.13 & 4.27 \\
\hline
\end{tabular}




\section{Supplementary Material}

State / UT

Andaman and Nicobar

Andhra Pradesh + Telangana Arunachal Pradesh

Assam

\begin{tabular}{l} 
Chandigarh \\
\hline Chhatlisgarh \\
\hline
\end{tabular}

Chhattisgarh

Dadra and Nagar Haveli

Daman and Diu

Delhi

\begin{tabular}{l} 
Goa \\
\hline Gujarat \\
\hline Garyana \\
\hline
\end{tabular}

Gujarat
Haryana

Himachal Pradesh

Jammu and Kashmir

Jharkhand

Karnataka

Kerala

Lakshadweep

Madhya Pradesh

Maharashtra

Manipur

Mizoram

Nagaland

Odisha

\begin{tabular}{l} 
Odisha \\
\hline Puducherry \\
\hline Punjab
\end{tabular}

Punjab

Rajasthan

Sikkim

Tamil Nadu

Tripura

Uttar Pradesh

\begin{tabular}{l}
\hline Uttar Prades \\
\hline Uttarakhand \\
\hline Uest Bengal \\
\hline
\end{tabular}

West Bengal

Total

$3 \%$ Potential in GWp as per CERC 5 acres/MWp

$3 \%$ Potential in GWp as per estimated benchmark area

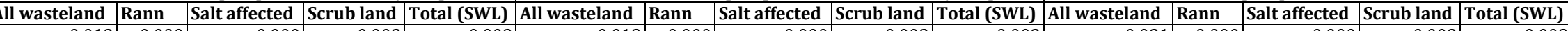
\begin{tabular}{rr|r|r|}
0.002 & 0.002 & 0.013 & 0.000 \\
\hline
\end{tabular}

\begin{tabular}{rr|r|r|r|r|r|r|r|}
\hline 32.736 & 0.000 & 2.385 & 25.121 & 27.506 & 33.120 & 0.000 \\
\hline
\end{tabular}

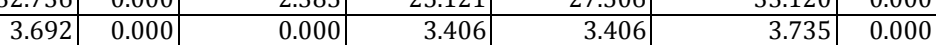
\begin{tabular}{r|r|r|r|}
0.002 & 0.021 & 0.000 & \\
\hline .828 & 44.967 & 0.000 & \\
\hline 3.946 & 3.995 & 0.000 &
\end{tabular}

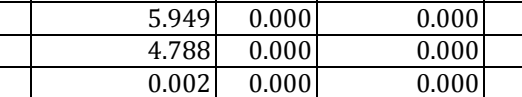
\begin{tabular}{|l|l|l|}
\hline 5.605 & 6.018 & 0.000 \\
\hline
\end{tabular} \begin{tabular}{|r|r|r|}
\hline 0.000 & 0.002 & \\
\hline 2.413 & 25.415 & \\
\hline 0.000 & 3.446 & \\
\hline 0.000 & 5.670 & \\
\hline
\end{tabular} \begin{tabular}{l|l|l|}
\hline 4.788 & 0.000 \\
\hline
\end{tabular} 0.000

$+$
\begin{tabular}{l|l|l}
7.355 & 0.000 \\
\hline 0.063 & 0.000
\end{tabular}

0.000
0.000
0.000
\begin{tabular}{l|l}
4.471 & 4.471 \\
0.002 & 0.002 \\
\hline 6.364 & 6.364
\end{tabular} \begin{tabular}{rr}
0.0000 & 5.670 \\
\hline 0.000 & 4.524
\end{tabular} \begin{tabular}{l|r|r|}
\hline 0.000 & 4.524 & 4.524 \\
\hline 0.000 & 0.002 & 0.002 \\
\hline
\end{tabular} \begin{tabular}{r|r|r|r|r|}
\hline 6.729 & 0.000 & 0.000 & 3.686 & 3.686 \\
\hline 5.440 & 0.000 & 0.000 & 6.340 & 6.340 \\
\hline
\end{tabular} \begin{tabular}{ll|l|}
\hline 0.000 & 0.002 & 0.002 \\
\hline 0.000 & 6.438 & 6.439 \\
\hline 0.000 & 0.064 & 0.064 \\
\hline
\end{tabular}

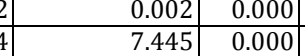
\begin{tabular}{lll}
0.000 & 0.002 & 0.002 \\
\hline 0.000 & 6.438 & 6.439 \\
\hline 0.001 & 0.012 & 0.064 \\
\hline
\end{tabular} \begin{tabular}{l|l|l|l|l|}
\hline 0.013 & 0.000 & 0.000 & 0.063 & 0.063 \\
\hline 0.102 & 0.000 & 0.000 & 0.011 & 0.013 \\
\hline
\end{tabular} \begin{tabular}{l|ll|l|l|}
\hline 0.102 & 0.000 & 0.000 & 0.011 & 0.013 \\
\hline 0.480 & 0.000 & 0.000 & 0.392 & 0.092 \\
\hline
\end{tabular} \begin{tabular}{rr}
0.102 & 0.000 \\
0.480 & 0.000 \\
\hline
\end{tabular} \begin{tabular}{r|r|}
\hline 55.441 & 25.198 \\
\hline
\end{tabular} 0.000

$\mid$
\begin{tabular}{r|r|r}
55.441 & 25.198 \\
\hline 0.752 & 0.000
\end{tabular}

$\begin{array}{r}0.000 \\ \hline 1.439 \\ \hline 0.041\end{array}$
\begin{tabular}{|l|l|l|l|}
\hline 0.063 & 0.063 & 0.064 & 0.000 \\
\hline 0.092 & 0.013 & 0.013 & 0.000 \\
\hline 0.092 & 0.103 & 0.000 \\
\hline
\end{tabular} \begin{tabular}{rr|r|}
\hline 6.439 & 9.131 & 0.000 \\
\hline-0.064 & 0.079 & 0.000 \\
\hline 0.013 & 0.017 & 0.000 \\
\hline
\end{tabular} \begin{tabular}{|l|l|l|l|l|}
\hline 0.000 & 0.064 & 0.064 & 0.079 & 0.000 \\
\hline 0.001 & 0.012 & 0.013 & 0.017 & 0.000 \\
\hline
\end{tabular} \begin{tabular}{r|r|r|}
0.000 & 0.092 & 0.092 \\
\hline 1.439 & 27.567 & 0.392 \\
\hline 0.041 & 0.561 & 0.602 \\
\hline
\end{tabular} \begin{tabular}{r|r}
0.092 \\
\hline 0.392
\end{tabular} \begin{tabular}{l|l|l|l|l|}
\hline 0.013 & 0.000 & 0.001 & 0.012 & 0.013 \\
\hline 0.103 & 0.000 & 0.000 & 0.093 & 0.093 \\
\hline
\end{tabular} \begin{tabular}{r|r|}
0.485 & 0.000 \\
\hline
\end{tabular} \begin{tabular}{ll|r|r}
0.000 & 0.093 & 0.093 \\
\hline 0.000 & 0.397 & 0.397 \\
\hline 1.456 & 27.890 & 54.838 \\
\hline
\end{tabular} \begin{tabular}{r|r|r|r|r|}
\hline .079 & 0.000 & 0.001 & 7.895 & 7.896 \\
\hline 0.017 & 0.000 & 0.002 & 0.079 & 0.079 \\
\hline 0.108 & 0.000 & 0.000 & 0.014 & 0.016 \\
\hline
\end{tabular}

$+$
\begin{tabular}{r|r|r|}
\hline 0.041 & 0.561 & 0.602 \\
\hline 0.004 & 5.802 & 5.806 \\
\hline
\end{tabular} $\mid$ \begin{tabular}{r|r|}
0.004 & 5.802 \\
\hline 0.090 & 7.321
\end{tabular} \begin{tabular}{r|r}
0.761 & 0.000 \\
\hline 20.296 & 0.000 \\
\hline
\end{tabular} \begin{tabular}{|r|r|r|r|r|r|r|r|}
\hline 1.456 & 0.397 & 0.397 & 0.650 & 0.000 & 0.000 & 0.532 & 0.0932 \\
\hline
\end{tabular} \begin{tabular}{|r|r|r|r|r|r|r|r|}
\hline 1.456 & 27.890 & 54.838 & 67.283 & 30.580 & 1.746 & 33.455 & 65.781 \\
\hline 0.041 & 0.567 & 0.609 & 0.764 & 0.000 & 0.042 & 0.570 & 0.611 \\
\hline
\end{tabular} \begin{tabular}{rr|r|r|r|r|r|r|}
\hline 0.004 & 5.870 & 5.874 & 17.722 & 0.000 & 0.003 & 5.125 & 5.129 \\
\hline 0.091 & 7.407 & 7.498 & 71.135 & 0.000 & 0.075 & 6.101 & 6.176 \\
\hline 0.000 & 9.042 & 9.042 & 11.595 & 0.000 & 0.000 & 10.639 & 10.639 \\
\hline
\end{tabular}

$+$

\begin{tabular}{r|r|r|r}
\hline 0.000 & 8.937 & 8.937 \\
\hline 0.779 & 10.191 & 10.970 & \\
\hline
\end{tabular}
\begin{tabular}{rr|r|r|}
\hline 12.776 & 0.000 & 0.779 \\
\hline 2.459 & 0.000 & 0.000 \\
\hline 0.001 & 0.000 & 0.000 \\
\hline 37.689 & 0.000 & 0.000
\end{tabular}

\begin{tabular}{r|r|}
\hline 10.970 \\
\hline
\end{tabular}

\begin{tabular}{rr|r|}
\hline 12.926 & 0.000 \\
\hline & 0.000 \\
\hline
\end{tabular}

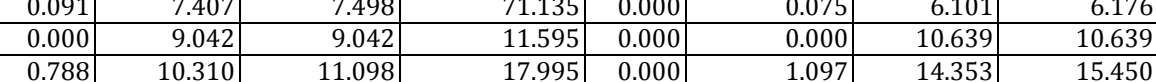
\begin{tabular}{|r|r|r|r|r|r|r|}
\hline 10.970 & 12.926 & 0.000 & 0.788 & 10.310 & 11.098 \\
\hline 2.073 & 2.488 & 0.000 & 0.000 & 2.097 & 2.097 \\
\hline 0.000 & 0.001 & 0.000 & 0.000 & 0.000 & 0.000 \\
\hline
\end{tabular} \begin{tabular}{r|rr|r|r|}
\hline 37.689 & 0.000 & 0.000 & 34.893 & 0.000 \\
\hline
\end{tabular}

\begin{tabular}{|r|r|}
\hline 0.001 & 0.000 \\
\hline
\end{tabular}
34.893

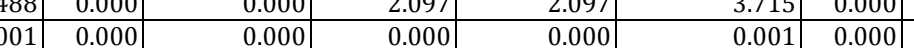
\begin{tabular}{rr|r|}
0.000 & 0.000 & 0.000 \\
\hline 0.000 & 35.302 & 35.302 \\
\hline 0.012 & 33.263 & 33.275 \\
\hline
\end{tabular}

\begin{tabular}{|r|r|r|r}
\hline 37.689 & 0.000 & 0.000 & \\
\hline 35.248 & 0.000 & 0.012 & \\
\hline 4.530 & 0.000 & 0.000 & \\
\hline 4.601 & 0.000 & 0.000 & \\
\hline
\end{tabular}

\begin{tabular}{|r|r|}
\hline 32.889 \\
\hline
\end{tabular}

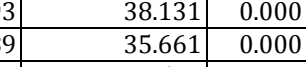

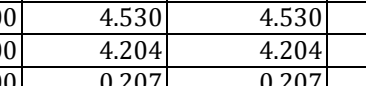

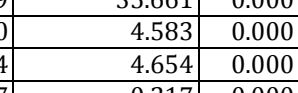
\begin{tabular}{r|r|r|}
\hline 0.012 & 33.263 & 33.275 \\
\hline
\end{tabular} \begin{tabular}{rr}
0.012 & 33.263 \\
\hline 0.000 & 4.583
\end{tabular} \begin{tabular}{r|r|}
0.001 & 0.000 \\
\hline 44.445 & 0.000 \\
\hline
\end{tabular} \begin{tabular}{r|r|}
4.530 & 0.000 \\
\hline 4.601 & 0.000 \\
\hline
\end{tabular}

\begin{tabular}{|r|r|r|r|r|r|r|r|} 
& 0.215 & 0.000 & 0.000 & 0.207 & 0.207 & \\
\hline 3.494 & 0.000 & 0.000 & 3.492 & 3.492 & \\
& 17.877 & 0.000 & 0.023 & 16.000 & 16.023 & \\
& 0.016 & 0.000 & 0.000 & 0.012 & 0.012 & \\
& 0.812 & 0.000 & 0.038 & 0.530 & 0.568 & \\
& 110.898 & 0.291 & 1.185 & 61.224 & 62.700 & \\
& 1.248 & 0.000 & 0.000 & 0.029 & 0.029 & \\
& 8.913 & 0.000 & 0.787 & 7.365 & 8.152 & \\
& 0.923 & 0.000 & 0.000 & 0.916 & 0.916 & \\
& 21.305 & 0.000 & 5.548 & 10.456 & 16.003 & \\
& 9.999 & 0.000 & 0.000 & 1.031 & 1.031 & \\
& 1.970 & 0.000 & 0.001 & 1.831 & 1.833 & \\
\hline $\mathbf{5 0 1 . 5 2 7}$ & $\mathbf{2 5 . 4 8 9}$ & $\mathbf{1 2 . 3 3 3}$ & $\mathbf{2 8 7 . 5 8 0}$ & $\mathbf{3 2 5 . 4 0 2}$ &
\end{tabular}
0.000 \begin{tabular}{r|r|r|r|r|}
\hline 4.654 & 0.000 & 0.000 & 4.253 & 4.583 \\
\hline
\end{tabular} \begin{tabular}{l|r|r|}
5.256 & 0.000 \\
\hline 4.253 & 5.264 & 0.000 \\
\hline
\end{tabular} \begin{tabular}{l|r|r|r|r|}
\hline 0.000 & 4.210 & 4.253 & 5.264 & 0.000 \\
\hline 0.000 & 3.533 & 3.533 & 0.257 & 0.000 \\
\hline
\end{tabular} \begin{tabular}{rrr}
0.000 & 0.210 & 0.210 \\
\hline 0.000 & 3.533 & 3.533 \\
\hline .023 & 16.188 & 16.211
\end{tabular} \begin{tabular}{r|r|r|r|r|r|r|r}
3.535 & 0.000 & 0.000 & 3.533 & 3.533 & 3.952 & 0.000 & \\
18.087 & 0.000 & 0.023 & 16.188 & 16.211 & 22.459 & 0.000 &
\end{tabular} \begin{tabular}{|l|r|r|r|}
\hline 0.000 & 4.810 & 4.810 \\
\hline 0.000 & 0.000 & 3.951 & 0.248 \\
\hline
\end{tabular} \begin{tabular}{r|r|r|r|r|r|r|r|}
\hline 0.000 & 3.533 & 3.533 & 3.952 & 0.000 & 0.000 & 3.951 & 3.951 \\
\hline 0.023 & 16.188 & 16.211 & 22.459 & 0.000 & 0.029 & 20.101 & 20.130 \\
\hline 0.000 & 0.012 & 0.013 & 0.023 & 0.000 & 0.000 & 0.018 & 0.018 \\
\hline 0.038 & 0.536 & 0.575 & 0.745 & 0.000 & 0.035 & 0.48 & 0.521 \\
\hline
\end{tabular} \begin{tabular}{r|r|r|r|r|r|r|}
0.016 & 0.000 & 0.000 & 0.012 & 0.013 & 0.023 & 0.000 \\
\hline 0.821 & 0.000 & 0.038 & 0.536 & 0.575 & 0.745 & 0.000 \\
\hline
\end{tabular} \begin{tabular}{r|r|r|r|r|r|r|r|}
\hline 112.197 & 0.294 & 1.199 & 61.942 & 63.435 & 123.220 & 0.323 \\
\hline 1.263 & 0.000 & 0.000 & 0.030 & 0.030 & 1.366 & 0.000 \\
\hline
\end{tabular} \begin{tabular}{r|r|}
\hline .2617 & 0.000 \\
\hline 0.934 & 0.000
\end{tabular} \begin{tabular}{r|r|}
\hline .017 & 0.000 \\
\hline 0.934 & 0.000 \\
\hline
\end{tabular} \begin{tabular}{r|r|r|r|r|}
\hline 0.000 & 0.030 & 0.030 & 1.366 & 0.000 \\
\hline 0.796 & 7.451 & 8.247 & 13.504 & 0.000 \\
\hline 0.000 & 0.927 & 0.927 & 1.096 & 0.000 \\
\hline
\end{tabular} \begin{tabular}{r|r}
01.554 & 0.000 \\
\hline 10.117 & 0.000
\end{tabular} \begin{tabular}{|r|r|r|r}
\hline 0.796 & 7.451 & 8.247 \\
\hline 0.000 & 0.927 & 0.927 \\
\hline 5.613 & 10.578 & 16.191 & \\
\hline
\end{tabular} \begin{tabular}{r|r|}
10.117 & 0.000 \\
\hline 1.994 & 0.000 \\
\hline 507.403 & 25.787
\end{tabular} \begin{tabular}{r|r|r|}
\hline 0.796 & 7.451 & 8.247 \\
\hline 5.613 & 10.578 & 16.191 \\
\hline 0.000 & 1.044 & 1.044 \\
\hline
\end{tabular} \begin{tabular}{rr}
0.513 \\
\hline 0.000 & 1.044 \\
\hline 0.001 & 1.853 \\
\hline
\end{tabular} $\begin{array}{r}16.191 \\ \hline 1.044\end{array}$ \begin{tabular}{rr|}
13.504 & 0.000 \\
\hline 1.096 & 0.000 \\
\hline 23.309 & 0.000 \\
\hline
\end{tabular} \begin{tabular}{r|r|r}
1.994 & 0.000 & \\
\hline $\mathbf{5 0 7 . 4 0 3}$ & $\mathbf{2 5 . 7 8 7}$ & \\
\hline
\end{tabular}

\begin{tabular}{r|r|r|}
0.001 & 1.853 & 1.854 \\
\hline $\mathbf{1 2 . 4 7 8}$ & $\mathbf{2 9 0 . 9 5 0}$ & $\mathbf{3 2 9 . 2 1 4}$ \\
\hline
\end{tabular} \begin{tabular}{|r|r|r|r|}
1.044 & 9.689 & 0.000 & \\
\hline 1.854 & 2.307 & 0.000 & \\
\hline $\mathbf{3 2 9 . 2 1 4}$ & $\mathbf{5 6 3 . 4 3 2}$ & $\mathbf{3 0 . 9 0 3}$ & \\
\hline
\end{tabular}

\begin{tabular}{r|r|r}
0.035 & 0.486 & 0.521 \\
\hline 1.316 & 68.027 & 69.667 \\
\hline 0.000 & 0.032 & 0.032 \\
\hline
\end{tabular}

\begin{tabular}{r|r|r}
\hline .316 & 68.027 & 69.667 \\
\hline 0.000 & 0.032 & 0.032 \\
\hline 1.192 & 11.159 & 12.351 \\
\hline
\end{tabular}

\begin{tabular}{|r|}
\hline 1.192 \\
\hline 0.000
\end{tabular}
\begin{tabular}{r|r|r|}
\hline 1.192 & 11.159 & 12.351 \\
\hline 0.000 & 1.088 & 1.088 \\
\hline 6.070 & 11.440 & 17.509 \\
\hline
\end{tabular} 6.070
0.000

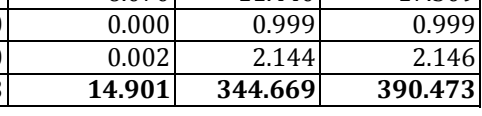




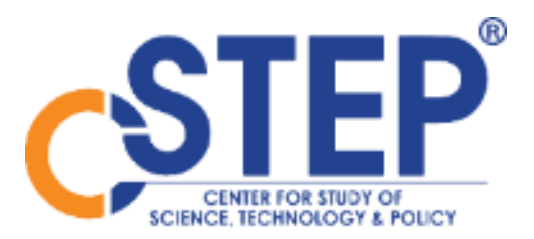

CENTER FOR STUDY OF SCIENCE, TECHNOLOGY AND POLICY,

\#18 \& 19, $10^{\text {th }}$ Cross, Mayura Street, Papanna Layout, Nagashettyhalli, RMV II Stage, Bengaluru-560094, Karnataka (India) Email: cpe@cstep.in

CENTER FOR STUDY OF SCIENCE, TECHNOLOGY AND POLICY, Studio \#206, International Home Deco Park (IHDP), Plot No. 7, Sector 127, Taj Expressway, Noida-201301, Uttar Pradesh (India)

Email: cpe@cstep.in 


\section{STEP}

\section{Center for Study of Science, Technology and Policy}

\section{Bengaluru Office}

\#18 \& $19,10^{\text {th }}$ Cross, Mayura Street,

Papanna Layout, Nagashettyhalli, RMV II Stage,

Bengaluru-560094, Karnataka (India)

Tel: +91 (80) 66902500

Fax: +91 (80) 23514269

Email: cpe@cstep.in

Website: www.cstep.in

\section{Noida Office}

Studio \#206, International Home Deco Park (IHDP),

Plot No. 7, Sector-127, Taj Expressway,

Noida-201301, Uttar Pradesh (India)

Tel: +91 (120) 4844003 